\author{
UNIVERSIDADE DE SÃO PAULO - USP \\ ESCOLA DE ENGENHARIA DE SÃO CARLOS - EESC
}

PAULO INFORÇATTI NETO

Estudo da viabilidade técnica e projeto de um mini-cabeçote de extrusão com rosca para impressoras tridimensionais portáteis 



\author{
UNIVERSIDADE DE SÃO PAULO - USP \\ ESCOLA DE ENGENHARIA DE SÃO CARLOS - EESC
}

PAULO INFORÇATTI NETO

\title{
Estudo da viabilidade técnica e projeto de um mini-cabeçote de extrusão com rosca para impressoras tridimensionais portáteis
}

Dissertação apresentada a Escola de Engenharia de São Carlos, da Universidade de São Paulo, como parte dos requisitos para a obtenção do título de Mestre em Engenharia Mecânica.

Área de concentração: Projeto Mecânico.

Orientadora: Prof ${ }^{a}$. Dr ${ }^{a}$. Zilda de Castro Silveira

São Carlos

2013 
AUTORIZO A REPRODUCÃO TOTAL OU PARCIAL RESTE TRABALHO, POR QUALQUER MEIO C’ONVENCIONAL OU ELETRONICO, PARA FINS DE ESTUDO E PESQUISA, DESDE QUE CITADA A FONTE.

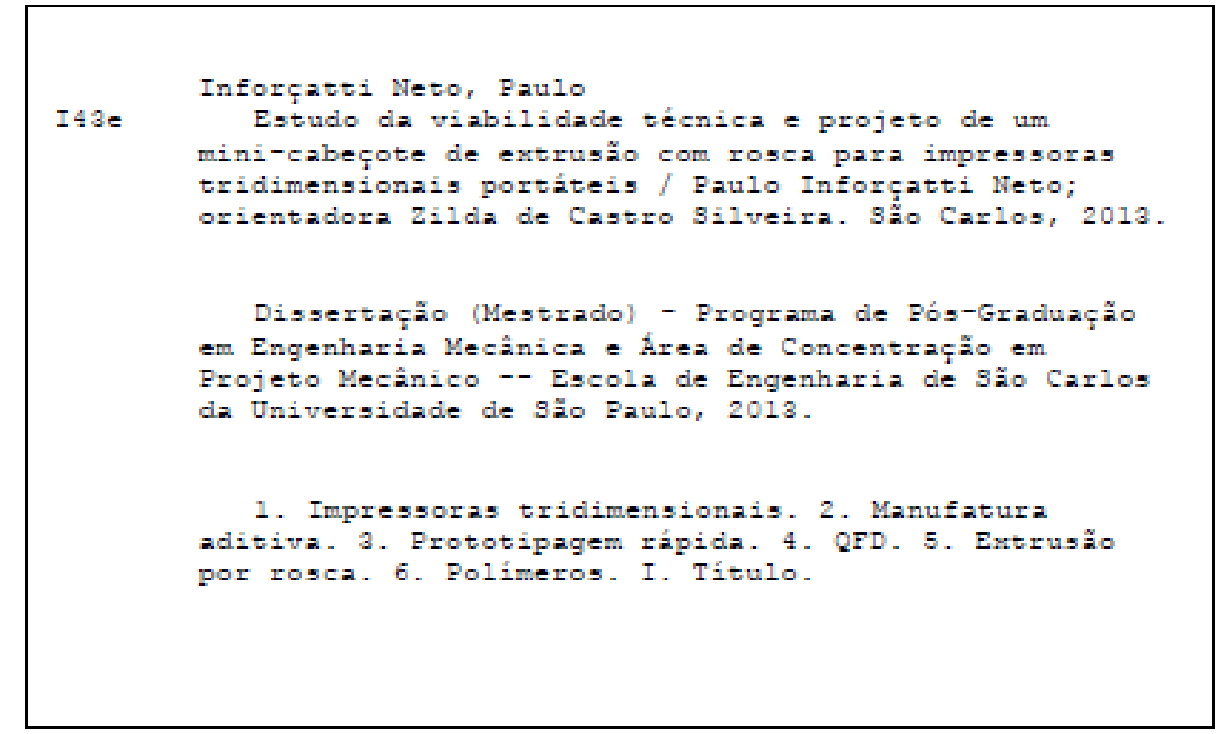




\section{FOLHA DE IULGAMENTO}

Candidato: Engenheiro PAULO INFORÇATTI NETO.

Título da dissertação: "Estudo da viabilidade técnica e projeto de um mini-cabeçote de extrusẫo com rosca para impressoras tridimensionais portáteis".

Data da defesa: 08/03/2013

Comissão Julgadora:

Prof. Dr. Zilda de Castro Silveira (Orientadora)

(Escola de Engenharia de São Carlos/EESC)

Prof. Associado Jonas de Carvalho

(Escola de Engenharia de São Carlos/EESC)

Prof. Dr. Marcos Akira D'Ávila

(Universidade Estadual de Campinas/UNICAMP)
Resultado:
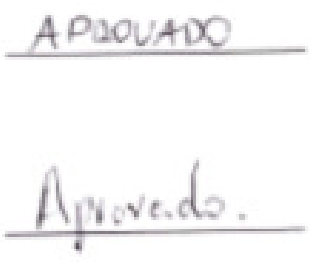

APROVADO

Coordenador do Programa de Pós-Graduação em Engenheira Mecânica:

Prof. Associado Marcelo Areias Trindade

Presidente da Comissão de Pós-Graduação:

Prof. Titular Denis Vinicius Coury 



\section{Dedicatória}

Dedico este trabalho à Deus, aos meus pais, meus irmãos, minha esposa, amigos, colegas de trabalho e orientadores que me auxiliaram, apoiaram e me incentivaram durante todo este tempo de trabalho. 



\section{Agradecimentos}

Primeiramente à Deus por proporcionar-me a conclusão de mais uma grande conquista.

Aos meus pais, lára Ivete C. Inforçati e Paulo Francisco Inforçati pelo incentivo e disposição em me ajudar sempre que precisei.

Aos meus irmãos, Marcelo Caliggiuri Inforçati e Maurício Calligiuri Inforçati por estarem sempre ao meu lado me apoiando.

A minha esposa Jamylle Novaes Inforçatti pelos maravilhosos momentos vividos e por não ter me deixado desistir no caminho.

A amiga e orientadora Prof ${ }^{\underline{a}}$. Dra ${ }^{\mathrm{a}}$. Zilda de Castro Silveira, pela valiosa atenção dispensada, pela garra e incansável disposição em colaborar com a execução deste trabalho.

Ao meu amigo Pedro Yoshito Noritomi pela disponibilidade e auxílio prestado.

Aos meus amigos Jorge Vicente, Izaque Maia, Marcelo Fernandes, Airton Moreira, Amanda Amorin, Arnaldo Luis Lixandrão, Daniel Takanori, Frederico David, Matheus Stoshy e a todos da DT3D (Divisão de Tecnologias Tridimensionais) do Centro de Tecnologia da Informação Renato Archer que de uma forma ou de outra contribuíram e me ajudaram.

E finalmente a todos que não foram citados acima mas que de alguma forma me ajudaram a vencer mais esta etapa da minha vida. 

Inforçatti Neto, P. (2013) Estudo da viabilidade técnica e projeto de um mini-cabeçote de extrusão com rosca para impressoras tridimensionais portáteis. Dissertação de mestrado, Departamento de Engenharia Mecânica, Escola de Engenharia de São Carlos, Universidade de São Paulo. 105p.

\section{RESUMO}

Este trabalho tem o objetivo de apresentar o desenvolvimento do projeto informacional e do projeto conceitual de um mini-cabeçote vertical de extrusão com rosca de seção variável intercambiável. A montagem e a validação funcional deste cabeçote é feita na impressora 3-D Fab@CTI de forma intercambiável, na qual o projeto da estrutura foi baseada no projeto Fab@home. O projeto envolve o estudo sistemático utilizando o QFD para identificação dos requisitos do usuário e a escolha do "cabeçote de deposição", como característica técnica mais importante conduz o desenvolvimento do projeto conceitual e parte do projeto preliminar do mini-cabeçote vertical de extrusão. Utilizando análise morfológica no projeto conceitual se obteve a configuração do projeto, no qual foi possível dimensionar os principais componentes do sistema proposto: rosca/cilindro e sistema de acionamento. Os materiais considerados para o dimensionamento mecânico, bem como das estimativas das geometrias das seções da rosca foram poliamida e PCL, este último material foi escolhido por ser um biomaterial e por apresentar características físico-químicas mais criticas para o dimensionamento do dispositivo. O projeto conceitual foi fabricado e montado para demonstrar sua funcionalidade de extrusão utilizando um material pastoso e pó sem processo de aquecimento. Este trabalho apresenta o projeto e a validação técnica de um mini-cabeçote intercambiável de extrusão por rosca para utilização em impressoras 3-D utilizadas em manufatura aditiva. A abordagem sistemática de projeto demonstra a importância de técnicas de metodologia de projeto durante o desenvolvimento de um produto, a fim de se obter qualidade no projeto de engenharia.

Palavras-chave: impressoras tridimensionais; manufatura aditiva; prototipagem rápida; QFD; extrusão por rosca; polímeros. 

Inforçatti Neto, P. (2013) Study of technical feasibility and design of a miniscrew extrusion head applied to three-dimensional desktop printers. Dissertation for master degree, Department of Mechanical Engineering, Engineering School of Sao Carlos, University of São Paulo. 105p.

\begin{abstract}
The purpose of this work is to present the study of the informational and conceptual design of the vertical mini-screw extrusion head applied to portable and open source additive manufacturing machine. The design was validated considering the proposal of interchangeable heads applied to Brazilian 3-D printer based on Fab@home mechanical design. It was developed a systematic study using QFD to identify user's requirements, supporting the choice of a " deposition head" as the most important technical characteristic, leading the design development of a mini vertical system based on a extrusion screw with variable section. The conceptual design using the morphological analysis defined the design configuration, allowing to make a pre-calculation of the main components of the proposed head: screw, barrel and actuation system. The deposition materials, considered for the theoretical calculations, were polyamide and PCL, being the last a biocompatible polymer. This choice lead to critical physicochemical properties related to system design. The conceptual design was manufactured and assembled, demonstrating its functionality to extrude a paste like and powder materials without heating. This work presented the design and the validation of an interchangeable mini-extruder screw head developed to a portable 3-D printer used in additive manufacturing process. The systematic approach demonstrated the importance of the design methodology tools during the product development to obtain quality in the design engineering.
\end{abstract}

Key-words: three-dimensional printer; additive manufacturing; rapid prototyping; QFD; screw extrusion; polymer. 



\section{Lista de Figuras}

Figura 2.1 - Gráfico de Temperatura $\times$ Volume específico. $(A=$ polímero amorfo, $B=$ polímero semicristalino, $\mathrm{C}=$ polímero cristalino) (CALLISTER, 2002) ...................7

Figura 2.2 - Esquema de um conjunto de moldagem por injeção (CANALE, et. al

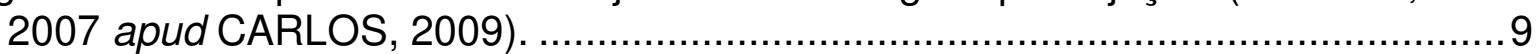

Figura 2.3 - Esquema de um conjunto de moldagem por extrusão .........................10

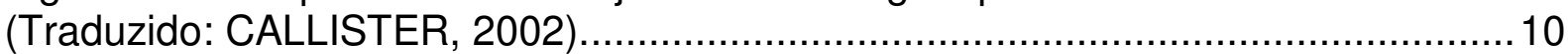

Figura 2.4 - Geometria de uma rosca extrusora simples (Fonte: RAUWENDAAL

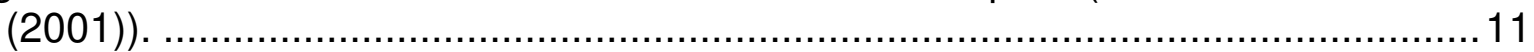

Figura 2.5 - Classificação de partículas (RAUWENDAAL, 2001).........................13

Figura 2.6 - Áreas de aplicações da manufatura aditiva (Traduzido: WOHLERS,

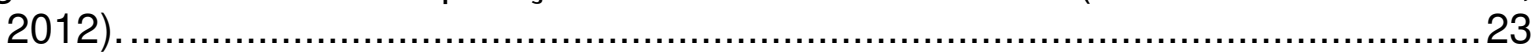

Figura 2.7 - Esquema do processo de estereolitografia (POWERS et al., 2007).....25

Figura 2.8 - Representação esquemática do processo de modelagem por deposição de fundidos (FDM) (Cortesia CTI Renato Archer).............................................26

Figura 2.9 - Representação esquemática do processo de impressão 3-D (Cortesia

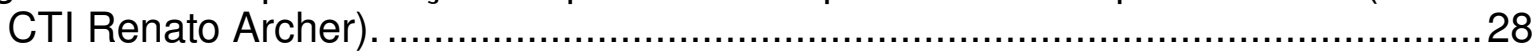

Figura 2.10 - Representação esquemática de um mecanismo de sinterização e fusão de pó à Laser (Cortesia CTI Renato Archer) ...........................................30

Figura 2.11 - Representação esquemática do processo de deposição de metais (LENS) (POWERS et al., 2007) ..................................................................... 32

Figura 2.12 - Ciclo de desenvolvimento de produtos (BACK et. al, 2008)...............34

Figura 2.13 - QFD de quatro fases (Fonte: www.numa.org.br) ............................. 37

Figura 2.14 - Matriz da Casa da Qualidade do QFD. ........................................... 38

Figura 2.15 - Representação de uma matriz com seus elementos constituintes

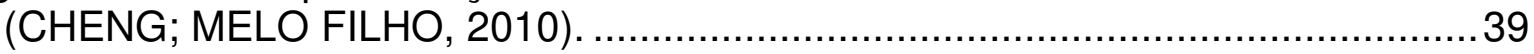

Figura 2.16 - Efeitos das diferentes fases do ciclo de vida sobre o custo do produto. (BLANCHARD; FABRYCKY, 1990 apud BACK e FORCELLINI, 2003)..............40

Figura 2.17 - Árvore funcional de um descascador de batatas (BAXTER, 2003) .....42

Figura 3.1 - (a) Projeto RepRap; (b) Projeto Fab@home........................................47

Figura 3.2 - (a) RapMan®; (b) 3-D-Bioplotter $\AA$................................................. 48

Figura 3.3 - Equipamento de biofabricação Janome Bioprinter..............................48

Figura 3.4 - Estrutura da Fab@CTI cortadas em acrílico.......................................49

Figura 3.5 - Pillow blocks e suportes com flanges da Fab@CTI construídos com a tecnologia SLS............................................................................................. 50

Figura 3.6 - Placa amplificadora da Xylotex para 4 motores de passo bipolares com padrão de controle step/dir....................................................................... 51

Figura 3.7 - Configuração das correntes dos motores na placa amplificadora

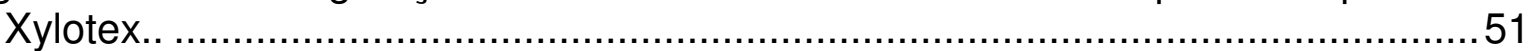

Figura 3.8 - Software Fab@Home versão 0.24 .....................................................52

Figura 3.9 - Máquina Fab@Home construída no CTI............................................54

Figura 3.10 - Sistema intercambiável da Fab@CTI. a) Conexão eletrônica; b) Fixação mecânica; c) Sistema intercambiável completo; d) Acoplamento do cabeçote FDM nas dobradiças do sistema intercambiável; e) Acoplamento completo do cabeçote FDM na máquina Fab@CTI..............................................55

Figura 3.11 - Cabeçote de extrusão de filamento da Fab@CTI. ..............................55

Figura 3.12 - Tecnologias de MA disponíveis na Fab@CTI. Na esquerda temos o cabeçote de deposição por meio de seringas e na direita o cabeçote de extrusão de filamentos. 
Figura 4.1 - Fluxograma desenvolvido para o estudo da viabilidade do mini-cabeçote de extrusão.

Figura 4.2 - Esquema da solução construtiva (uso de seringa) da patente número US 8287959 B2.

Figura 4.3 - Esquema da Patente número US 6.866.807 B2 (2005) .......................63 63

Figura 4.4 - Matriz de contradições técnicas (ver apêndice A.1) ..........................6 68

Figura 4.5 - Matriz da qualidade para melhoria de um projeto de impressora 3-D de deposição. (ver apêndice A.1).

Figura 5.1 - Diagrama Matéria-Sinal-Energia da impressora 3-D. ....................... 74

Figura 5.2 - Diagrama Matéria-Sinal-Energia do subsistema "cabeçote de extrusão"............................................................................................. 75

Figura 6.1 - Esboço da primeira solução de construção para o mini-cabeçote de

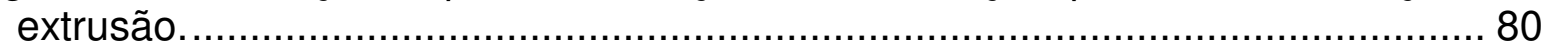

Figura 6.2 - Dimensionamento da rosca de extrusão. ....................................... 83

Figura 6.3 - Modelo tridimensional CAD da primeira proposta de solução do cabeçote de extrusão. ................................................................................... 84

Figura 6.4 - Diagrama de funcionamento do cabeçote de extrusão no sistema da Fab@CTI.

Figura 6.5 - Mock-up do cabeçote de extrusão e seu acoplamento no equipamento Fab@CTI.

Figura 6.6 - Mini-rosca extrusora empenada produzida em SLM após pósprocessamento e remoção de suporte.

Figura 6.7 - Mini-rosca extrusora produzida por usinagem em aço inoxidável 304. 88

Figura 6.8 - Sistema de redução produzido em SLM após pós-processamento e remoção de suporte.

Figura 6.9 - a) Montagem do cabeçote na bancada de testes; b) bico de extrusão intercambiável

Figura 6.10 - a) Alimentação do cabeçote com nylon Duraform® PA; b) Carreamento do pó a frio até a superfície de extrusão.

Figura 6.11 - a) Alimentação do cabeçote com creme dental; b) Carreamento do creme dental a frio até a superfície de extrusão............................................... 92

Figura 6.12 - Verificação das zonas do parafuso de extrusão conforme previsto no pré-dimensionamento do parafuso. ................................................................ 92

Figura 6.13 - Filamentos de poliamida 12 obtidos nos testes e validação...............93

Figura 6.14 - Verificação das zonas do parafuso de extrusão conforme previsto no pré-dimensionamento do parafuso após teste à quente................................... 93

Figura 6.15 - a) Impressão 3-D utilizando o cabeçote de extrusão no equipamento Fab@CTI; b) Vista das camadas do objeto produzido em poliamida 12; c) Vista da parte superior do objeto produzido em poliamida 12. 


\section{Lista de Tabelas}

Tabela 2.1 - Temperaturas de fusão e transição vítrea para alguns polímeros comuns (Traduzido: CALLISTER, 2002) ..................................................... 8

Tabela 2.2 - Polímeros sintéticos biorreabsorvíveis - poli( $\alpha$-hidróxi ácidos) (BARBANTI et al, 2005).

Tabela 2.3 - Processo X Materiais disponíveis (Traduzido: WOHLERS, 2012).......24

Tabela 3.1 - Principais parâmetros de controle do software Fab@Home versão 0.24 .

Tabela 4.1 - Lista de requisitos do usuário. 67

Tabela 4.2 - Características técnicas obtidas para uma impressora 3-D portátil e de baixo custo

Tabela 5.1 - Análise morfológica do cabeçote de extrusão. 76

Tabela 6.1 - Parâmetros de projeto para o pré-cálculo do conjunto cilindro e rosca. 82

Tabela 6.2 - Parâmetros de projeto para o pré-cálculo da rosca de extrusão. 



\section{Lista de Abreviaturas e Siglas}

3-D Tridimensional

ABS Acrilonitrila butadieno estireno

ASI American Supplier Institute

ASTM American Society for Testing and Materials

CAD Desenho auxiliado por computador

CAE Engenharia auxiliada por computador

CAM Manufatura auxiliada por computador

CNC Controle numérico computadorizado

CR Razão de compressão

CTI Centro de Tecnologia da Informação Renato Archer

DT3D Divisão de Tecnologias Tridimensionais

EBM Fusão por feixe de elétrons

EUA Estados Unidos da América

FDM Modelagem por fusão e deposição

GDP Gestão de desenvolvimento do produto

HSC High Speed Cutting

LENS Fabricação da forma final a laser

MA Manufatura Aditiva

MIT Massachusetts Institute of Technology

PC Computador pessoal

PC Policarbonato

PCL poli( $\varepsilon$-caprolactona)

PGA poli(ácido glicólico)

PLA Poli(ácido láctico)

PLGA poli(ácido láctico-co-ácido glicólico)

PPO Óxido de Polifenileno

PROIND Programa para incentivo do uso da MA na indústria

PS Poliestireno

PTFE Politetrafluoroetileno

PU Poliuretano

PVC Poli Cloreto de Vinila 


$\begin{array}{ll}\text { PWM } & \text { Modulação por largura de pulso } \\ \text { QD } & \text { Desdobramento da qualidade } \\ \text { QFD } & \text { Desdobramento da função qualidade } \\ \text { QFDR } & \text { Desdobramento da função qualidade no sentido restrito } \\ \text { RAM } & \text { Random Access Memory } \\ \text { RPM } & \text { Rotações por minuto } \\ \text { SLM } & \text { Selective Laser Melting } \\ \text { SLPR } & \text { Selective Laser Powder Remelting } \\ \text { SLS } & \text { Sinterização seletiva a laser } \\ T_{g} & \text { Transição vítrea } \\ T_{m} & \text { Temperatura de fusão } \\ \text { USB } & \text { Universal Serial Bus }\end{array}$




\section{Sumário}

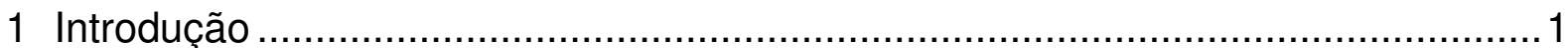

1.1 Motivação do trabalho ................................................................

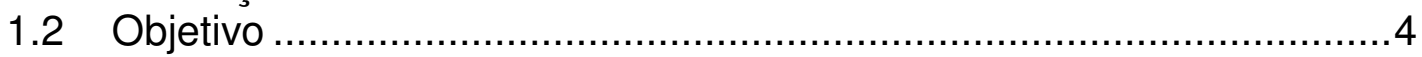

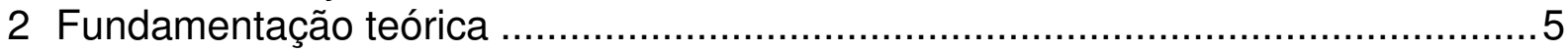

2.1 Introdução aos polímeros industriais ............................................ 5

2.1.1 Processamento de polímeros ............................................8

2.1.2 Bio-polímeros ..................................................................... 16

2.2 Manufatura aditiva ..................................................................... 21

2.2.1 Processos de Fotopolimerização ............................................25

2.2.2 Processos baseado em fusão...............................................26

2.2.3 Processos de laminação de camadas ....................................27

2.2.4 Processos de impressão....................................................... 27

2.2.5 Processo de sinterização/fusão de pó .....................................29

2.3 Considerações sobre sistemática de projeto em engenharia ..............33

2.3.1 Projeto informacional: Metodologia QFD ................................ 35

2.3.2 Projeto Conceitual................................................................40

3 Desenvolvimento da impressora 3-D (Fab@CTI) e cabeçotes de seringa e FDM 45

4 Viabilidade técnica e física de um mini-cabeçote de extrusão com rosca de seção variável

4.1 Definição das necessidades do usuário ......................................64

4.1.1 Montagem e análise do QFD (Quality Function Deployment) para uma impressora 3-D portátil e de baixo custo................................................66

5 Desenvolvimento do projeto conceitual...................................................... 73

6 Construção do protótipo funcional do mini-cabeçote de extrusão com rosca

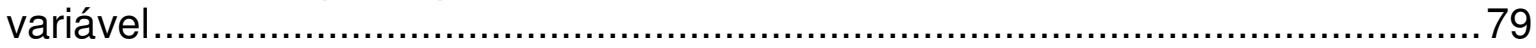

6.1 Mock-up utilizando tecnologias de MA ...................................... 86

6.2 Testes de validação do mini-cabeçote de extrusão..........................89

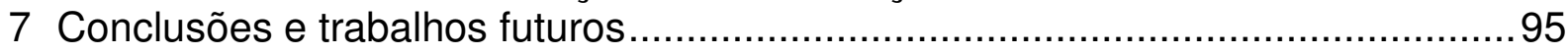

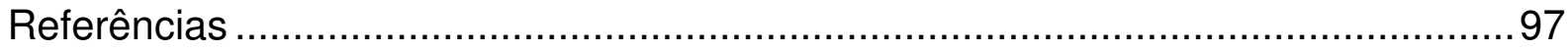

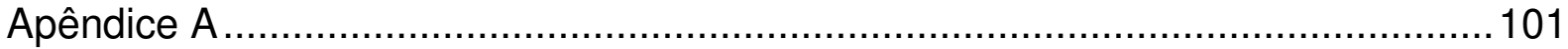





\section{Introdução}

Nos últimos anos, o ciclo de desenvolvimento de novos produtos, bem como a adaptação e melhoria de produtos consolidados têm incorporado novas tecnologias provenientes das mais diversas áreas do conhecimento humano. Há um conjunto de conhecimentos, que agregam valor ao produto, que incluem, por exemplo, tecnologia da informação, parcerias fornecedores-clientes, serviços de pós-venda e metodologias que apoiam o processo do desenvolvimento do projeto, seja um componente, máquina ou equipamento de engenharia ou bens de consumo.

O processo de desenvolvimento do projeto está inserido no ciclo de desenvolvimento de um produto. Nesta fase, há etapas específicas, porém correlacionadas que transformam uma necessidade de melhoria ou de uma nova solução em um produto definido e manufaturável.

O uso de tecnologias de apoio a engenharia, mais especificamente os sistemas CAD (Computer Aided Design) representou inicialmente, uma sistematização do desenho técnico mecânico ou "prancheta eletrônica", que reduziu significativamente o tempo da elaboração dos desenhos técnicos, para fabricação e montagem.

Através das últimas décadas, os sistemas CAD foram continuamente melhorados quanto aos algoritmos de construção e processamento dos modelos computacionais, e integrados a outros sistemas de engenharia, como CAE (Computer Aided Engineering) e CAM (Computer Aided Manufacturing). Na década de 70, a tecnologia CNC (Control Numeric Command) causou uma mudança gradativa nos processos de usinagem com remoção (subtração) de material. $\mathrm{O}$ uso do CNC e sua melhoria (HSC - High Speed Cutting) tornaram os processos de fabricação mais flexíveis, minimizando os erros humanos, aumentando a produtividade, reduzindo os restos e processamento posterior, assim como permite a fabricação das geometrias (partes) mais complexas.

Às exigências de produção e características geométricas citadas anteriormente somam-se grupos de produtos, os quais possuem uma produção em 
pequeno número ou mesmo uma fabricação personalizada, geometrias ainda mais complexas, bem como aplicações específicas de pesquisa. Na metade dos anos 80 , do século XX surgiu a Prototipagem Rápida (RP), um termo que definia um grupo de tecnologias que literalmente construíam protótipos na fase inicial do desenvolvimento de um produto materializado de forma rápida e automática (CAMPBELL et al, 2012).

Com a evolução da tecnologia e as novas demandas de aplicação dos protótipos, a aplicação da tecnologia da prototipagem rápida também evoluiu deixando o âmbito da mera visualização para soluções funcionais. Com isso, o projeto de modelos virtuais passou a considerar a materialização com a finalidade de cumprimento das funções previstas no projeto. Um reflexo desta nova faceta de aplicação da tecnologia de prototipagem rápida com finalidade funcional foi a alteração da sua denominação para Manufatura Aditiva (MA) (ASTM F2792-10).

Esses desenvolvimentos da tecnologia de MA foram impulsionados por necessidades principalmente do mercado industrial. No entanto, a evolução atraiu usuários de outras áreas do conhecimento, dentre as quais se destaca a área de pesquisa, principalmente aquelas que integram aplicações interdisciplinares.

Apesar dos constantes e expressivos desenvolvimentos das máquinas comerciais de MA, raros são os casos em que elas estão perfeitamente adaptadas para aplicações em pesquisa, principalmente na flexibilidade para implementação de tecnologias emergentes e no acesso aos protocolos de controle e funcionamento da tecnologia implementada na máquina. Essas características dificultam o uso de máquinas comerciais como base para desenvolvimento de novas tecnologias e aplicações em ambiente de pesquisa.

Por este motivo, surgiu a necessidade de desenvolvimento de equipamentos com a tecnologia de hardware e software abertos facilitando o acesso às tecnologias de manufatura aditiva, para o desenvolvimento em diversas áreas de pesquisa. Dentre estes equipamentos, podem-se destacar iniciativas como: RepRap e a Fab@home. 
Com relação ao tipo de material utilizado nessas máquinas, os polímeros apresentam um interesse particular devido à sua ampla faixa de aplicação. Estes materiais podem apresentar propriedades físico-químicas de especial interesse, aliadas à versatilidade de processamento, que lhes conferem um conjunto de técnicas de estruturação favorável a aplicação em MA. Além disso, alguns materiais poliméricos apresentam características favoráveis para aplicação em dispositivos com interação biológica.

Dessa forma, o desenvolvimento de pesquisas com novas técnicas de deposição e estruturação de matéria-prima polimérica utilizando a MA representa uma necessidade e avanços no domínio de processos adequados para obtenção de bio-protótipos e de protótipos de pesquisa. A melhoria dos cabeçotes de deposição é fundamental para se obter precisão dimensional e propriedades físico-mecânicas adequadas para as aplicações almejadas, principalmente na área de engenharia médica e bioengenharia.

Este trabalho trata da concepção, construção e validação de um protótipo funcional de um mini-cabeçote vertical de extrusão com rosca de seção variável, para utilização em impressoras 3-D portáteis, de baixo custo e de interface aberta.

\subsection{Motivação do trabalho}

A grande motivação para a realização desta pesquisa são os trabalhos desenvolvidos em parceria entre as áreas da engenharia e da saúde, que resultam em novas áreas de pesquisa e conhecimento, como a engenharia biomédica, a bioengenharia e engenharia tecidual.

A partir de 2006, atendendo ao planejamento estratégico do CTI (2006 a 2010), foi iniciada a construção de uma máquina básica de MA à qual permitisse a intercambiabilidade de cabeçotes de deposição. Seu principal objetivo foi permitir a obtenção de protótipos de pequenas dimensões e geometrias complexas com aplicações em bioengenharia e biofabricação. Em 2007, o CTI integrou-se a rede de 
desenvolvimento mundial Fab@Home, iniciando o projeto Fab@CTI, com a finalidade de atender as especificações propostas no planejamento estratégico.

A Fab@CTI conta com solução de intercambiabilidade de cabeçote implementada e dispõe de dois cabeçotes intercambiáveis para duas técnicas de estruturação diferentes (deposição de material por êmbolo em seringa e deposição de material fundido a partir de filamento). Apesar da disponibilidade destas soluções, há aplicações em que existe maior facilidade ou interesse no uso de materiais poliméricos originalmente em pó. No CTI há grande quantidade de rejeito de poliamida em pó dos equipamentos de MA SLS o qual pode ser utilizado para aplicações em pesquisa no equipamento Fab@CTI.

Neste contexto, há grande motivação no desenvolvimento de soluções para o uso de diferentes técnicas de estruturação de materiais poliméricos em pó implementadas na Fab@CTI. Dentre as soluções, a extrusão por rosca oferece características de maior interesse, tais como: alimentação contínua; melhor controle de deposição; facilidade de implementação (quando comparado com outras técnicas de MA a base de pó, como SLS); possibilidade de extrusão de múltiplos materiais controladamente e ainda, otimização nos parâmetros de projeto com diferentes materiais.

\subsection{Objetivo}

Este trabalho tem como objetivo apresentar o estudo da viabilidade técnica e o desenvolvimento do projeto e construção do protótipo funcional de um minicabeçote de extrusão vertical com rosca de seção variável, para aplicação em impressoras tridimensionais portáteis de baixo custo, em específico na impressora base Fab@CTI. 


\section{Fundamentação teórica}

Neste capítulo são apresentados os conceitos básicos utilizados neste trabalho: desde a definição de polímeros e bio-polímeros, MA e uma breve explicação sobre o desenvolvimento de projeto em engenharia.

\subsection{Introdução aos polímeros industriais}

O uso de polímeros naturais, derivados de plantas e animais tem sido utilizado há muitos séculos. Esses materiais incluem madeira, borracha, algodão, lã, couro e seda. Com a industrialização muitos materiais poliméricos incluindo borrachas e fibras foram fabricadas, denominando-se polímeros sintéticos. Desde a Segunda Guerra Mundial, houve um crescente estudo e desenvolvimento de materiais poliméricos e compósitos, principalmente como substituto de materiais metálicos quando há, por exemplo, necessidade de redução de peso, melhoria de propriedades físicas e mecânicas. Entretanto, novas áreas têm criado novas demandas, como por exemplo, áreas da saúde e engenharia civil.

A resposta dos polímeros aos esforços mecânicos em altas temperaturas está relacionada à sua estrutura molecular dominante. Uma das possíveis classificações desses materiais é feita em função do seu comportamento frente às alterações de temperatura. Os polímeros podem ser classificados em três grupos: termoplásticos, termorrígidos (ou termofixos) e elastômeros (RAUWENDAAL, 2001).

Os materiais termoplásticos se tornam macios e deformáveis quando aquecidos (processos reversíveis) e endurecem quando são resfriados (RAUWENDAAL, 2001). Portanto, uma característica importante desses materiais é que eles podem ser reciclados. Exemplos de polímeros termoplásticos são: polietileno, PVC, polipropileno, poliestireno, poliéster, acrílicos, poliamidas, celuloses, policarbonatos e PTFE.

Os materiais termorrígidos são polímeros que se tornam permanentemente rígidos, quando submetidos à aplicação de calor, sendo geralmente mais resistentes 
que os materiais termoplásticos. Exemplos de polímeros termorrígidos são: epóxis, resinas fenólicas e resinas poliéster.

Os materiais elastoméricos são capazes de resistir a elevadas deformações, se comportando de maneira elástica e ao cessar a força que provoca a deformação o material retorna completamente ou quase ao seu estado inicial (RAUWENDAAL, 2001).

A temperatura de fusão $\left(T_{m}\right)$ de um polímero termoplástico corresponde à temperatura de transformação do material sólido em um líquido. Há diversas diferenças entre a fusão dos polímeros, em relação aos materiais cerâmicos e metálicos, uma vez que as características deste material são determinadas pela sua estrutura molecular e morfologia lamelar cristalina.

A fusão dos diferentes tipos de polímeros pode acontecer sobre uma vasta faixa de temperaturas. Além disso, o comportamento dos polímeros neste estado depende da história térmica, em particular da temperatura na qual ele sofreu cristalização.

A transição vítrea $\left(T_{g}\right)$ ocorre em polímeros amorfos e semicristalinos, devida a uma redução no movimento dos segmentos de cadeias pela diminuição da temperatura que ocorre em todo o material que não se cristalizou. Corresponde à transformação gradual de um líquido em um material com as características de borracha e então para um sólido amorfo ou vítreo. A temperatura em que o polímero experimenta a transição do estado com característica de elastômero para o estado em que o polímero é rígido e duro é chamada de $\mathrm{T}_{\mathrm{g}}$. Essa sequência de eventos pode ocorrer na ordem reversa, quando um sólido a baixa temperatura é aquecido. Nessa condição o material sofre mudanças significativas em suas propriedades como: rigidez, capacidade térmica e coeficiente de expansão térmica.

As $T_{m}$ e $T_{g}$ são parâmetros muito importantes para o processamento de polímeros. Elas definem respectivamente o limite superior e inferior de temperaturas para um grande numero de aplicações. As temperaturas Tm e Tg são representadas 
em um gráfico que relaciona as temperaturas ao volume específico do material, como apresentado na Figura 2.1.

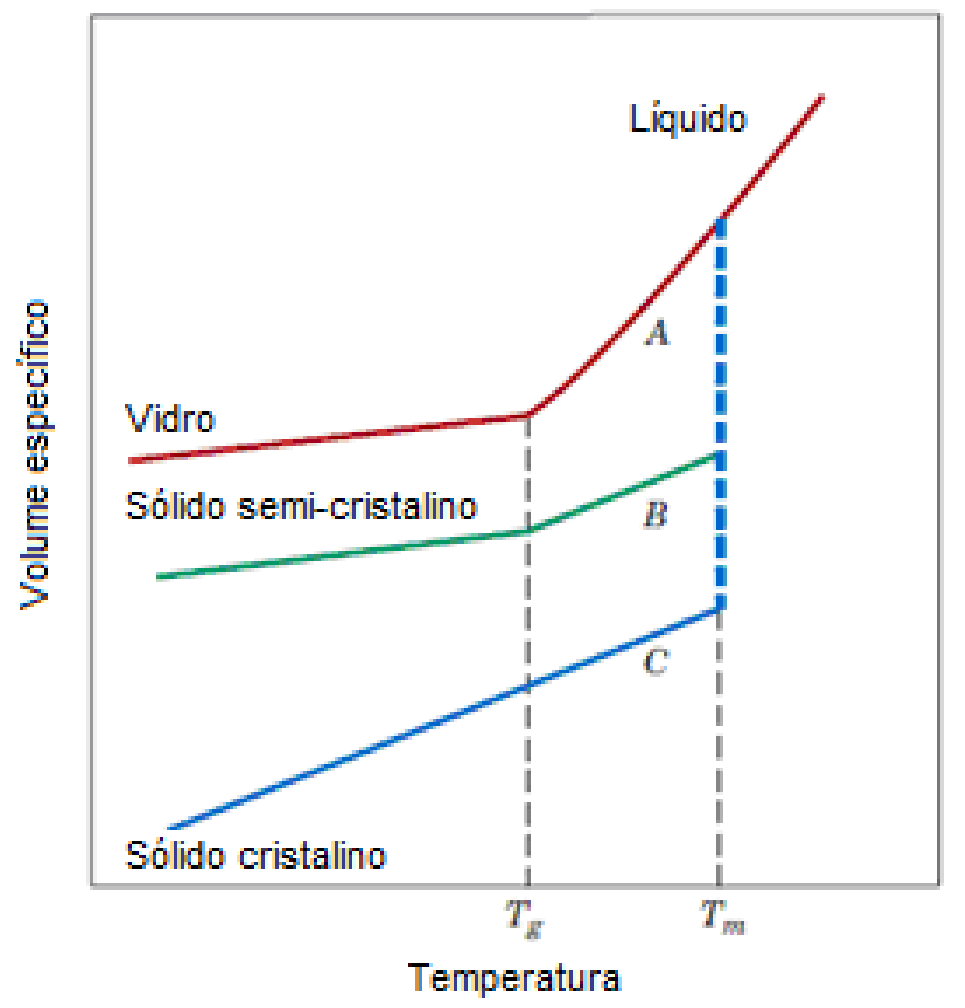

Figura 2.1 - Gráfico de Temperatura $\times$ Volume específico. $(A=$ polímero amorfo, $B=$ polímero semicristalino, $C=$ polímero cristalino) (CALLISTER, 2002).

$\mathrm{Na}$ Tabela 2.1 são apresentadas as temperaturas de transição vítrea e de fusão para os polímeros de maior uso na indústria de processamento de plásticos. 
Tabela 2.1 - Temperaturas de fusão e transição vítrea para alguns polímeros comuns (Traduzido: CALLISTER, 2002).

\begin{tabular}{lcc}
\hline \multicolumn{1}{c}{ Material } & $\begin{array}{c}\text { Temperatura } \\
\text { de Transição } \\
\left.\text { Vítrea [ }{ }^{\circ} \mathbf{C}\right]\end{array}$ & $\begin{array}{c}\text { Temperatura } \\
\text { de Fusão [ㅜㅜ] }\end{array}$ \\
\hline Polietileno (Baixa densidade) & -110 & 115 \\
\hline Politetrafluoretileno & -97 & 327 \\
\hline Polietileno (Alta densidade) & -90 & 137 \\
Polipropileno & -18 & 175 \\
Nylon® 6,6 & 57 & 265 \\
\hline Poliéster (PET) & 69 & 262 \\
Poli (Cloreto de polivinilo) - & 87 & 212 \\
PVC & & 240 \\
Poliestireno & 100 & 265 \\
\hline Policarbonato & 150 & \\
\hline
\end{tabular}

\subsubsection{Processamento de polímeros}

Uma grande variedade de técnicas é empregada na conformação de materiais poliméricos. A escolha do método depende de vários fatores como por exemplo: tipo de polímero (termoplástico ou termorrígido); temperatura de fusão, temperatura de transição vítrea, geometria e dimensões do produto acabado.

A conformação de materiais poliméricos pode envolver gradientes de temperaturas e/ou aplicação de pressão. Os termoplásticos amorfos são conformados acima da temperatura de transição vítrea. Para termoplásticos semicristalinos são utilizadas temperaturas acima do ponto de fusão. $O$ benefício econômico de se utilizar termoplásticos é que eles podem ser reciclados (finitamente, até se degradarem).

O processo de moldagem é o método mais comum para conformar materiais poliméricos. As técnicas de moldagem incluem compressão, sopro, injeção e 
extrusão. Em todos esses casos uma quantidade de plástico granulado ou viscoso é forçada, com elevação da temperatura e aplicação de pressão, a escoar e preencher um molde, que dará a forma final do componente (CARLOS, 2009).

A moldagem por injeção é uma das técnicas mais utilizadas para polímeros termoplásticos. A quantidade correta de polímero é alimentada, a partir de um sistema de alimentação para o interior do cilindro, através de um pistão. Essa carga é empurrada pelo pistão para uma câmara de aquecimento na qual o material termoplástico se funde para formar um líquido viscoso. Em seguida, o plástico é impelido pelo movimento do pistão através de um bico injetor para o interior do molde. A grande vantagem é a velocidade com que as peças podem ser produzidas, uma vez que para termoplásticos a solidificação da carga injetada é quase imediata (CARLOS, 2009). O equipamento é constituído por dois componentes principais: Unidade de injeção - funde e pressiona o polímero fundido (funciona como uma extrusora); Unidade de fechamento - abre e fecha o molde em cada ciclo, conforme a Figura 2.2 ilustra.

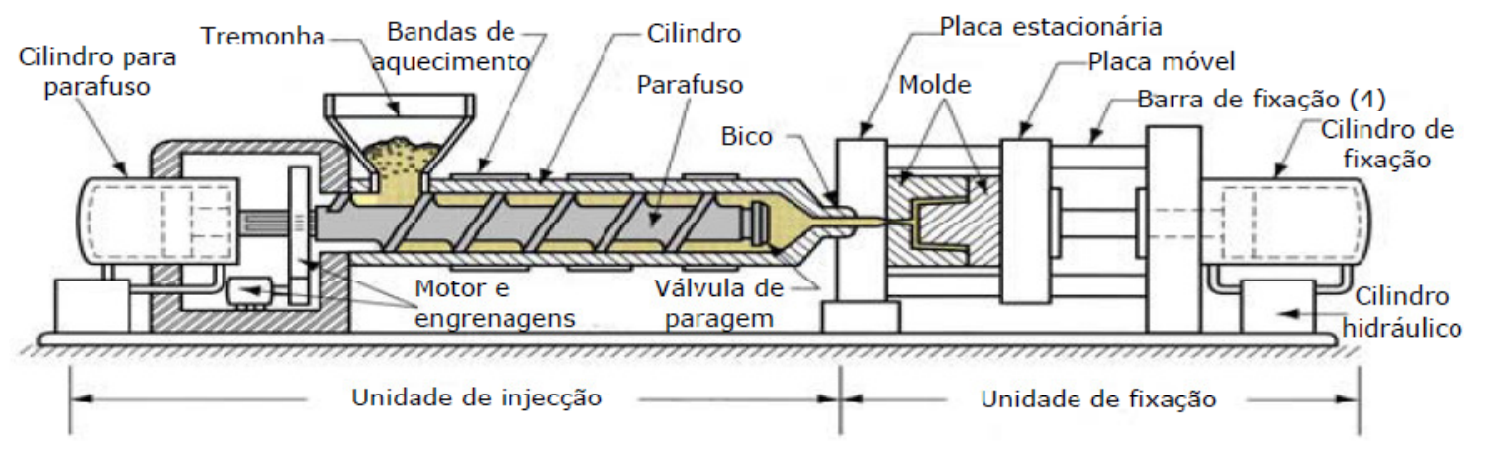

Figura 2.2 - Esquema de um conjunto de moldagem por injeção (CANALE, et. al 2007 apud CARLOS, 2009).

O ciclo de injeção compreende: injeção; compactação e resfriamento; abertura do molde; ejeção da peça; fechamento do molde.

O processo de extrusão é uma forma de moldagem antiga, sem uma data precisa de início. Em escala industrial, ocorreu no século XIX, para a fabricação de tubos de chumbo, peças cerâmicas, eletrodos de carbono, grafite de lapiseira e polímeros. O termo "extrusão" é de origem latina e significa: "ex" - força e "tudere" 
empurrar. É um processo de conformação que produz peças com diferentes comprimentos e seção transversal constante forçando o material a passar através de um cabeçote sob condições de pressão e temperatura controlada (Fonte: http://emc5744.barra.prof.ufsc.br/parte\%202\%20 revisada.pdf).

No processo de conformação por extrusão uma massa fundida de material é empurrada, através de um pistão ou parafuso sem fim para o orifício de uma matriz, conforme ilustra a Figura 2.3. A solidificação do segmento extrudado é acelerada por sopradores ou por um borrifador de água. A técnica é empregada para comprimentos contínuos como bastões, tubos, canais de mangueira, folhas finas e filamentos.

$\mathrm{Na}$ indústria de alimentos, o uso do processo de extrusão produz, por exemplo, salsichas, cereais, massas de alimentos e "salgadinhos" (RAUWENDAAL, 2001).

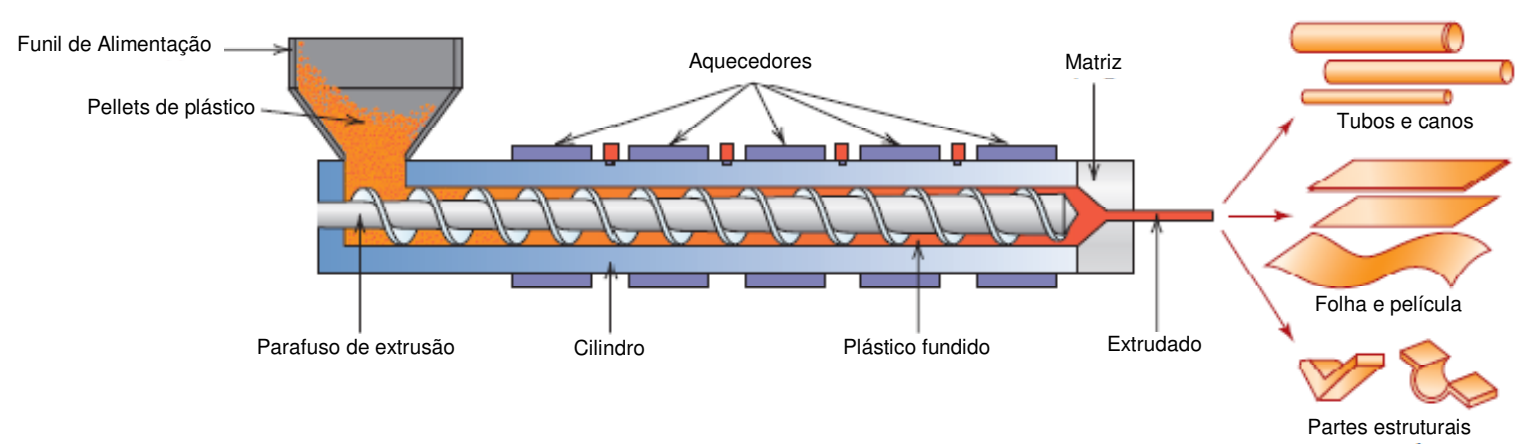

Figura 2.3 - Esquema de um conjunto de moldagem por extrusão (Traduzido: CALLISTER, 2002).

Na extrusão, a rosca gira a uma razão constante. Uma máquina que opera por injeção (torpedo) apresenta operações diferentes de uma extrusora: no processo de extrusão há um deslizamento de atraso ou retorno com a rotação da rosca, para a preparação da fusão, e então a mistura é pressionada através dos bicos.

Segundo Rauwendaal (2001), grande parte dos polímeros são extrudados em estado amolecido. Entretanto, algumas aplicações envolvem a extrusão em estado sólido. Se o polímero que alimenta o sistema de extrusão se encontra em estado sólido e o material amolecido é transportado ao longo da rosca extrusora, o 
processo é chamado de extrusão de plastificação. Neste caso, a extrusão desempenha uma função adicional, denominada amolecimento (ou derretimento), além de regular a função de extrusão. Em outras aplicações, o sistema de extrusão é alimentado com o polímero amolecido, denominado extrusão de alimentação derretida. Neste caso, o sistema de extrusão atua puramente como uma bomba, desenvolvendo a pressão necessária para forçar o polímero amolecido para a matriz.

Há dois tipos básicos de extrusoras: contínua e descontínua (batelada). As extrusoras contínuas são capazes de estabilizar fluxo contínuo de material, enquanto que no processo por bateladas elas operam ciclicamente.

As roscas extrusoras podem ser classificadas como rosca extrusora (processos contínuos); extrusoras de disco e extrusoras alternativas (processos descontínuos). De acordo com Rauwendaal (2001), a rosca simples é o mais importante tipo de extrusora utilizada na indústria de polímeros. As vantagens incluem custo relativamente baixo, projeto mais básico, superfície mais resistente aos esforços e confiabilidade e desempenho favorável para a relação custo/desempenho.

Uma rosca plastificadora de extrusão ou extrusora de estágio único, para aplicação industrial possui três diferentes seções apresentada na Figura 2.4.

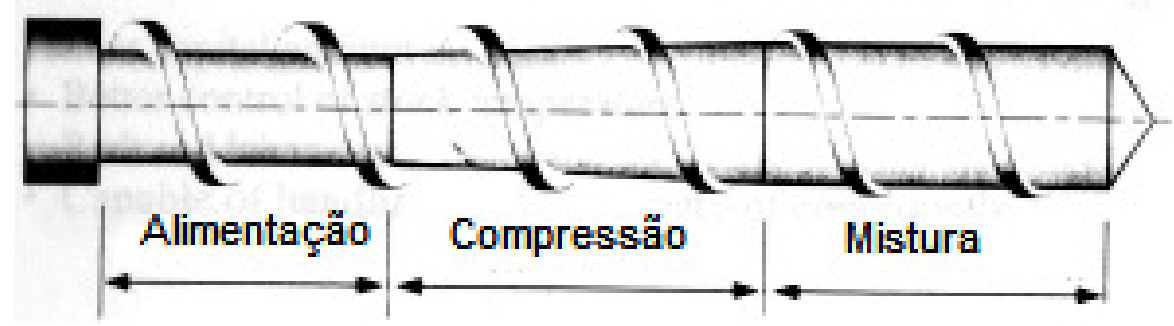

Figura 2.4 - Geometria de uma rosca extrusora simples (Fonte: RAUWENDAAL (2001)).

A dimensão de uma rosca de extrusão é descrita através de seus diâmetro (D) e comprimento (L). O comprimento é dado, normalmente pela relação "L/D". 
Segundo Chung (2000) as três seções distintas em uma rosca convencional são: (a) seção de alimentação; (b) seção de compressão e (c) seção de mistura ou dosagem. A relação das áreas das seções transversais do canal de alimentação, para o canal de pressão é denominada razão de compressão (CR).

As extrusoras industriais são normalmente projetadas a partir diâmetro do cilindro de extrusão, conforme norma adotada. Sendo o cilindro estacionário e a rosca rotativa, as forças de atrito irão atuar no material, em ambos os elementos, sobre o cilindro bem como sobre a superfície da rosca. Essas forças de atrito são responsáveis pelo transporte direto do material e também pelo calor gerado no processo nas seções de homogeneização e plastificação. As condições das zonas funcionais dependem das propriedades dos polímeros, geometria dos elementos e das condições operacionais. Esses requisitos podem ser descritos por um conjunto de dados geométricos, como por exemplo, tamanho da raiz e do canal, profundidade dos canais, passo da rosca, ângulo de avanço e ângulo de hélice.

O projeto preliminar de uma rosca extrusora pode ser iniciado considerando inicialmente as condições estáticas do elemento "rosca", que incluem: resistência à torção da raiz da rosca; resistência mecânica do avanço da rosca e deflexão lateral da rosca (de forma análoga a uma barra em balanço). Para cada seção de uma rosca simples pode ser realizado um estudo otimizado: na seção de transporte de sólido devem-se verificar os valores e relação entre a profundidade do canal e a taxa de transporte; na seção de amolecimento pode-se verificar a relação entre o ângulo de hélice com índice da lei das potências e gradiente de pressão; e na seção de na seção de plastificação verificar a relação entre o ângulo de avanço e o passo, bem como a relação de compressão.

Esses cálculos são apresentados em Freitas (2011) e no capítulo 6 são apresentados os valores obtidos para a geometria da rosca e do cilindro, bem como do sistema de acionamento.

As roscas extrusoras podem ser ventiladas, para que gases voláteis possam escapar ou para que se possa adicionar ao polímero: aditivos, carga mineral e elementos para reação química. 
A escolha do método utilizado para conformação de um determinado polímero depende de alguns fatores, como por exemplo, da escolha do próprio polímero, geometria e tamanho da peça final. Em se tratando de um polímero termoplástico, devem ser consideradas as propriedades reológicas (curvas de escoamento e ponto de fusão), temperatura operacional, tempo de resfriamento, após a moldagem; sendo um termofixo, considera-se a temperatura e tempo de cura.

A temperatura (ou ponto) de fusão descreve a transformação de fase de um sólido cristalino para um líquido. Chung (2000) explica que esse termo é utilizado somente para polímeros cristalinos, porque polímeros amorfos sem cristalização não apresentam o mesmo ponto de fusão (pode ocorrer acima do $\mathrm{Tg}$, para polímeros amorfos termoplásticos). Chung (2000) descreve o processo de fusão como uma mudança de comportamento sólido para liquido, em polímeros amorfos ou quase sólido.

Segundo Rauwendaal (2001), há uma grande variedade de partículas poliméricas utilizadas no processo de extrusão, estando em uma faixa de $1 \mu \mathrm{m}$ a 10 mm. A Figura 2.5 classifica as partículas sólidas em função de suas dimensões.

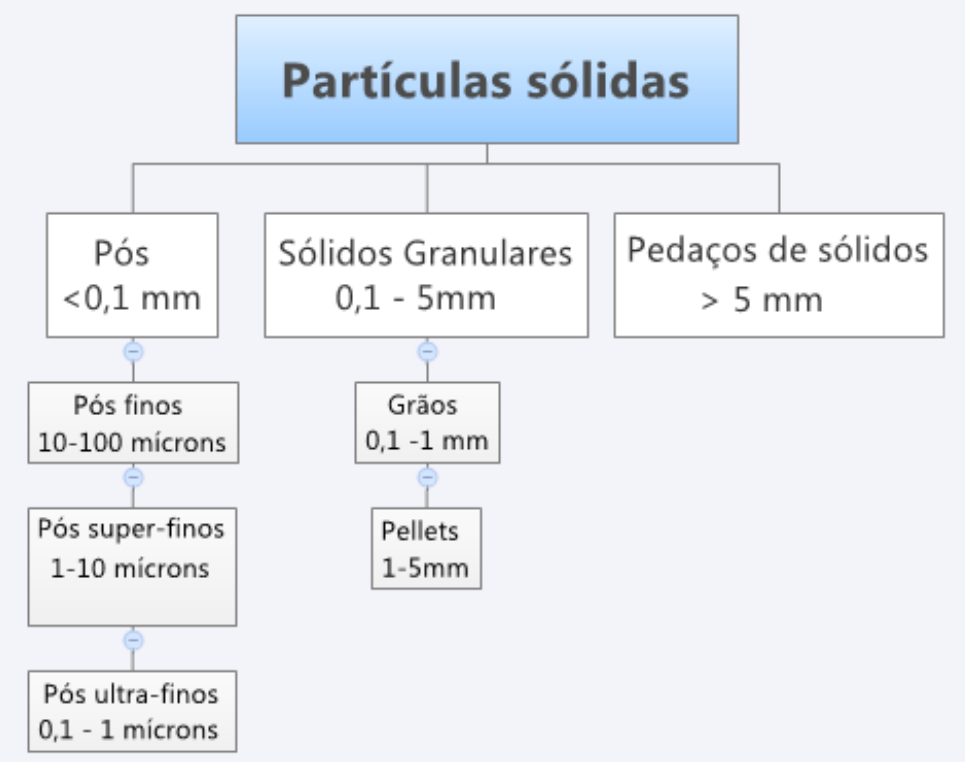

Figura 2.5 - Classificação de partículas (RAUWENDAAL, 2001). 
De acordo com Rauwendaal (2001) o processamento de polímeros feitos com extrusoras envolve o uso de material em alguma forma sólida alimentado pela rosca de extrusão, que é amolecido e transportado pela rotação da rosca até o final do percurso projetado. Os projetos com rosca única e dupla para extrusão, constituem as configurações mais comuns neste tipo de processamento.

A mistura pode ser dividida em dois tipos: distributiva e dispersiva. Na mistura dispersiva ocorre a redução em tamanho de um componente presente na mistura. Um exemplo desse tipo de mistura é a inserção de um pigmento dentro de um polímero, no qual o tamanho aglomerado do pigmento é reduzido a um valor inferior a um tamanho especifico, para manter uma qualidade superficial satisfatória do produto final. $\mathrm{Na}$ mistura distributiva há ausência de uma resistência coesiva, simples ou não dispersiva. Um exemplo deste tipo de mistura é a mistura de dois polímeros miscíveis durante o estágio de derretimento, como por exemplo: Poliestireno (PS) e Óxido de Polifenileno (PPO).

A mistura de um polímero com um componente semi-sólido (carga mineral) fornece um compósito, como por exemplo, a combinação de mica com polipropileno produz um compósito termoplástico. Uma mistura feita com diferentes polímeros fornece uma blenda, como por exemplo, polietileno e poliamida. Uma blenda é considerado miscível se os polímeros forem completamente dissolvidos, em cada uma das fases, e a tensão interfacial entre os componentes for igual a zero. Porém, a maioria dos sistemas poliméricos possui uma solubilidade limitada e uma tensão interfacial diferente de zero e grande parte das blendas são considerados imiscíveis, pois produzem uma blenda multifásica. Exemplos comerciais de blendas são: Texin (Bayer) composto por PU-PC; Bayblend (Bayer) composto por PC-ABS. A mistura pode ainda, ser definida como um processo para redução de não uniformidade de composição.

O processo básico envolvido na mistura consiste em induzir movimento relativo entre as partes em mistura. Podem ocorrer basicamente três tipos de movimento: 
Difusão: é a distribuição controlada de um material dentro de outro sem qualquer força de direcionamento externa. A contribuição da difusão para o processo de mistura é fundamentalmente determinada pelo coeficiente de dispersão e 0 tempo disponível para mistura. Quanto menor o coeficiente de dispersão, maior o tempo necessário para que a difusão tenha influência na mistura. Para o amolecimento de polímeros com elevada viscosidade, o coeficiente de dispersão possui normalmente um valor muito pequeno. Como resultado, em muitas operações de mistura de polímeros durante um processo de extrusão, o tempo disponível para mistura é muito curto para que a dispersão ocorra e se tenha um efeito significativo da difusão sobre o processo de mistura. Para os estágios finais de mistura, quando as dimensões se reduzem à escala micrométrica, pode haver uma influência da difusão. No entanto, esse mecanismo é importante para mistura de gases e líquidos de baixa viscosidade.

Turbulência: escoamento turbulento é o movimento de um fluido com velocidade instantânea e pressões que se alteram caoticamente. O movimento turbulento ocorre, quando as forças de inércia interagem com as forças viscosas dominantes de um fluido. A razão entre as forcas inerciais e viscosas pode ser quantificada de forma adimensional pelo número de Reynolds.

O número de Reynolds que indica transição para o regime turbulento ocorre na faixa de 2.100 à 4.000 , sendo que acima de 4.000 o fluido encontra-se em regime turbulento. Números de Reynolds típicos em processamento de polímeros estão entre 0 e 1 devido a alta viscosidade. Portanto, o processamento de polímeros possui um baixo número de Reynolds, que caracteriza regime laminar.

Movimento de convecção: o movimento de convecção é definido como um fluxo de massa em um fluido induzido pela desigualdade de massa molar ou influências externas como diferenças de pressão ou forças de campo, sendo o mecanismo predominante no processamento de polímeros. As forças de condução do movimento convectivo são tipicamente a aplicação de uma diferença de pressão, que cria um escoamento; ou um movimento no contorno, que também cria um escoamento. Em roscas de extrusão o escoamento é uma combinação do movimento de contorno com as diferenças de pressão. O movimento de contorno 
ocorre devido à rotação da rosca e as diferenças de pressão são geradas por essa rotação. O escoamento através do bico de extrusão é um escoamento puro de pressão, a menos que haja um movimento de contorno nessa região, como uma extrusão tipo wire-coating.

A rosca de extrusão é um elemento mecânico que utiliza o movimento de rotação para o deslocamento do material. A rosca é fabricada a partir de um aço-liga com elevada resistência térmica e à corrosão, bem como resistência mecânica à torção e flexão, devendo apresentar superfície polida. A função de projeto da rosca é deslocar o material polimérico através da matriz; misturar convenientemente o material polimérico; ter comprimento suficiente para promover o amolecimento, reduzindo a viscosidade do material.

A geometria da rosca muda para cada tipo de polímero, bem como ao longo de sua própria geometria. Esta diferença de geometria ocorre porque os termoplásticos diferem entre si quanto às propriedades térmicas (capacidade calorífica, calor latente de fusão, temperatura de fusão cristalina e temperatura de transição vítrea); quanto às propriedades reológicas (curvas de escoamento e viscosidade) e quanto às propriedades mecânicas, como por exemplo, dureza superficial e resistência à compressão). Rauwendaal (2001) e Béreaux et al. (2009) citam os fatores críticos, que influenciam a saída (vazão) do material como: geometria da rosca, reologia do material, propriedades de derretimento do polímero e condições de processamento.

\subsubsection{Bio-polímeros}

Biomateriais são materiais que interagem com sistemas biológicos para avaliar, tratar, aumentar ou repor algum tecido, órgãos ou função do organismo. $O$ termo "biocompatível" pode ser utilizado para caracterizar biomateriais e sua "biocompatibilidade", definida como a qualidade de não causar efeitos tóxicos ou danosos ao organismo hospedeiro. Porém, no contexto da aplicação, este termo deve ser usado com cautela, pois nenhum material é capaz de gerar uma resposta adequada em todas as situações (SENEDESE, 2011). 
Os biomateriais são fundamentais na engenharia de tecidos principalmente na estruturação dos scaffolds. O scaffold pode ser definido uma estrutura porosa temporária utilizada para facilitar o crescimento de células funcionando como suporte estrutural para formação de novos tecidos biológicos (IKEGAMI, 2007). Diversos polímeros de origem sintética e natural têm sido amplamente estudados para esta finalidade.

A construção de scaffolds, por necessitar de geometrias complexas, vem se mostrando como uma evolução natural para a aplicação no uso da tecnologia de MA, motivando assim o desenvolvimento de equipamentos que utilizam biomateriais como matéria-prima.

O primeiro passo para a reconstrução de um órgão ou tecido preconiza a seleção do suporte para as células. Durante a seleção são considerados o tipo, local da lesão e sua extensão, fatores que influenciam na estratégia de aplicação da estrutura.

O desenvolvimento de scaffolds deve seguir regras primárias, sendo estas: servir como um substrato de adesão para células, facilitando a localização e distribuição das mesmas quando implantadas; promover suporte mecânico para o crescimento das células, mantendo a sua estrutura original e guiar o desenvolvimento de novos tecidos com sua função definida.

Segundo Ikegami (2007), em relação às propriedades físico-químicas e mecânicas, o scaffold deve apresentar as seguintes características:

- Ser altamente poroso com os poros interconectados, diâmetros entre $200 \mu \mathrm{m}$ e $600 \mu \mathrm{m}$, para obter um considerável crescimento das células e fluxo dos nutrientes;

- Ser feito de materiais biocompatíveis ou biodegradáveis com reabsorção controlada e taxa de degradação;

- Apresentar superfície adequada para adesão, proliferação e diferenciação das células. 
No processo de escolha dos materiais empregáveis na fabricação de scaffolds para a cultura de células alguns critérios gerais devem ser seguidos para encontrar um equilíbrio entre suas propriedades mecânicas e o tempo necessário para a degradação conforme a aplicação. Para isto, no caso de polímeros, o material ideal deveria ser configurado considerando condições de desempenho e adequação, como por exemplo: possuir propriedades mecânicas que se adaptem à aplicação, permanecendo suficientemente resistente até que a região envolvida esteja curada; não promover inflamação ou resposta tóxica; ser metabolizado no organismo após cumprir o seu propósito, sem deixar traços; ser facilmente processável até a obtenção do formato final; e permitir processos de esterilização.

A degradação do polímero no organismo está associada à sua síntese, no que se refere às ligações hidroliticamente instáveis na cadeia principal. Os fatores que influem nesse processo incluem: a seleção dos monômeros, a seleção do iniciador, as condições do processo e a presença de aditivos. Estes fatores, por sua vez, influenciam a hidrofilia, cristalinidade, as temperaturas de fusão e transição vítrea, peso molecular e distribuição de peso molecular, grupo terminal, sequência de distribuição e presença residuais de monômeros ou aditivos.

Para o processamento de polímeros hidrofílicos alguns cuidados devem ser tomados tanto no armazenamento do material quanto no processo em si, a preocupação com a redução da umidade do ambiente e o controle da temperatura de trabalho evita a degradação prematura do mesmo. Nesse último caso, devido à forma como os polímeros biodegradáveis são sintetizados, o equilíbrio térmico tornase fundamental para evitar a reação inversa que resulta na formação de monômeros. Nos processos que empregam altas temperaturas, o excesso de monômeros que são formados pode atuar como plastificante, alterando as propriedades mecânicas e podendo catalisar a hidrólise do material, alterando a cinética da degradação (VOZZI, 2001).

As pesquisas que visam o desenvolvimento e fabricação de scaffolds têm gerado grandes discussões e diversos trabalhos no mundo científico. Em meio a este cenário, os polímeros biorreabsorvíveis têm ganhado enorme destaque. 
Biorreabsorvíveis são materiais poliméricos e dispositivos sólidos que mostram degradação por meio da diminuição de tamanho e que são reabsorvidos in vivo; isto é, materiais que são eliminados por rotas metabólicas do organismo. Biorreabsorção é um conceito que reflete a eliminação total do material e dos subprodutos de degradação (compostos de baixo peso molecular) sem efeitos colaterais residuais. O uso da palavra "biorreabsorção" é feito quando a eliminação é total.

Devido à falta de padronização dos termos aplicados aos conceitos de biodegradação e biorreabsorção, as definições utilizadas ao longo deste trabalho foram baseadas naquelas fornecidas por Vert (2009), um dos pesquisadores pioneiros no estudo de materiais poliméricos biorreabsorvíveis.

Biodegradável é um termo utilizado para polímeros e dispositivos sólidos que devido à degradação macromolecular sofrem dispersão in vivo, mas sem a eliminação dos produtos e subprodutos pelo organismo. Polímeros bio-degradáveis podem ser atacados por elementos biológicos de forma que a integridade do sistema seja afetada, formando-se fragmentos ou outros subprodutos de degradação, que podem ser removidos do seu local de ação, mas não necessariamente do organismo.

Dentre os polímeros sintéticos biodegradáveis e biorreabsorvíveis encontramse os poli(a-hidróxi ácidos), representantes de uma classe de poliésteres alifáticos sintéticos, dos quais fazem parte o PGA, PLA, PLGA, PCL, seus copolímeros (polimerização de monômeros diferentes) e outros. A Tabela 2.2 apresenta algumas propriedades destes polímeros.

No caso da utilização de polímeros biorreabsorvíveis para a fabricação de scaffolds podem ser seguidas duas estratégias. Na primeira, o material polimérico é desenvolvido de forma a suportar física e mecanicamente as células, da inoculação até o reimplante no paciente. $O$ implante do conjunto polímero e células ocorrem com um tecido prematuro formado e o polímero é substituído a partir de sua degradação in vivo, numa razão proporcional ao crescimento celular e à solicitação mecânica. Sua função é proporcionar suporte para o crescimento celular e 
adicionalmente servir como substituto mecânico/estrutural do tecido original até a formação do novo tecido e sua biorreabsorção completa.

Tabela 2.2 - Polímeros sintéticos biorreabsorvíveis - poli(a-hidróxi ácidos) (BARBANTI et al, 2005).

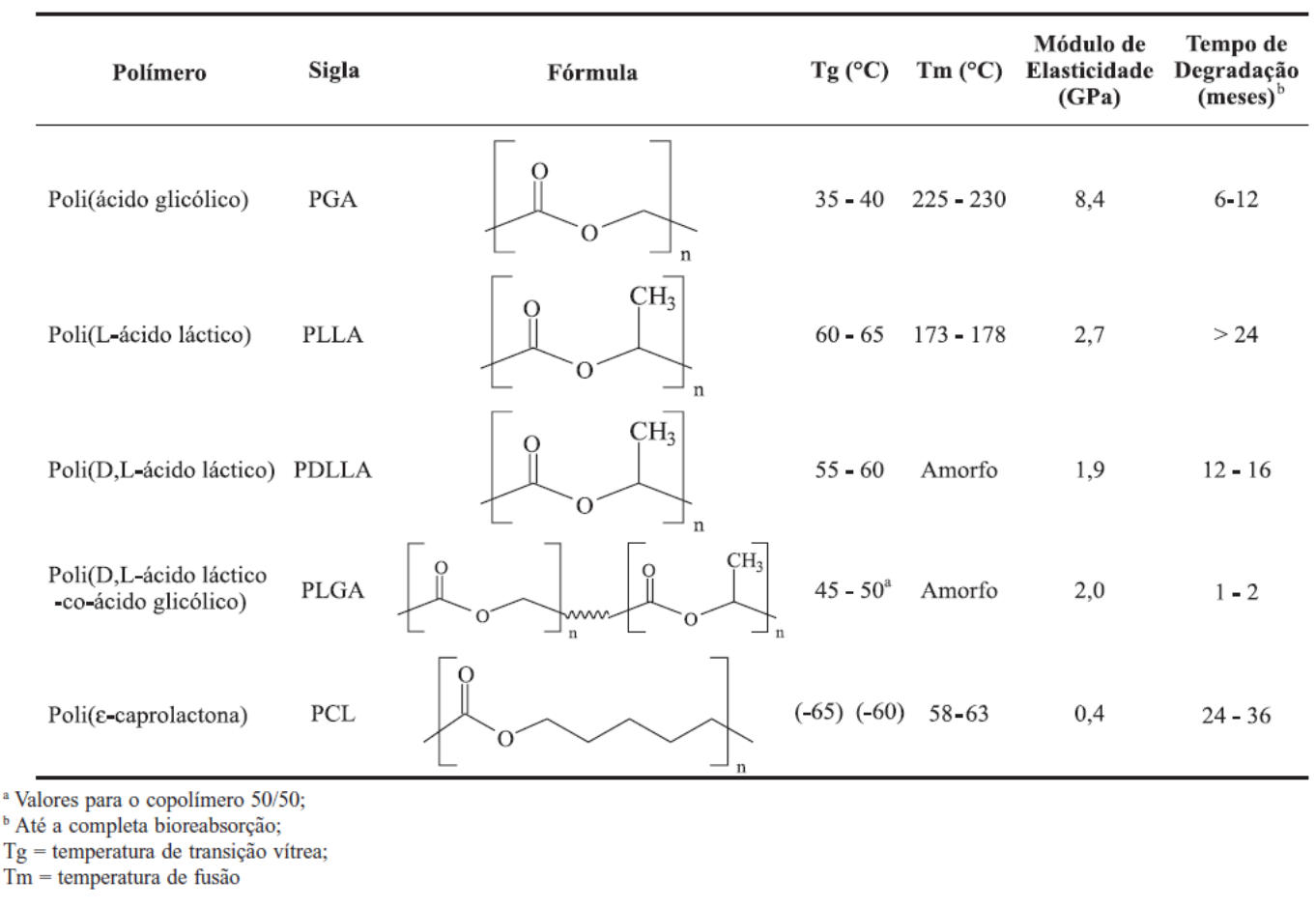

Já na segunda estratégia, o implante ocorre com tecido maduro formado. $\mathrm{O}$ suporte polimérico é dimensionado com propriedades mecânicas e tempo de degradação adequado para a inoculação das células até a sua inserção num biorreator, onde ocorrerá a formação de tecido maduro. Nesta etapa, as células semeadas proliferam e secretam a matriz extracelular durante a cultura in vitro, enquanto o polímero é degradado e reabsorvido gradualmente, permitindo espaço para a proliferação celular e formação do tecido no reator biológico. Somente após a formação do tecido, o implante é inserido no organismo.

A produção de scaffolds pode ser feita de várias formas, no entanto o estudo da prototipagem rápida para este fim mostra características de interesse, tais como a possibilidade de construir diretamente modelos 3-D (micro e macro) de geometria complexa a partir de deposição em camadas. Os scaffolds devem substituir 
estruturas orgânicas de alta complexidade geométrica e biológica, as quais são obtidas diretamente com prototipagem rápida.

\subsection{Manufatura aditiva}

Prototipagem Rápida (PR) é um termo que a indústria de manufatura tem discutido por muitos anos. Definida na metade dos anos 80, a PR foi utilizada para descrever uma série de tecnologias, que constrói protótipos de produtos nos estágios iniciais do desenvolvimento do projeto de uma maneira rápida e automatizada. Uma variedade de diferentes técnicas combina essencialmente camadas planas de materiais dispostas sequencialmente para formar um objeto sólido tridimensional.

Segundo Campbell, et al. (2012) não há referência do termo "Prototipagem Rápida" que faça alusão a uma abordagem genérica como manufatura "baseada em camadas". Pode-se observar que, a aplicação atual desta tecnologia vai muito além de uma simples prototipagem. A partir da introdução das tecnologias chave, o desenvolvimento da PR tem sido fundamentalmente incremental. As primeiras máquinas incluíam cura por fotopolimerização. Luo et al. (2002) citam que a primeira máquina comercial de PR, a Stereolithography Apparatus (SLA) que foi comercializada em 1988. Posteriormente, outros processos de PR foram se desenvolvendo como a sinterização seletiva a laser (SLS); modelagem por fusão e deposição (FDM) desenvolvida pela Stratasys e laminação por folhas (LOM) desenvolvida pela Helisys. Todas essas tecnologias ainda são utilizadas, com exceção do LOM em função do excesso de material utilizado no processo. Em 1993, foi incluída a deposição baseada em partícula e a impressora 3-D licenciada pelo MIT.

O conhecimento e a experiência gerados ao longo desses anos têm impulsionado o que se desenha como "indústria de impressão tridimensional" a desenvolver impressoras tridimensionais, para aplicações em diversas áreas com custos reduzidos. O objetivo primário das tecnologias de PR foi a produção de 
modelos prototipados, o seu desenvolvimento inclui novas soluções construtivas e manufatura direta de produtos de consumo.

Grande parte das tecnologias comerciais têm atuado em melhorias como controle de velocidade dos eixos de deslocamento, precisão dimensional e propriedades dos materiais. O aumento de interesse das indústrias e centros de pesquisa promove a redução do custo de aquisição destas máquinas voltadas a PR e, ainda amplia sua faixa de aplicações. O reconhecimento da indústria destas tecnologias é evidente pelo desenvolvimento de padrões através da ASTM e ISO. Campbell, et al. (2012) e Gibson, et al. (2010) citam o reconhecimento das tecnologias de PR, que conduziu ao uso regular do termo Manufatura Aditiva, (MA, dentro da indústria de manufatura) e Impressão 3-D para o público geral - usuários.

A ASTM (American Society for Testing and Materials) adotou o termo Manufatura Aditiva, para os processos envolvendo técnicas de prototipagem rápida (GIBSON et al., 2010). Assim, na Manufatura Aditiva um modelo é gerado, a partir de um sistema tridimensional (CAD) sendo fabricado diretamente sem a necessidade de planejamento convencional de processo. A manufatura aditiva envolve a manufatura de peças complexas, através da adição de material, camada por camada, a partir de um modelo CAD (WOHLERS, 2012).

O termo "projeto" em MA pode ser entendido como o projeto de produto que pode ser um projeto industrial, projeto técnico de engenharia mecânica ou projeto de um bem de consumo; projeto de arquitetura e projeto de moda (fashion design).

Segundo Wohlers (2012), cada vez mais a manufatura aditiva vem crescendo e sendo aplicada em diversas áreas conforme demonstra a figura 2.6. 


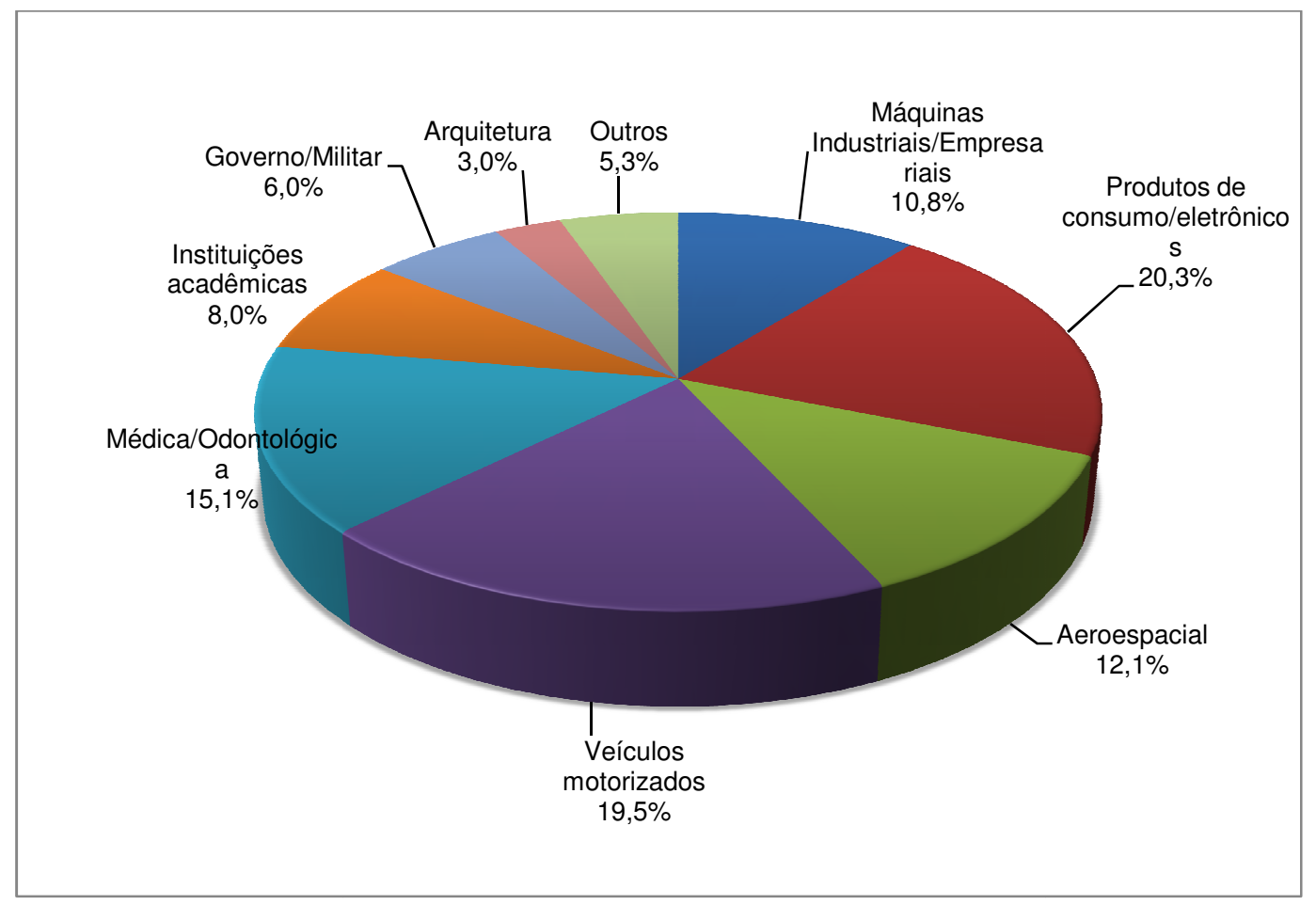

Figura 2.6 - Áreas de aplicações da manufatura aditiva (Traduzido: WOHLERS, 2012).

Há uma grande diversidade de processos para a manufatura aditiva. Uma forma de classificá-los é considerar a matéria-prima e como a peça é construída. A tabela 2.3 mostra as intersecções entre os processos de MA e as disponíveis famílias materiais. 
Tabela 2.3 - Processo X Materiais disponíveis (Traduzido: WOHLERS, 2012).

\begin{tabular}{|c|c|c|c|c|c|c|c|}
\hline & $\begin{array}{c}\text { Extrusão } \\
\text { de } \\
\text { material }\end{array}$ & $\begin{array}{l}\text { Jato de } \\
\text { material }\end{array}$ & $\begin{array}{l}\text { Jato de } \\
\text { material } \\
\text { ligante }\end{array}$ & $\begin{array}{c}\text { Fotopolimerização } \\
\text { em tanque }\end{array}$ & $\begin{array}{c}\text { Laminação } \\
\text { de folha }\end{array}$ & $\begin{array}{c}\text { Fusão } \\
\text { em leito } \\
\text { de pó }\end{array}$ & $\begin{array}{c}\text { Deposição } \\
\text { direta de } \\
\text { energia }\end{array}$ \\
\hline $\begin{array}{l}\text { Polímeros, } \\
\text { misturas de } \\
\text { polímeros }\end{array}$ & $\bar{x}$ & $\bar{X}$ & $\bar{x}$ & $\bar{x}$ & $X^{1}$ & $\bar{X}$ & \\
\hline Compósitos ${ }^{2}$ & & $x$ & $\mathrm{X}$ & $x$ & & $\mathrm{X}$ & \\
\hline Metais & & $\mathrm{X}$ & $x$ & & $x$ & $x$ & $x$ \\
\hline Metais híbridos ${ }^{3}$ & & & & & $x$ & & $\mathrm{x}$ \\
\hline Cerâmicas & & & $x$ & $x$ & & $\mathrm{X}$ & \\
\hline $\begin{array}{l}\text { Padrões de } \\
\text { fundição }\end{array}$ & & $\mathrm{X}$ & $\mathrm{X}$ & $X$ & & $X$ & \\
\hline $\begin{array}{l}\text { Moldes de } \\
\text { areias e } \\
\text { revestimentos }\end{array}$ & $\mathrm{X}$ & & $\mathrm{X}$ & & & $x$ & \\
\hline Papel & & & & & $X$ & & \\
\hline
\end{tabular}

Notas de rodapé:

1 - O sistema de laminação de folhas sólidas, que já não está disponível comercialmente, usava o PVC.

2 - Inclui materiais preenchidos.

3 - Materiais híbridos são mais tipicamente produzidos usando fabricação aditivo por meio de ultrassons. Materiais graduados são produzidos em sistemas de deposição direta de energia.

De acordo com Luo et al. (2002) e Gibson et al. (2010) os principais processos de MA podem ser classificados de acordo com a natureza da matériaprima:

- Resinas fotossensíveis (acrílicas, elastoméricas);

- Materiais sólidos (termoplásticos, madeira, papel, acrílico);

- Materiais em pó (cerâmico, plástico, metal, elastômeros);

No próximo item são apresentados os processos de manufatura aditiva mais utilizada na indústria e centros de pesquisa. 


\subsubsection{Processos de Fotopolimerização}

$O$ processo de fotopolimerização consiste na polimerização de uma resina líquida fotocurável, que se solidifica como resultado de irradiação eletromagnética. A grande maioria dos polímeros comerciais é curável na faixa do espectro ultravioleta.

- Processos de cura por ponto

A terminologia mais usada para a cura por ponto de fotopolímeros é a estereolitografia. Neste processo as peças são construídas ponto a ponto, linha por linha, camada por camada numa cuba de resina líquida fotocurável, como mostra a Figura 2.7.
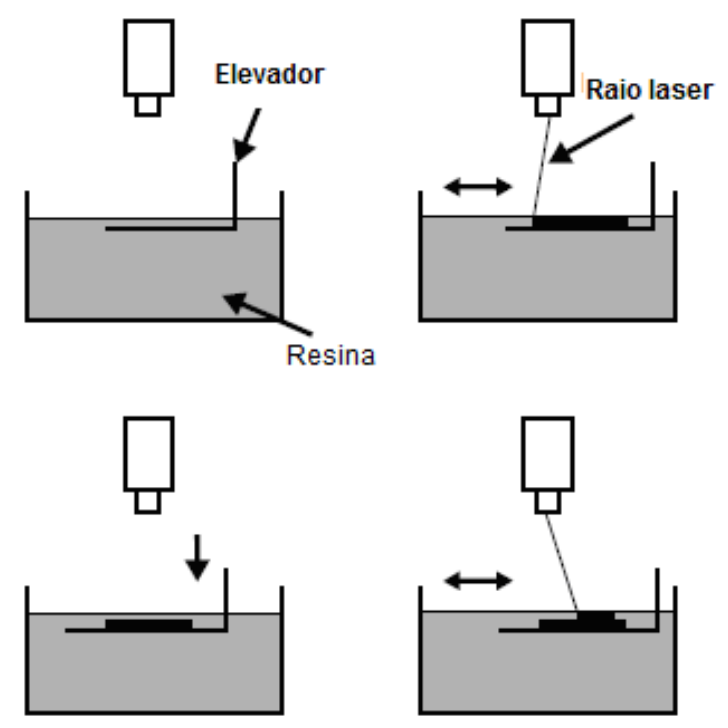

Figura 2.7 - Esquema do processo de estereolitografia (POWERS et al., 2007).

Inicialmente uma fina camada é formada no topo, através de um mecanismo de recobrimento. Um raio laser focado precisamente, desenha a seção transversal da camada, na superfície de resina líquida. A resina é curada por toda a trajetória feita pelo laser, criando uma camada sólida que fica aderida na plataforma. A plataforma é deslocada para um nível inferior, por um sistema de movimentação e uma nova camada é feita sobre a camada recém-formada. Um exemplo comercial desta tecnologia é a iProTM 9000 XL da empresa 3-D Systems Corporation. 


\section{- Processos de cura por camada}

Para superar as limitações de velocidade pela cura de polímero usando uma fonte de energia por ponto, foi desenvolvido um processo que utiliza projetores DLP para curar camadas inteiras em um único passo o qual. Alguns exemplos comerciais desta tecnologia é a ULTRA² da empresa EnvisionTEC GmbH, a V-Flash e a ZBuilder $\Theta^{\circledR}$ Ultra da empresa 3-D Systems Corporation.

\subsubsection{Processos baseado em fusão}

O processo de manufatura aditiva baseado em fusão de filamento (FDM) utiliza normalmente um termoplástico. O processo FDM utiliza um cabeçote de fusão, que se movimenta na direção $\mathrm{X}$ e $\mathrm{Y}$. Através desse cabeçote aquecido, se desloca um filamento de material, que é extrudado em estado semi-amolecido por um bico injetor. Esse material é depositado sobre um substrato, de acordo com a geometria da peça. Após a deposição, a camada se solidifica devido à condução térmica, conforme a Figura 2.8 ilustra.

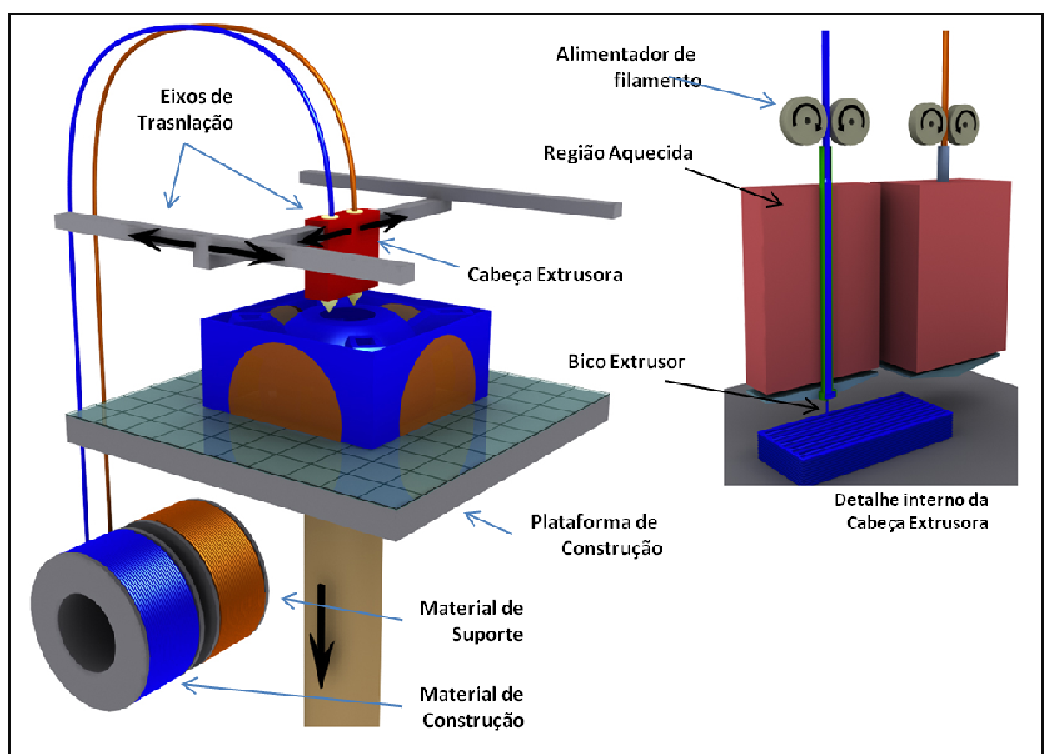

\section{FDM}

Figura 2.8 - Representação esquemática do processo de modelagem por deposição de fundidos (FDM) (Cortesia CTI Renato Archer). 
Uma grande variedade de materiais pode ser usada como materiais de construção, tendo como exemplo, poliolefinas, poliamidas, polifenilsulfonas,

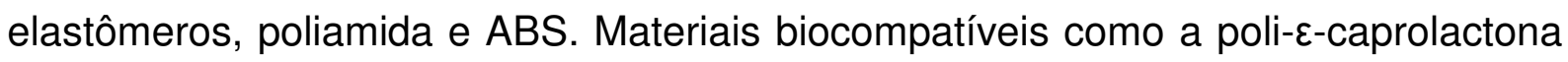
tem sido utilizada, para aplicações em engenharia teciduals. Um exemplo comercial desta tecnologia é a FORTUS 900mc da empresa Stratasys Ltd.

\subsubsection{Processos de laminação de camadas}

Uma das primeiras técnicas de manufatura aditiva a serem comercializadas foi a LOM (Manufatura Laminar de Camadas). Esta técnica consiste na laminação camada por camada de folhas de material, sendo que cada folha representa um corte de seção transversal da peça. Muitos outros processos foram feitos, a partir deste princípio, sendo as alterações referentes as mudanças do material empregado na lâminas/camadas, ou a forma pela qual as camadas são aderidas, utilizando-se cola ou solda dependendo do material.

\subsubsection{Processos de impressão}

Há alguns tipos de tecnologias de manufatura aditiva desenvolvidas utilizando-se a impressão de partículas. Esses processos podem ser classificados como: impressão por aglutinantes ou impressão direta. Os processos de impressão por aglutinantes envolvem a impressão seletiva de finas gotas de fluído em uma base de pó, criando uma forma de corte de seção transversal, através da adesão do pó. No processo de impressão direta o material usado na peça construída é diretamente impresso através do bico de impressão.

\section{- Processo de impressão por aglutinante}

No Massachusetts Institute of Technology, EUA, professores e alunos desenvolveram e patentearam a tecnologia básica para o processo de impressão por aglutinante. Este processo foi chamado de impressão tridimensional, ou impressão 3-D. Neste processo, o aglutinante líquido é depositado seletivamente, por spray ou impressão na forma de finas gotas, através de um cabeçote de impressão montado sobre uma base de pó, conforme ilustra a Figura 2.9. Depois da 
deposição o aglutinante umidifica, e através de uma reação química adere às partículas de pó entre elas e também com as partículas da última camada. $O$ cabeçote, normalmente o mesmo utilizado por impressoras de jato de tinta, contém vários bicos de injeção paralelos, possibilitando que o cabeçote de impressão preencha uma área de definida a cada impressão.

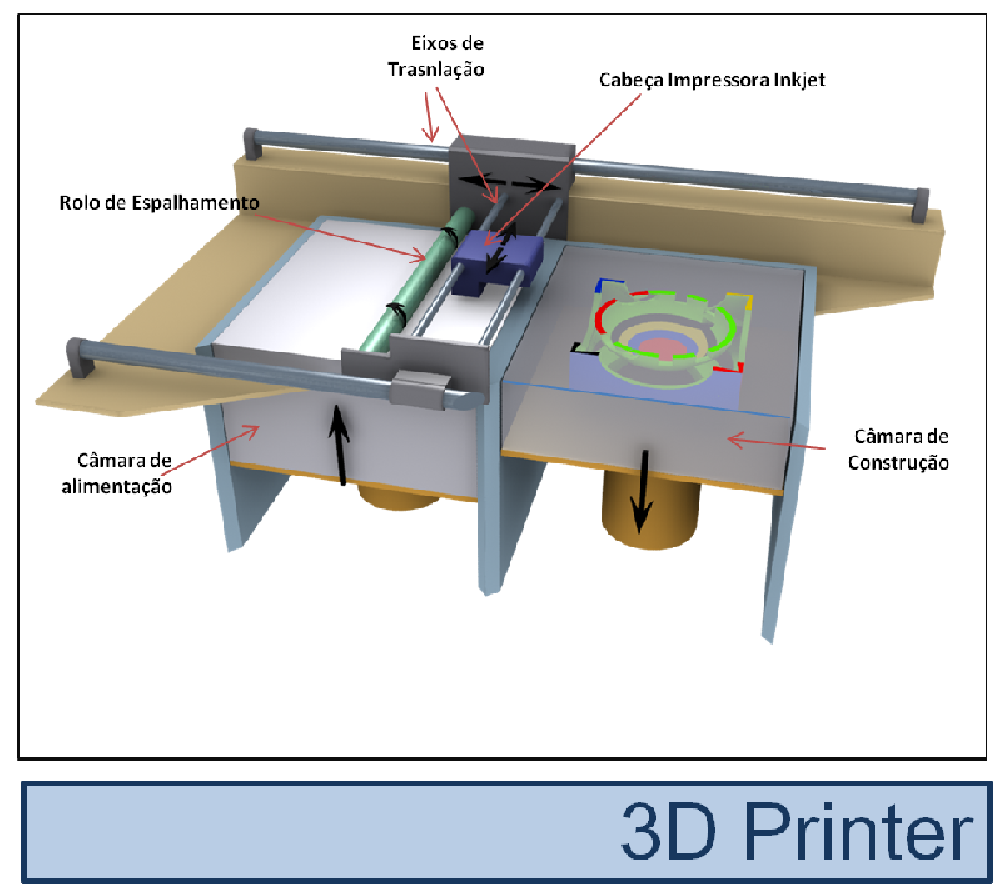

Figura 2.9 - Representação esquemática do processo de impressão 3-D (Cortesia CTI Renato Archer).

O cabeçote de impressão se desloca sobre a área, que contém pó e onde será gerada a peça. As áreas da base de pó, que ficam fora da geometria da peça, se mantêm soltas e servem de suporte para as outras camadas que serão impressas subsequentemente. Depois da formação de uma camada, a plataforma se desloca para baixo, em uma distância pré-definida, e expõe uma nova superfície de pó. O aglutinador é impresso novamente, de acordo com a seção transversal correspondente. $\mathrm{O}$ processo inteiro ocorre em temperatura ambiente. As vantagens desta tecnologia estão relacionadas com a facilidade de operação e custo reduzido de operação e manutenção. A grande desvantagem deste processo é a limitação de geometria, resolução e acabamento superficial. Um exemplo comercial desta tecnologia é a ZPrinter ${ }^{\circledR} 850$ da empresa 3-D Systems Corporation. 
- Processo de impressão direta

O processo de impressão direta pressiona o material de construção diretamente na forma da peça. Um exemplo deste processo é a R66®PLUS da empresa Solidscape Inc. que utiliza dois cabeçotes injetores de cera, no qual um deles deposita uma cera de construção que será a peça final, e o outro deposita uma cera de suporte a qual servira de sustentação para construção do protótipo. Posteriormente, a cera de suporte é removida, obtendo assim o protótipo final conforme modelo projetado no CAD. Esse sistema possibilita um elevado grau de precisão, bem como um acabamento superficial de qualidade, mas o tempo de geração da peça é relativamente elevado.

Outro exemplo deste processo bastante conhecido é a Objet Connex500 TM comercializado atualmente pela empresa Stratasys Ltd.. Este equipamento utiliza múltiplos cabeçotes de jato de resina fotossensível. Neste processo, os jatos da resina tanto de modelo como de suporte é depositado em uma plataforma e curado instantaneamente por meio de uma luz que incide sob a resina após sua deposição. Desta forma, o protótipo é construído dentro do equipamento camada-a-camada. Depois de finalizado, o protótipo é retirado e levado para uma estação de jateamento de água para remoção do suporte da peça. Por se tratar de múltiplos cabeçotes de jato, esta tecnologia permite um protótipo com múltiplos materiais cujas propriedades reológicas são alteradas ao longo do processo de fotopolimerização.

\subsubsection{Processo de sinterização/fusão de pó}

A Figura 2.10 representa esquematicamente um processo de sinterização a base de pó. Neste processo uma fina camada de pó fundível por calor, é depositada numa plataforma de construção usando um rolo de contra-rotação para seu espalhamento. Este processo é feito dentro de uma câmara fechada cheia de gás inerte, que é mantida a uma temperatura elevada abaixo do ponto de fusão do material em pó, usando-se um aquecedor. Esse procedimento minimiza a quantidade de energia requerida pelo laser no processo, e previne o empenamento da peça durante sua construção. 


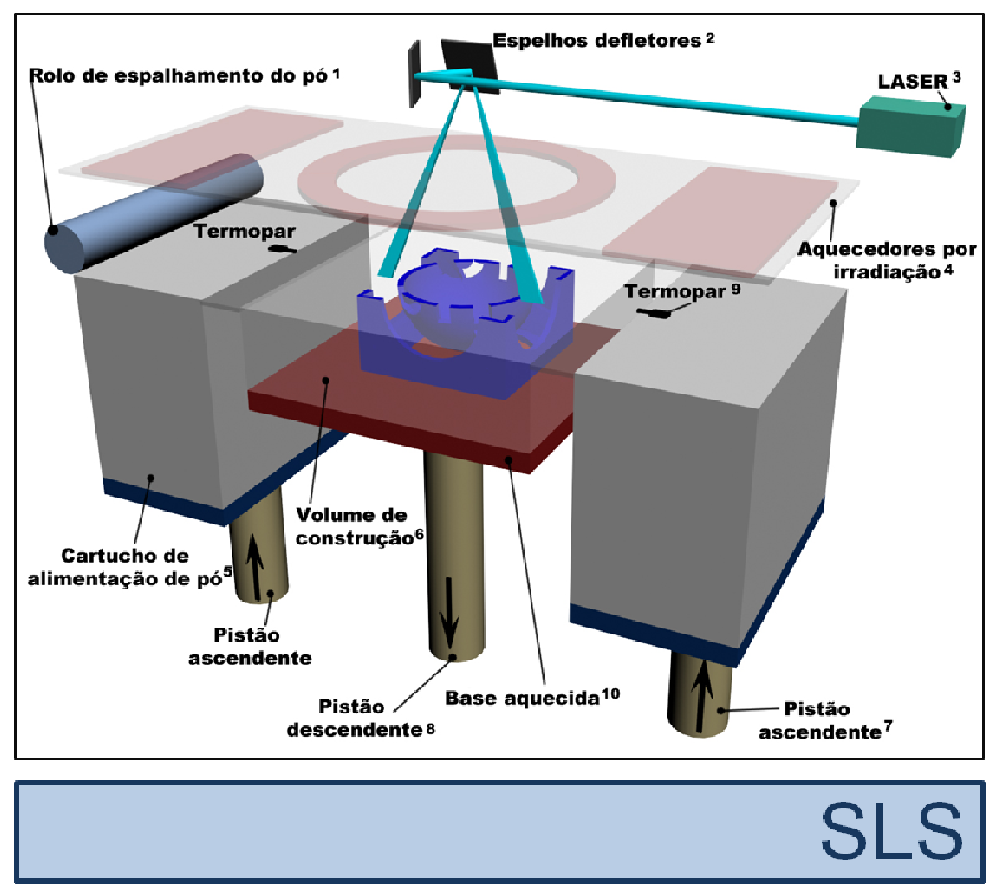

Figura 2.10 - Representação esquemática de um mecanismo de sinterização e fusão de pó à Laser (Cortesia CTI Renato Archer).

Um laser precisamente focado ou um raio de elétrons é direcionado sobre a base de pó, que é amolecido e percorre a trajetória da seção transversal da peça. $O$ pó no contorno está solto e funciona como suporte para camadas a serem feitas posteriormente. Após a obtenção de uma camada, a plataforma se desloca e deixa à mostra uma nova camada de pó, para a criação de uma nova camada com contorno da peça.

- Processo de sinterização de polímeros à base de pó

A tecnologia básica para a fusão de polímeros à base de pó foi desenvolvida na Universidade do Texas em Austin nos EUA, entre os anos 80 e 90 . O processo SLS foi originalmente desenvolvido para produzir protótipos de material termoplástico em pó. Esse princípio foi estendido para as cerâmicas e metal, para a fabricação e ferramentas e partes funcionais. Parâmetros importantes do processo se relacionam com: intensidade e precisão do laser, escaneamento, características do pó e temperaturas envolvidas no processo. 
A principal vantagem desse processo é a versatilidade com a qual a sinterização com laser pode ter utilizando diferentes materiais, como polímeros, cerâmicas e até metais. Estes processos não requerem suporte externo, que economiza tempo na construção e limpeza da peça. A precisão e o acabamento superficial das peças sinterizadas a laser dependem do tamanho da partícula do pó, da região de foco do laser e da espessura da camada sinterizada. Um exemplo comercia desta tecnologia é a SProTM 230 da empresa 3-D Systems.

\section{- Processo de fusão de metais à base de pó}

Há alguns processos em desenvolvimento, para a produção direta de peças usando fusão de metais à base de pó. Estes métodos utilizam fonte de alta energia, um rígido controle de atmosfera e novas estratégias de escaneamento. O SLPR foi desenvolvido pelo Instituto Fraünhofer de Tecnologia à Laser em Aachën na Alemanha. Este processo foi bem sucedido aplicado a alguns tipos de metais e cerâmicas. Este processo também é conhecido como Fusão Seletiva à Laser e têm fornecido precisão e rugosidade superficiais abaixo de $50 \mu \mathrm{m}$. Uma nova variação nos processos de fusão de metais à laser, à base de pó é a EBM traduzido como Fusão por Feixe de Elétrons. Este processo faz uso de um feixe de elétrons como fonte de calor em substituição ao laser e foi desenvolvido pela Universidade de Tecnologia de Chalmers na Suécia.

Neste processo, um feixe de elétrons é focado em uma superfície de pequena espessura, com uma pré-distribuição de pó, dentro de uma câmara à vácuo, causando fusão localizada e re-solidificação. Alguns benefícios do EBM, em relação ao processo a laser são: alta eficiência de conversão de energia, maior facilidade de manipulação do feixe, quanto à focalização e deslocamento, com movimentação mais rápida. A desvantagem do EBM é que os materiais de sinterização devem ser eletricamente condutivos e há a necessidade de criação de ambientes à vácuo.

- Processos de deposição de metais

O processo de deposição de metais envolve completo derretimento e deposição de pós metálicos, através de raio laser focado de alta potência, como 
fonte de calor para construção de peças tridimensionais. Devido ao processo envolver completo derretimento e solidificação do material em pó em todos os pontos, as peças resultantes têm alta densidade ao longo do processo em contraste com as peças sinterizadas parcialmente porosas produzidas em muitos processos de fusão à base de pó, conforme a Figura 2.11 ilustra.

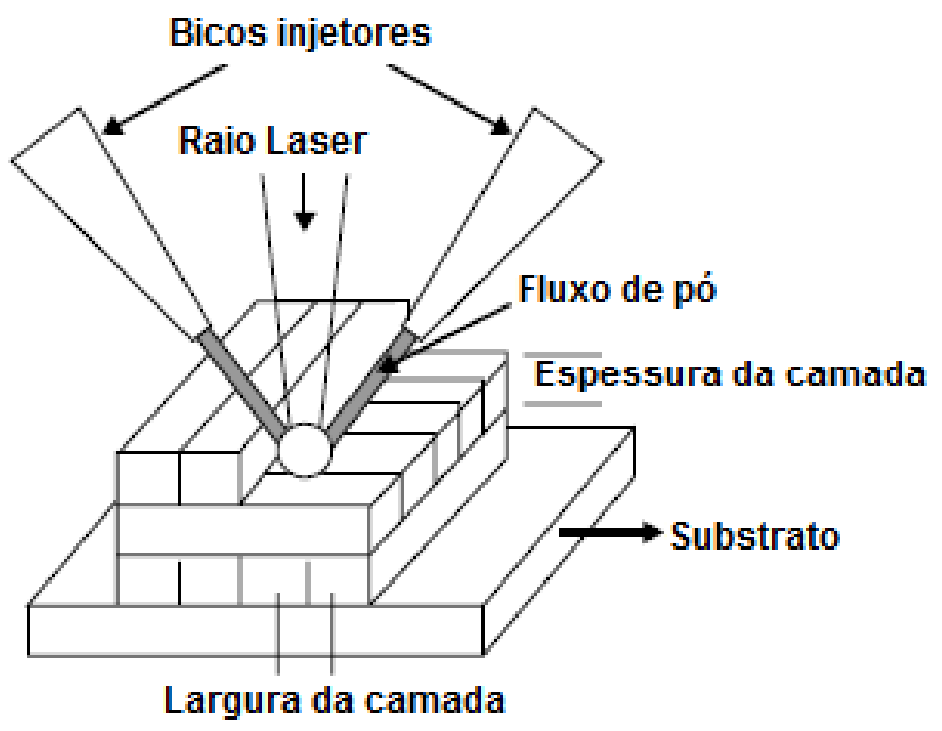

Figura 2.11 - Representação esquemática do processo de deposição de metais (LENS) (POWERS et al., 2007)

Neste processo um raio laser é diretamente focado sobre o substrato situado numa plataforma de construção movida e controlada por computador. O laser gera uma pequena massa liquefeita, a partir do material amolecido no substrato, no qual o material em pó é injetado. Esse material amolecido é solidificado após a retirada do laser. Como resultado, um perfil de material soldado à camada abaixo é formado ao longo da linha de escaneamento do laser. Uma camada é formada pelo número consecutivo de caminhos sobrepostos. Este processo ocorre dentro de uma câmara de gás inerte. Este processo requer suportes para a construção de perfis sem apoio na peça. Entretanto, máquinas avançadas com 5 eixos são capazes de gerar perfis, sem apoio sem a necessidade de estruturas de suportes.

O processo de deposição de metais tem a capacidade de produzir peças densas totalmente funcionais em metais e cerâmicas, não sendo capaz de produzir 
peças em plástico. Esta habilidade de produzir peças densas é a maior vantagem deste processo, além da formação de microestruturas finas e refinadas, sendo que com ele peças que antes não pudessem ser processadas através de técnicas convencionais formando geometrias complexas e intrincadas cavidades internas agora são produzidas. As limitações deste processo são: baixa resolução e acabamento superficial, baixa velocidade de construção, em relação a outras tecnologias de manufatura aditiva.

\subsection{Considerações sobre sistemática de projeto em engenharia}

A atual complexidade dos projetos de engenharia de diversos produtos técnicos, bens de consumo desenvolvidos cada vez mais próximos aos anseios do cliente final e de dispositivos que envolvam conhecimentos interdisciplinares ressaltam a importância da aplicação de abordagens sistemáticas de apoio às tomadas de decisões técnicas no processo de desenvolvimento do projeto. Além de guiar, o desenvolvimento do projeto, algumas ferramentas e técnicas pertencentes ao campo de pesquisa da metodologia e teoria de projeto podem intensificar a capacidade inventiva da equipe multidisciplinar e gerar produto com elevado valor agregado.

Segundo Back (1983, p. 10), "O projeto de um componente ou um sistema apresenta em cada caso características e peculiaridades próprias. Mas à medida que um projeto é iniciado e desenvolvido desdobra-se uma sequência de eventos, numa ordem cronológica, formando um modelo, o qual quase sempre é comum a todos os projetos. Estes eventos ou fases do projeto são de forma gerais bastante distintos e devem ser sequenciados e encaixados de modo a transformar recursos em objetos úteis [...]".

Basicamente, a motivação para melhoria de produtos existentes e o desenvolvimento de novos produtos é a solução de um problema, caracterizando-se por três componentes: 
- Uma situação inicial indesejada, ou seja, existência de uma situação insatisfatória.

- Uma situação final desejada, ou seja, alcançar uma situação satisfatória ou o resultado desejado.

- Obstáculos que, num dado momento, impede a transformação da situação inicial indesejada na situação final desejada.

Para alcançar esse ponto a atividade de projeto deve passar por diversas etapas. Estas formam uma sequencia aproximada, embora na prática os projetistas ocasionalmente circulem ou retrocedam através das etapas (SLACK et al., 2002). Há vários modelos de ciclo de desenvolvimento de produtos propostos na literatura pertinente. O modelo proposto por Back, et. al (2008) apresenta as divisões no ciclo de desenvolvimento do produto, detalhando cada fase, conforme apresentado na Figura 2.12.

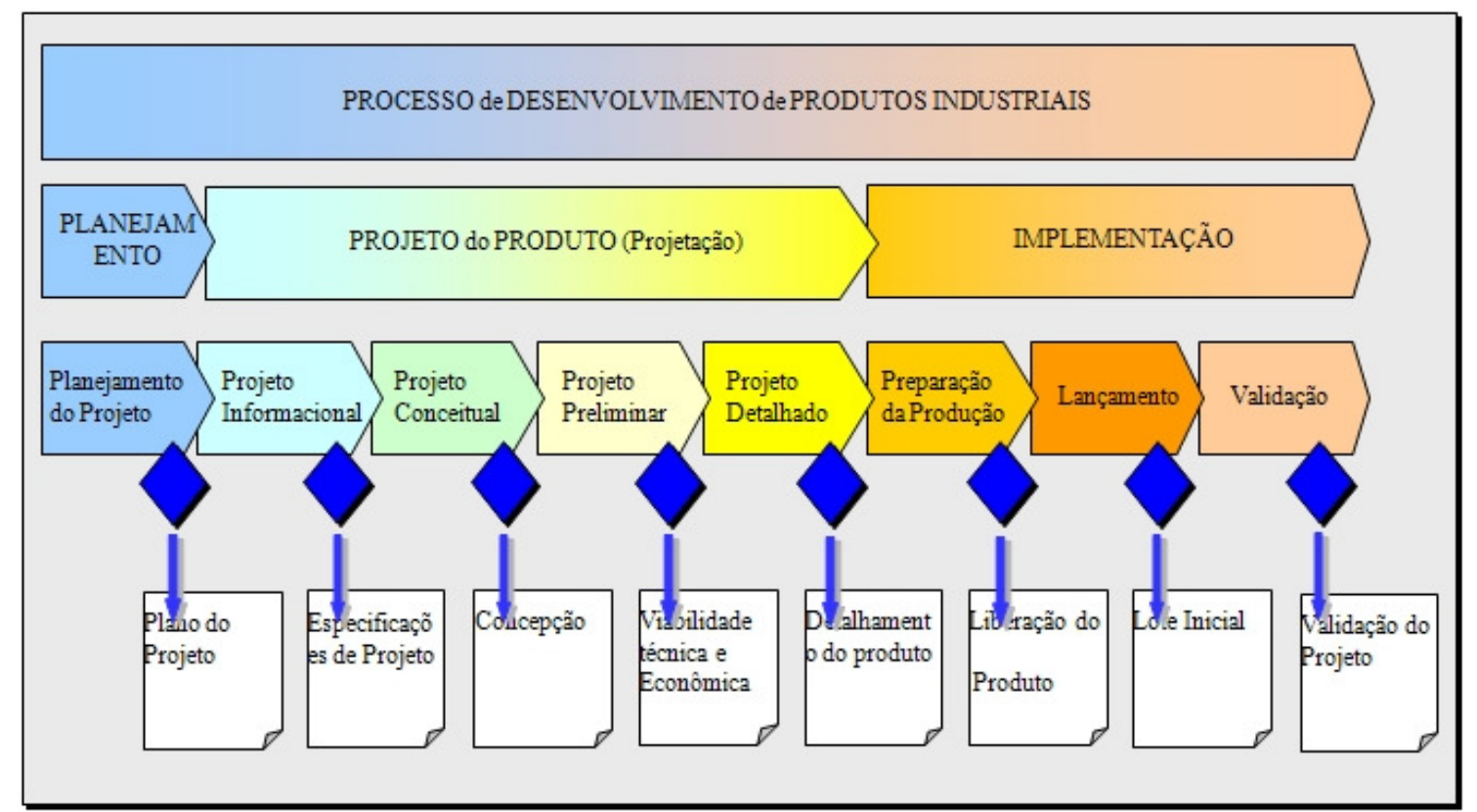

Figura 2.12 - Ciclo de desenvolvimento de produtos (BACK et. al, 2008).

As etapas do projeto referentes ao projeto informacional (ou viabilidade técnica e física) e projeto conceitual constituem a primeira parte do projeto de um produto, que englobam a fase de levantamento de requisitos do usuário e sua conversão em características técnicas e identificação antecipadamente de contradições técnicas transferidas para o projeto conceitual, cuja fase final fornecerá configurações e informações do produto, para a próxima etapa: projeto preliminar. 
$\mathrm{Na}$ segunda parte do projeto do produto seguem as fases do projeto preliminar, na qual são efetuados os pré-dimensionamentos com síntese e análise dos componentes de forma analítica e numérica, com o auxílio de programas de apoio à engenharia. Uma vez que o projeto conceitual tenha satisfeito as restrições de projeto e condições hipotéticas operacionais, segue-se o projeto detalhado, no qual há a formalização do produto em linguagem técnica, com as definições de tolerâncias dimensionais e de forma e posição.

Atualmente, muitas empresas possuem uma quinta fase referente à engenharia experimental, na qual novos produtos e produtos em comercialização são testados para a determinação de sua vida útil em termos de confiabilidade e durabilidade e efetuar para melhorias, respectivamente.

\subsubsection{Projeto informacional: Metodologia QFD}

Para Rozenfeld et al. (2006) é muito importante que os requisitos do usuário sejam entendidos e convertidos adequadamente em características técnicas. Outro ponto a ser considerado é que os clientes normalmente se expressam pelas falhas dos produtos, ou o que não foi satisfatório na sua experiência com o uso deste. $\mathrm{O}$ autor também salienta que existem alguns requisitos dos clientes, que são considerados básicos, sendo que sua presença não gera um aumento na satisfação, pois é considerada obrigatória no produto. Estes requisitos, normalmente não são considerados pelos clientes, a menos que não estejam inclusos no produto, ou seja, se não estiverem no produto os clientes ficarão insatisfeitos, se estiverem os clientes ficarão neutros.

Os requisitos dos clientes devem agora ser transformados em informações que possam ser utilizadas no projeto, pois segundo Rozenfeld et al. (2006) as informações provenientes dos clientes são geralmente vagas e subjetivas, não oferecendo assim o grau de comunicação necessário para o desenvolvimento adequado de um produto. Ainda segundo o autor é importante que as informações que irão caracterizar o produto, estejam de acordo com a linguagem técnica de engenharia, ou seja, estas informações devem ser de alguma forma mensuráveis. A 
descrição do desempenho esperado mais os parâmetros mensuráveis são chamados de requisitos do produto.

A metodologia Quality Function Deployment (QFD), especificamente a primeira matriz ou tabela (casa da qualidade) é utilizada para traduzir as necessidades e vontades dos clientes em um documento técnico organizado análogo a um banco de dados do usuário.

Segundo Pahl e Beitz o QFD é uma metodologia para planejamento e controle da qualidade de projeto. Ela é útil para um planejamento do produto e do processo, sistematicamente voltado ao cliente. Os requisitos do cliente são precisamente convertidos em características técnicas do produto, e essas novamente em sequenciamentos de fabricação e exigências da produção.

Cheng e Melo Filho (2010) definem o QFD como sendo: " uma forma de comunicar sistematicamente informação relacionada com a qualidade e de explicitar ordenadamente trabalho relacionado com a obtenção da qualidade, tem como objetivo alcançar o enfoque da garantia da qualidade durante o desenvolvimento de produtos e é subdividido em Desdobramento da Qualidade (QD) e Desdobramento da Função Qualidade no sentido restrito (QFDr).

Segundo Cheng e Melo Filho (2010), a metodologia QFD tem aplicações em produtos de consumo (bem tangível ou serviço), que são adquiridos pelo consumidor final, como por exemplo, linhas brancas, alimentos industrializados, produtos eletrônicos e veículos, como também para produtos industriais intermediários, pertencentes a uma cadeia produtiva entre cliente e fornecedor, como por exemplo, peças conformadas, matéria-prima, filmes flexíveis para embalagens. Inicialmente, o método QFD tinha dois objetivos básicos: (a) auxiliar no processo de desenvolvimento de um novo produto, buscando, traduzindo e transmitindo as necessidades e vontades dos clientes/usuário final; e (b) garantir a qualidade do projeto. Cheng e Melo Filho (2010) apresentam a importância do método dentro da Gestão de Desenvolvimento do Produto (GDP). 
Há algumas variações sobre as versões da metodologia QFD. As duas versões mais adotadas nos Estados Unidos (por duas instituições diferentes) são: uma versão mais simplificada, que consiste no desdobramento de quatro matrizes (planejamento do produto, desdobramento dos componentes, planejamento do processo e planejamento da produção). Essa versão, adotada pela American Supplier Institute (ASI) foi desenvolvida por Makabe e transmitida ao ASI por Don Clausing (Cheng e Melo Filho, 2012), conforme ilustra simplificadamente a Figura 2.13.

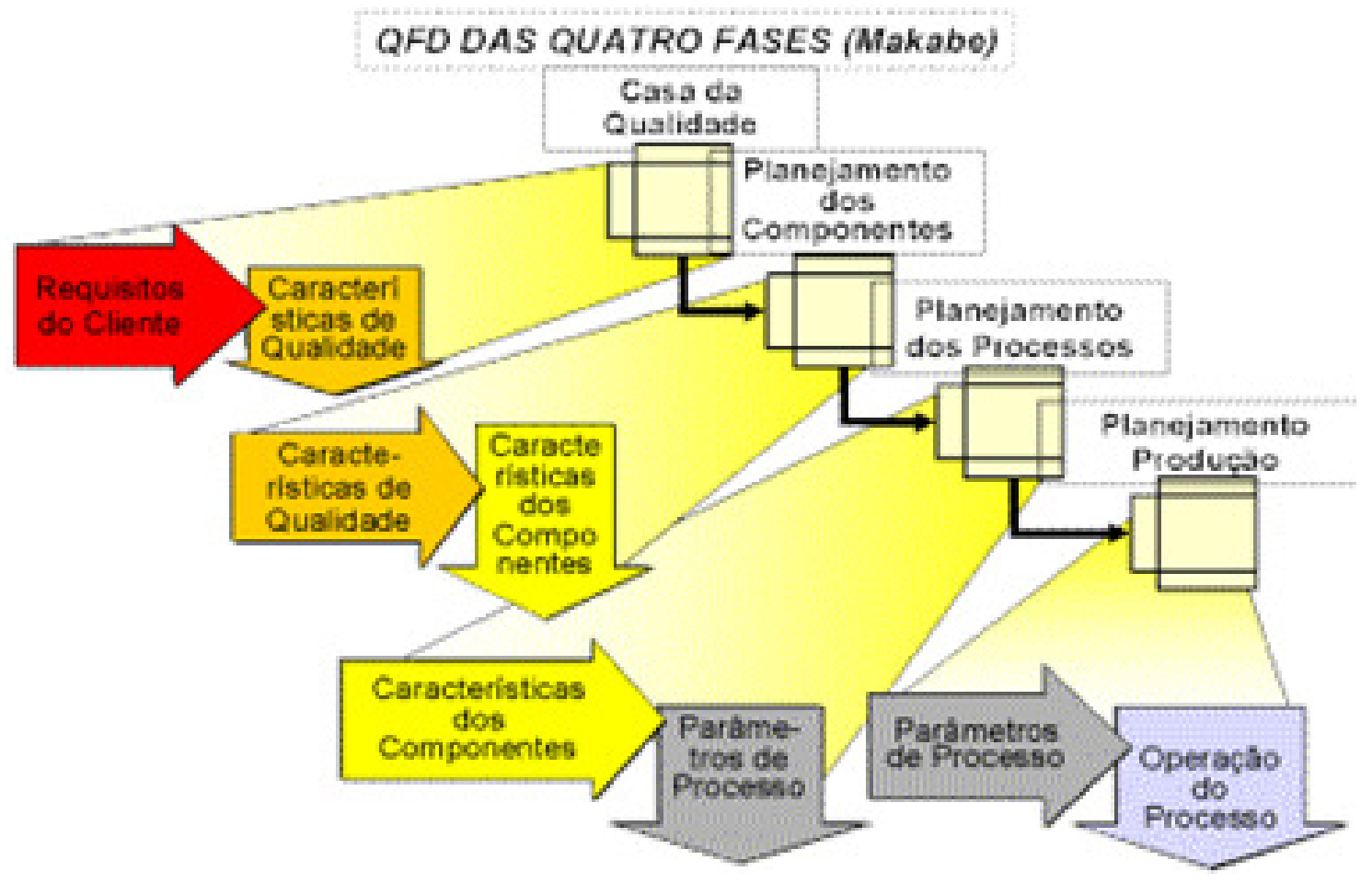

Figura 2.13 - QFD de quatro fases (Fonte: www.numa.org.br).

A técnica QFD foi desenvolvida no Japão em 1966, nos estaleiros da Komatsu (Mitsubishi Heavy Industry) em Kobe, liderado pelo especialista em metodologia da qualidade Ph.D Yoji Akao. Ferramentas como o QFD, foram desenvolvidas com o objetivo de responder a um mercado cada vez mais dinâmico, que incorporavam conceitos de redução do ciclo de vida do produto e o surgimento de inovações tecnológicas em um período cada vez menor, com um aumento progressivo na complexidade dos produtos. Grandes e multinacionais organizações adotaram em alguma fase inicial do projeto, o desenvolvimento do QFD, como por exemplo: Ford, General Motors, AT\&T Bell Laboratories, HP, Procter\&Gamble, Jaguar e Xerox (Cheng, 1995). 
Um exemplo da vantagem competitiva proporcionada pela utilização do QFD foi uma redução de custos em $61 \%$ e a introdução de uma maior variedade de modelos de veículos no período de 1977 a 1984 pela Toyota Autobody (Cheng, 1995). Neste período, o tempo do ciclo de desenvolvimento do produto foi reduzido em um terço, com um aumento correspondente na qualidade devido a redução do número de alterações de engenharia. Segundo Cheng e Melo Filho (2010), no Brasil, há relatos de aplicações do QFD desde 1995 principalmente na indústria automotiva e de alimentos.

O desdobramento parte da "voz" do consumidor final ou do cliente intermediário, dependendo do elo da cadeia produtiva em questão, passando por características da qualidade do produto final, subsistemas e componentes através de desdobramentos sistemáticos incluindo: características de qualidade do produto, funções, parâmetros de controle, processos, mecanismos, componentes, padrões, cujas escolhas dependem da natureza de cada projeto.

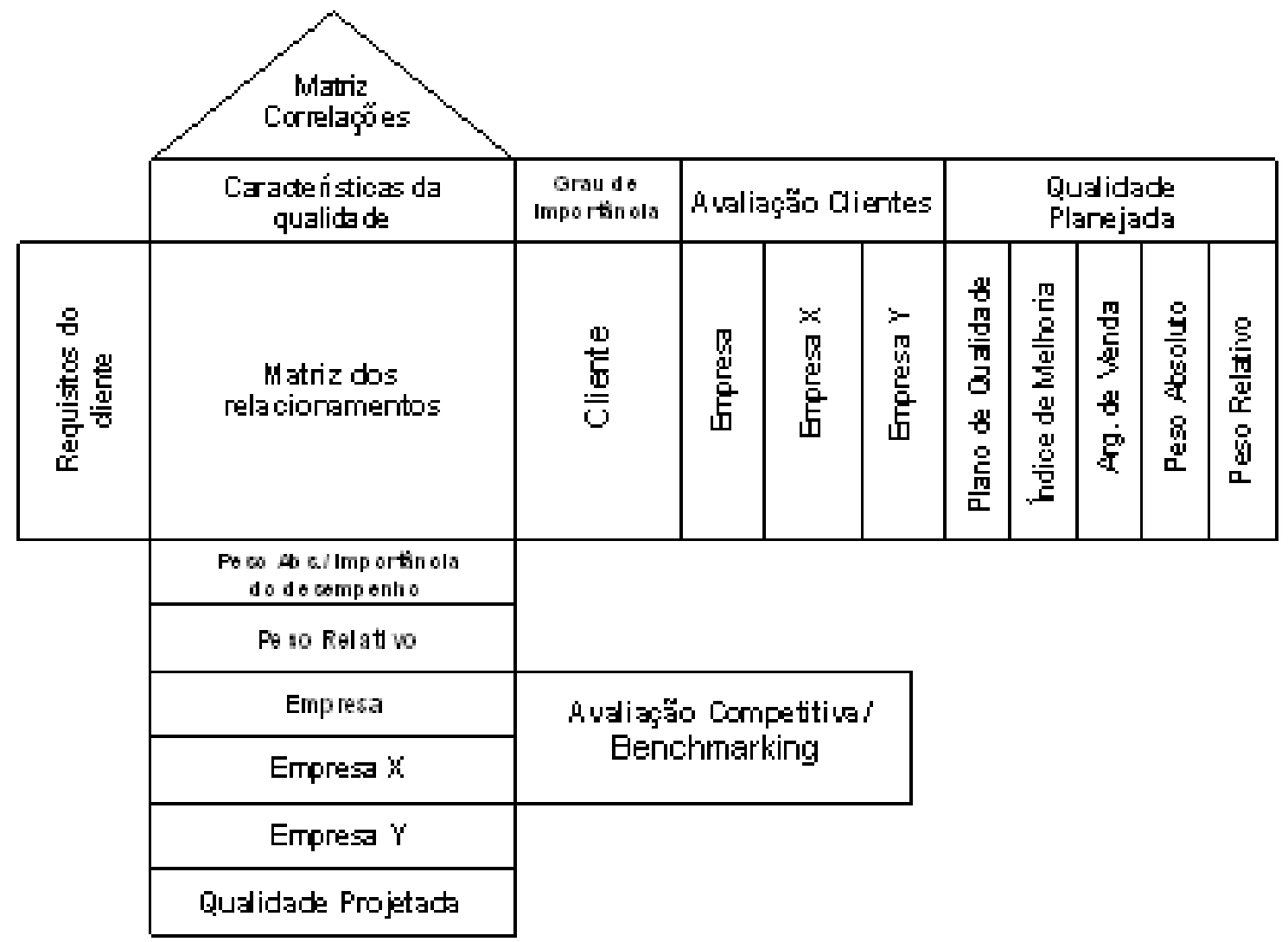

Figura 2.14 - Matriz da Casa da Qualidade do QFD. 
A primeira e principal matriz do QFD é a chamada House of Quality (Casa da Qualidade). Ela permite, de forma clara, converter as necessidades do cliente, frequentemente formuladas de maneira vaga, nas características de qualidade do produto a ser desenvolvido, que pode ser representada pelas Figuras 2.14 e 2.15 :

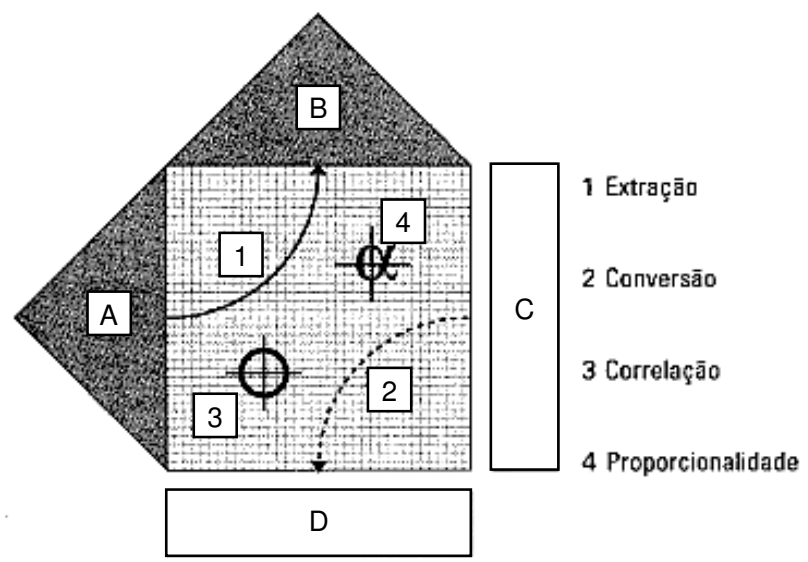

Figura 2.15 - Representação de uma matriz com seus elementos constituintes (CHENG; MELO FILHO, 2010).

$\mathrm{Na}$ matriz o objetivo é explicitar as relações entre as "duas tabelas". As relações podem ser de três tipos: qualitativa, quantitativa e de intensidade. No tipo qualitativo o processo é de extração conforme indicado na Figura 2.15. Na relação quantitativa, a relação é de correlação e proporcionalidade. A extração ocorre quando é obtida uma tabela a partir da outra, ou quando são obtidos elementos de uma tabela, a partir de elementos de outra tabela. A conversão é um processo quantitativo, no qual o objetivo é obter o grau de importância dos elementos de uma tabela para outros elementos da tabela. A correlação visa identificar as relações entre os elementos desdobrados das duas tabelas diferentes, definida pela equipe de desenvolvimento do projeto. A proporcionalidade visa identificar as relações entre os elementos desdobrados da mesma tabela, indicados por números ou símbolos.

A matriz de correlações ou matriz de "conflitos" antecipa as relações entre os parâmetros de maior relevância na melhoria do produto. Essa antecipação e suas respectivas alternativas construtivas sejam através de soluções técnicas consolidadas ou processos inovativos fornecem agilidade na solução de problemas, ao longo do desenvolvimento do projeto. $O$ resultado da primeira matriz é a 
identificação de características técnicas importantes para o usuário final, considerando também as melhorias propostas pela equipe técnica.

\subsubsection{Projeto Conceitual}

Com os desdobramentos e avaliações iniciais do projeto a ideia original tornase um conceito, que é refinado e detalhado para se tornar um produto. A cada etapa, com as decisões de projeto, diminuí o número de alternativas consideradas, reduzindo as incertezas progressivamente. $\mathrm{Na}$ fase inicial do processo do projeto, $\mathrm{o}$ custo para se alterar o conceito, antes que decisões fundamentais tenham sido tomadas é relativamente baixo conforme a Figura 2.16 ilustra.

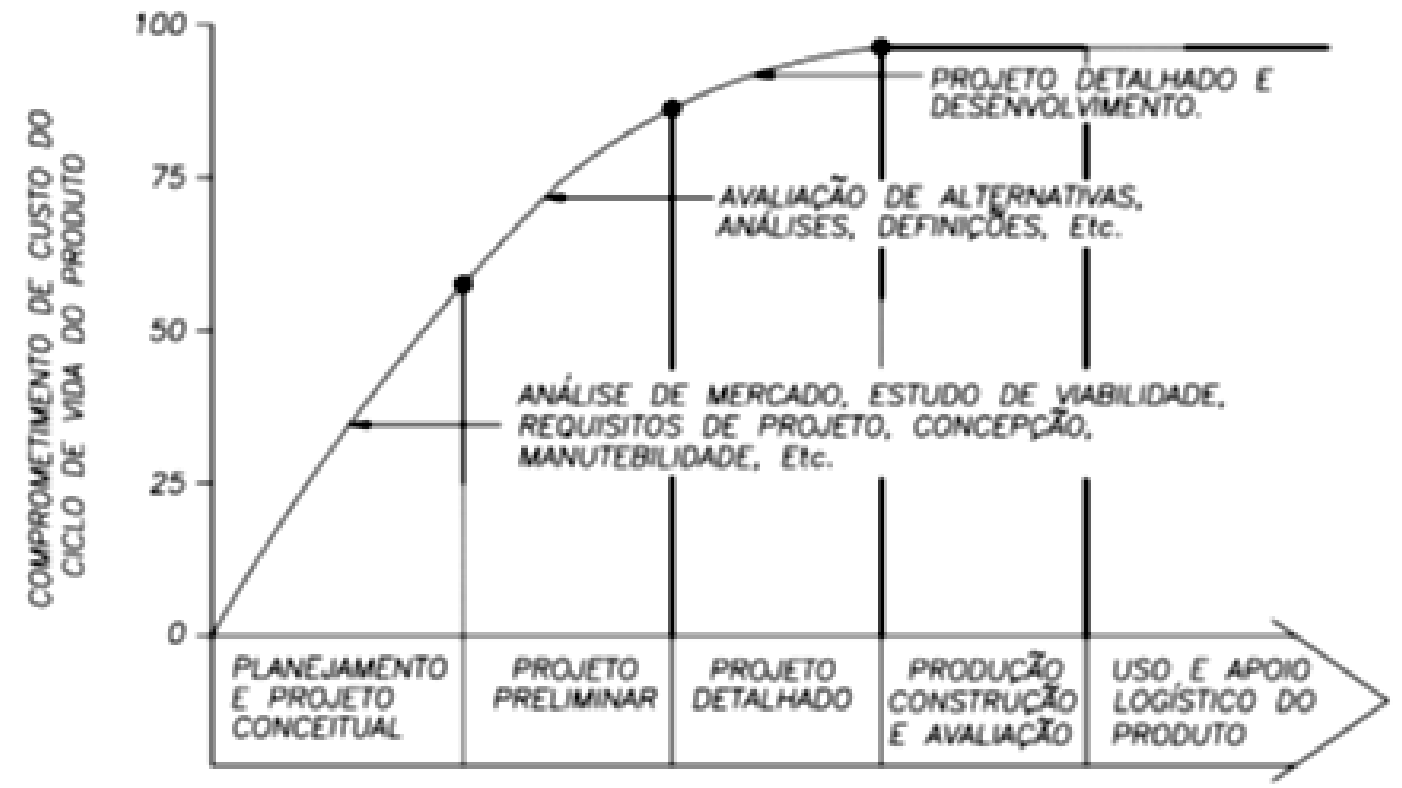

Figura 2.16 - Efeitos das diferentes fases do ciclo de vida sobre o custo do produto.

(BLANCHARD; FABRYCKY ${ }^{1}, 1990$ apud BACK e FORCELLINI, 2003).

O projeto conceitual tem o objetivo de produzir princípios de projeto para um produto melhorado ou uma inovação. Ele deve ser suficiente para satisfazer as exigências do consumidor e diferenciar o novo produto de outros produtos existentes no mercado. Especificamente, o projeto conceitual deve mostrar como o novo

${ }^{1}$ B. S. BLANCHARD e FABRYCKY. W. J. Systems Engineering and Analysis. Prentice - Hall. 1990. 
produto será feito para atingir os benefícios básicos (BAXTER, 2003). A entrada do projeto conceitual pode ser a lista de requisitos obtidos, no projeto informacional.

Nesta etapa, os conhecimentos básicos e tecnológicos da engenharia, bem como a capacidade de abstração são fundamentais, para nortear a busca e avaliação de soluções. Pahl e Beitz (2005) propõem que "no procedimento para chegar a uma solução nova, duradoura, não se deve deixar-se conduzir somente por idéias fixas ou convencionais ou se dar por satisfeito com elas. Pelo contrário, é preciso verificar cuidadosamente se caminhos inovadores e práticos que levem a solução são passíveis de implementação".

Segundo Baxter (2003) há dois aspectos fundamentais, para se obter sucesso no projeto conceitual: $1^{\circ}$. Fazer o possível para gerar o maior número possível de conceitos e 2 o. Selecionar o melhor deles.

O objetivo do projeto conceitual pode variar bastante, dependendo do tipo de produto. Isso se deve, em grande parte, aos diversos tipos de restrições colocadas às oportunidades de produto. Pode-se procurar definir as fronteiras e o espaço do problema, sendo que a atenção deve ser concentrada principalmente nas necessidades do consumidor e, em menor grau, na viabilidade de fabricação do produto.

A geração de conceitos exige muita intuição, imaginação e raciocínio lógico. A maior dificuldade no projeto conceitual é liberar a mente para se chegar a conceitos originais.

Segundo Baxter (2003), usando-se simplesmente a imaginação e a intuição, é possível gerar alguns conceitos novos. Contudo aplicando-se técnicas de pensamento estruturadas pode-se chegar à melhores resultados. As técnicas estruturadas citadas pelo autor são: análise da tarefa, análise das funções do produto, análise do ciclo de vida, concepção do estilo, semântica do produto, simbolismo do produto, a emoção provocada pelo produto e por ultimo a seleção do conceito. 
A análise da tarefa: parte do principio de que todos os produtos são projetados para serem usados, de alguma forma, pelo homem e ao examinar-se a interface homem-produto, em detalhe pode-se descobrir que ela é geralmente complexa e pouco compreendida. A análise da tarefa explora as interações entre 0 produto e seu usuário através de observações e análises. Os resultados dessas análises são usados para gerar novos conceitos, levando-se em consideração métodos ergonômicos e antropométricos (XIMENES, 2011):

A análise das funções do produto: é um tipo de análise mais analítica do produto, voltada para o consumidor. As funções do produto são apresentadas como são percebidas e avaliadas pelo consumidor, sendo que para produtos de maior complexidade ou aqueles cujas funções não são entendidas pelo consumidor, devese realizar pesquisas formais de mercado. Para conduzir a análise tem-se que perguntar: como e por quê? Dessa forma se desenha uma árvore funcional e proposições de soluções conceituais para cada uma das questões. A Figura 2.17 exemplifica o desdobramento de funções, para um produto simples (descascador de batatas).

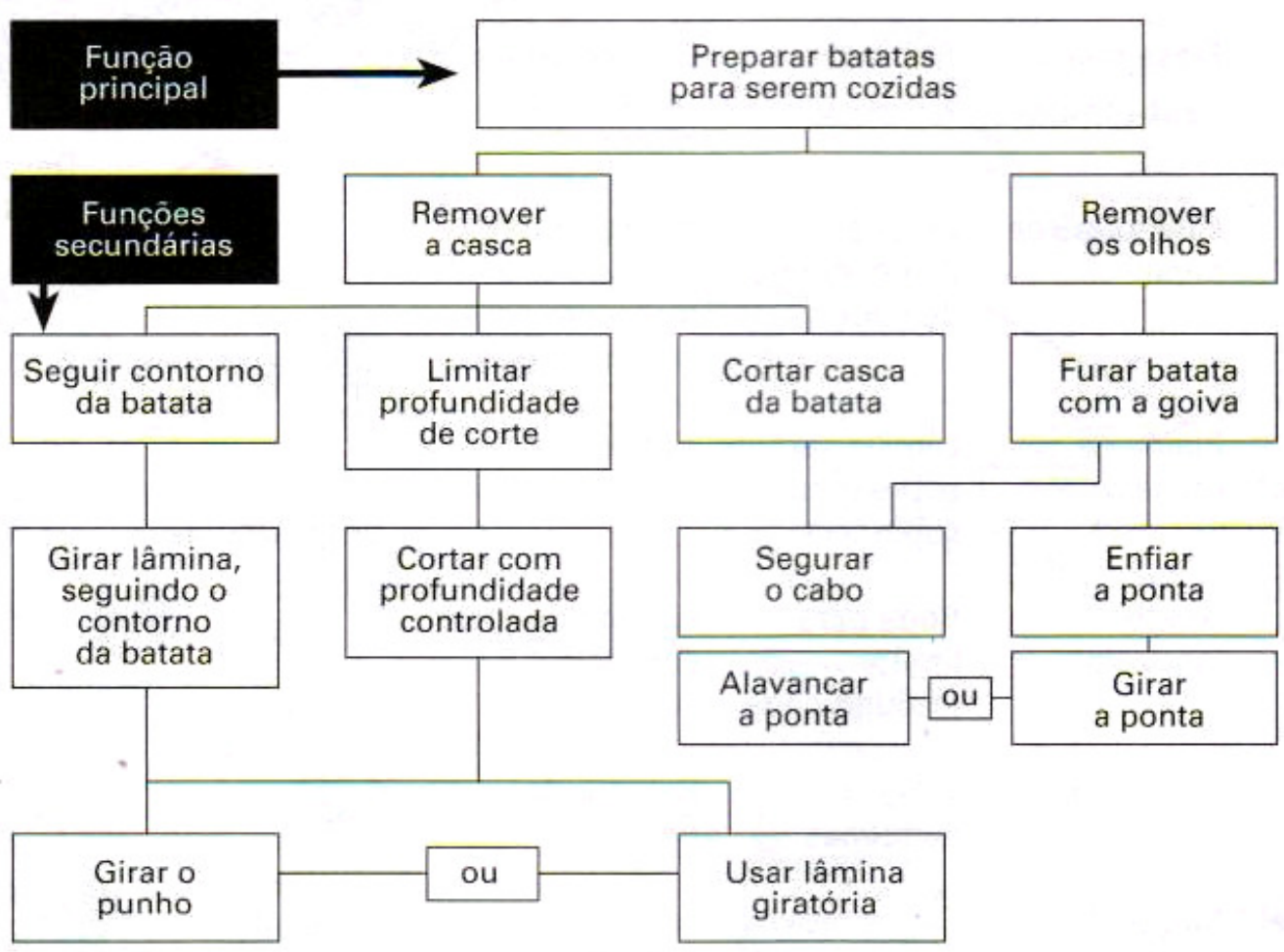

Figura 2.17 - Árvore funcional de um descascador de batatas (BAXTER, 2003). 
A análise de valor: procura aumentar o valor relativo (em relação ao custo) das peças e componentes e do produto como um todo, sem comprometer as suas funções, baseando-se na estratégia de: identificar as funções do produto, estabelecer valores para essas funções e procurar realizar essas funções com o mínimo custo, sem perda de qualidade.

Com a geração de um número significativo de conceitos deve-se selecionar àqueles viáveis, para seguir com o processo de desenvolvimento. 


\section{Desenvolvimento da impressora 3-D (Fab@CTI) e cabeçotes de seringa e FDM}

Neste capítulo será apresentado um breve histórico do desenvolvimento da impressora 3-D Fab@CTI e as duas soluções construtivas de cabeçotes de extrusão (deposição).

A manufatura aditiva como descrita no item 2.2 é uma tecnologia que tem se consolidado no mercado e nas áreas de pesquisas, a cada ano. $\mathrm{Na}$ área de pesquisa, a obtenção de protótipos cada vez mais resistentes (e funcionais) para aplicações industriais; obtenção e manufatura de bio-protótipios e aplicações na área de nanotecnologia. Revistas de circulação mundial como a Scientific American (http://www.scientificamerican.com/) denominam a manufatura aditiva como a precursora da "quarta revolução industrial: a era das máquinas livres". A utilização de vários diferentes materiais e de vários materiais para a construção de um mesmo protótipo, especificamente é um desafio para aplicações nas áreas de saúde. As máquinas EBM (Electron Beam Melting) de impressão 3-D têm sido exploradas para uso de materiais diferentes em protótipos (Fonte: http://web.ncsu.edu/abstract/technology/3d-printing/).

Entretanto, as máquinas comerciais utilizadas em manufatura aditiva possuem tecnologias encapsuladas (devido ao serviço de garantia e manutenção) e dependência de materiais (normalmente importados). Essas condições praticamente inviabilizam o uso dessas máquinas em ambientes de pesquisa, que requerem tecnologia aberta, tanto para acesso aos mecanismos de impressão tridimensional, hardware e programas computacionais (de interface). A inserção significativa da manufatura aditiva na obtenção de protótipos visuais, funcionais e até mesmo componentes finais também impulsionam sua aplicação em centros de pesquisa e desenvolvimento, tanto para a melhoria da precisão e repetibilidade do projeto mecânico, quanto das tecnologias de deposição. Além desses requisitos, estudos e desenvolvimento de materiais poliméricos e cerâmicos, com porosidade controlada (permeabilidade), bem como biomateriais sinalizam uma nova perspectiva dentro de aplicações da área de saúde tecnologia. 
Segundo Pearce (2012) o mundo vive uma quarta revolução industrial: "A Era das Máquinas Livres". Com o projeto e construção das primeiras máquinas de prototipagem rápida, na década de 80 , para fins comerciais observou-se um crescente interesse no desenvolvimento de novas tecnologias para obtenção de modelos físicos com diferentes materiais. O elevado custo dessas máquinas, como por exemplo, custo de manutenção e aquisição de materiais, que causa forte dependência do fornecedor (Stratasys, 3-D Systems, Object) tem apontado para soluções específicas de máquinas de impressão tridimensional "doméstica".

Essas soluções se baseiam na manufatura de poucos produtos ou de peças individualizadas podendo ter geometrias complexas, com custo e tempo reduzidos. De fato, dadas as devidas proporções, uma mudança de paradigma, quando se compara ao início da industrialização no final do século 18 , que visava a produção em massa e alto nível de padronização.

A primeira impressora tridimensional representante dessa nova "Era das Máquinas Livres" foi desenvolvida no projeto RepRap apresentada na (Figura 3.1 (a). Desenvolvida inicialmente por Adrian Bowyer em 2006 na Universidade de Bath, Reino Unido. O objetivo inicial foi a geração de objetos tridimensionais, com deposição por filamento fundido, com custo reduzido. Entretanto, trouxe uma característica adicional de também se autoreplicar e, atualmente apresenta variações de projetos. A impressora Fab@home, apresentada na Figura 3.1 (b) foi desenvolvida na Universidade de Cornell e representa outro exemplo da construção de impressoras portáteis, com melhor projeto mecânico básico e de controle, com custo reduzido para utilização para hobbistas e laboratórios. Esses exemplos de impressoras tridimensionais representam esforços convergentes da área de pesquisa em obter e promover software, impressora 3-D e microcontroladores livres e de interface abertas. 


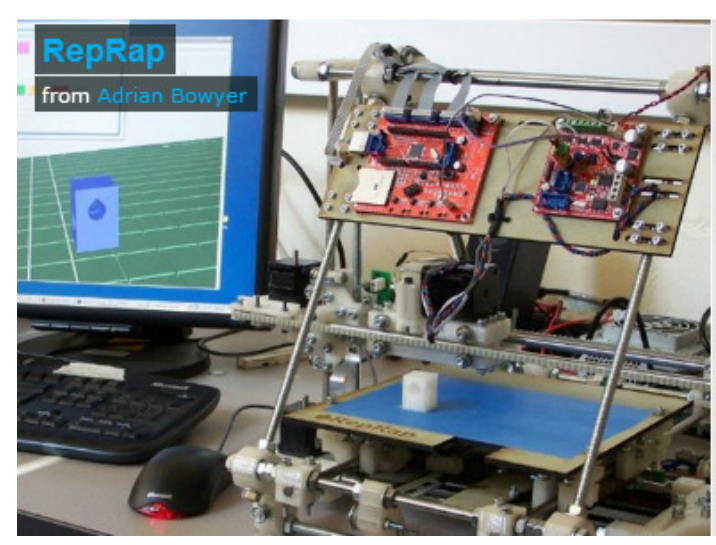

(a) Fonte: www.reprap.org

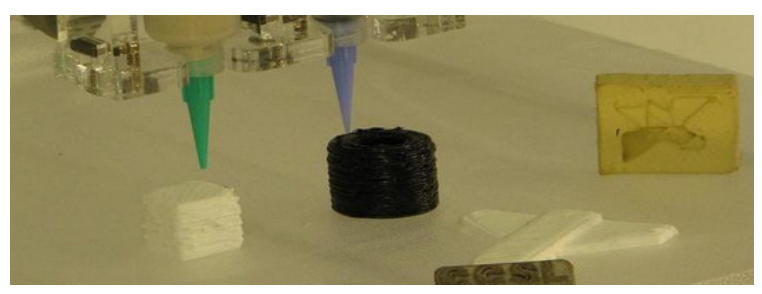

(b) Fonte: http://www.fabathome.org/

Figura 3.1 - (a) Projeto RepRap; (b) Projeto Fab@home.

Nos últimos anos têm surgido iniciativas de pesquisadores e "hobbistas" no desenvolvimento de tecnologias, para necessidades específicas na vertente de máquinas livres. Exemplos dessas iniciativas são: Projeto RepRap, criado em 2004 por Dr. Adrian Bowyer e Ed Sells cujo objetivo principal é criar uma máquina de prototipagem de baixo custo que seja capaz de imprimir sua próprias peças. Outro projeto open souce é o Fab@Home desenvolvido na Universidade de Cornell (MALONE; LIPSON, 2007). A impressora foi planejada para ser versátil e lidar com diversos materiais, que podem ser depositados por meio de seringa.

O avanço alavancado pelas impressoras tridimensionais abertas, portáteis e de baixo custo também promove uma movimentação na área comercial para atender demandas, desde estudantes até escritórios de engenharia, arquitetura e áreas de bioengenharia. Por exemplo, a Robtec representante no Brasil da 3-D Systems comercializa uma impressora denominada RapMan® ilustrada pela Figura 3.2 (a), com área de impressão de 270 x 205 x 210 mm, com preço básico no ano de 2012 de $R \$ 5.990,00$ (Fonte: http://www.impressora3d.com.br/).

A impressora 3-DBioplotter® da Envisiontec (http://envisiontec.com/products/ 3d-bioplotter/) apresenta aplicação nas áreas de engenharia teciduals para obtenção de scaffolds, a partir de um conjunto de bio-materiais, incluindo hidrogéis, polímeros com cerâmica e metais. A impressora é ilustrada na Figura 3.2 (b) 


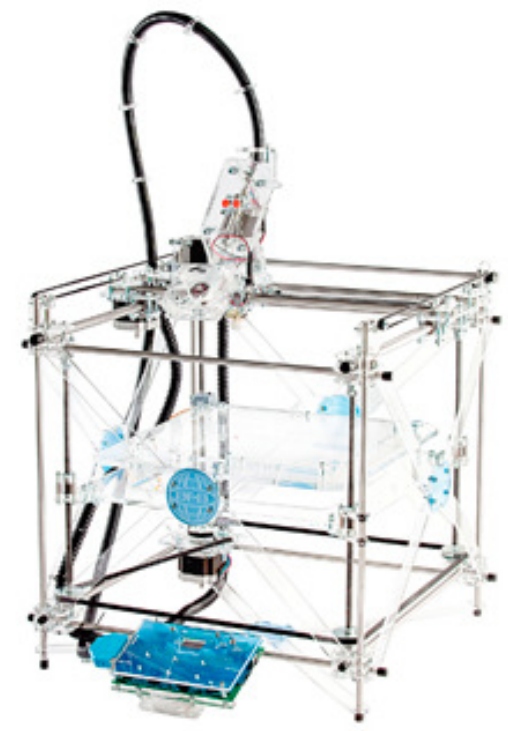

(a)

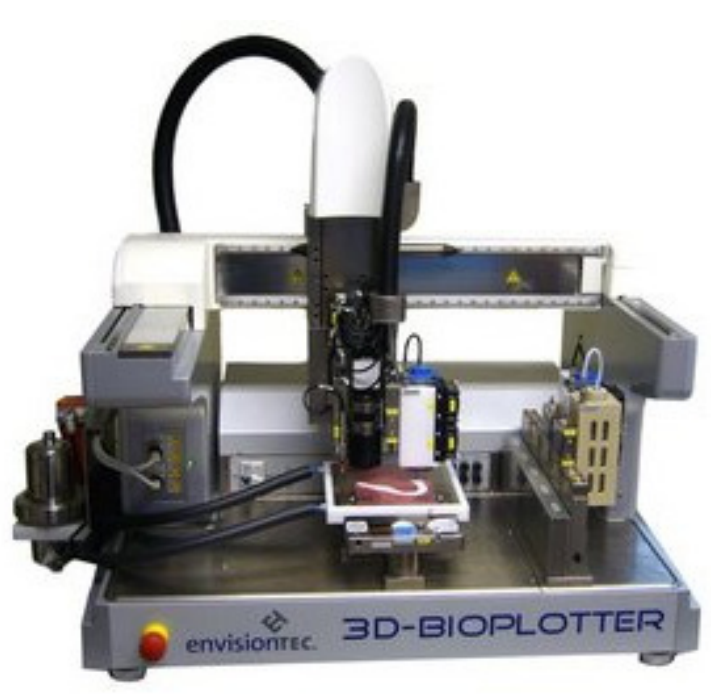

(b)

Figura 3.2 - (a) RapMan®; (b) 3-D-Bioplotter®.

$\mathrm{Na}$ área de biofabricação iniciou-se o desenvolvimento de máquinas personalizadas para deposição de esferoides para criação de tecidos como é o caso da Janome Bioprinter (Figura 3.3) cujos estudos preliminares foram realizados no CTI em conjunto com a Medical University of South Carolina .

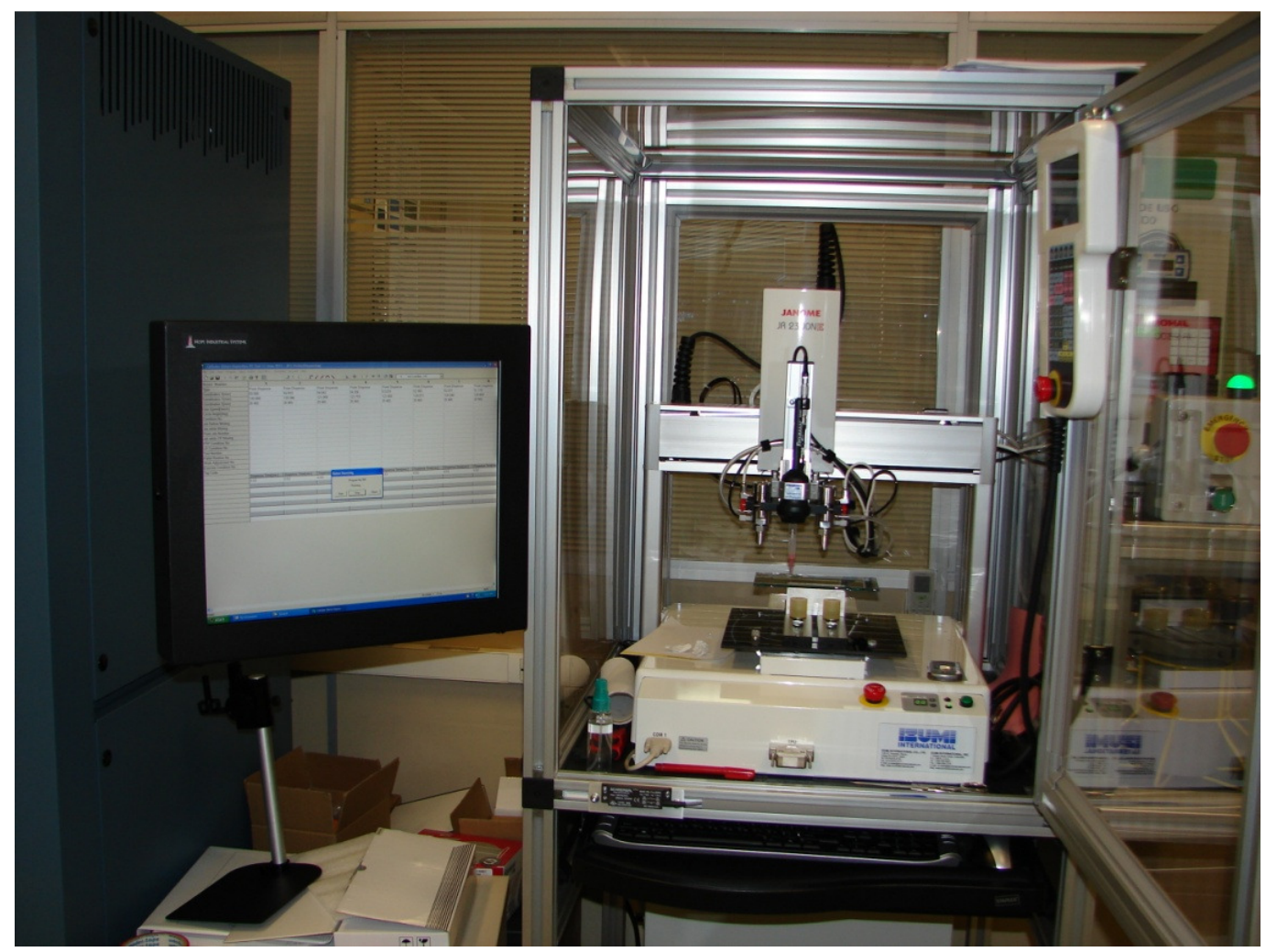

Figura 3.3 - Equipamento de biofabricação Janome Bioprinter. 
Com foco na indústria, a MA (processo de produção de objetos de geometrias complexas utilizando deposição geralmente camada a camada foi desenvolvida para o uso em produtos otimizados e de qualidade. Atualmente esta tecnologia está presente em vários campos do conhecimento principalmente na área de saúde, indo desde o auxílio a cirurgias complexas até pesquisas em engenharia de tecidos, a qual cada vez mais vem buscando na MA, meios de reproduzir geometrias de alta complexidade como, por exemplo, scaffolds - característica essa que é inerente à tecnologia em questão. A aplicação biomédica também é um dos focos do trabalho (SILVA; MEURER E.; MEURER M., 2004).

Assim, visando atender o planejamento estratégico do CTI 2006 - 2010 de implementar um equipamento de manufatura aditiva flexível, de pequeno porte, para aplicações em pesquisa e com arquitetura de hardware e software abertos, o Centro de Tecnologia da Informação Renato Archer (CTI), aderiu ao projeto Fab@Home o qual foi montado e adaptado denominando Fab@CTI. (INFORÇATTI NETO, 2007).

Para a montagem da versão inicial da Fab@CTI, utilizou-se um conjunto de placas em acrílico conforme distribuído pelo projeto Fab@Home, que pode ser visto na Figura 3.4.

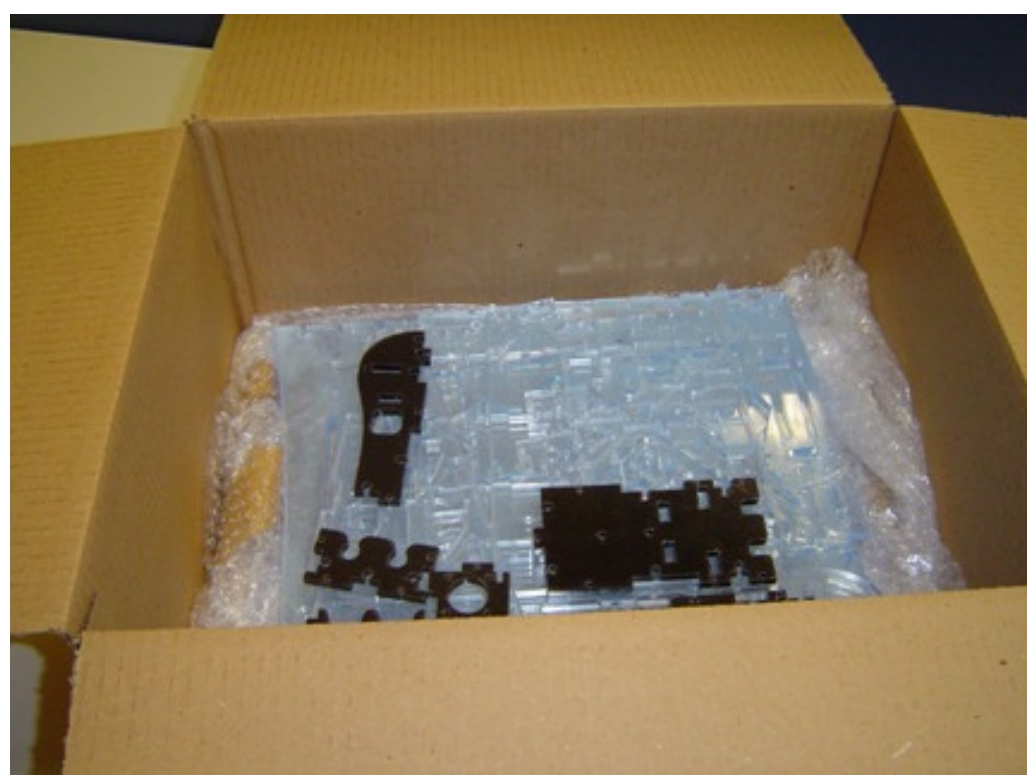

Figura 3.4 - Estrutura da Fab@CTI cortadas em acrílico. 
Além das partes estruturais em acrílico, foram utilizadas peças construídas em outras tecnologias de MA, no conceito de autorreplicação conforme apresentado na Figura 3.5.

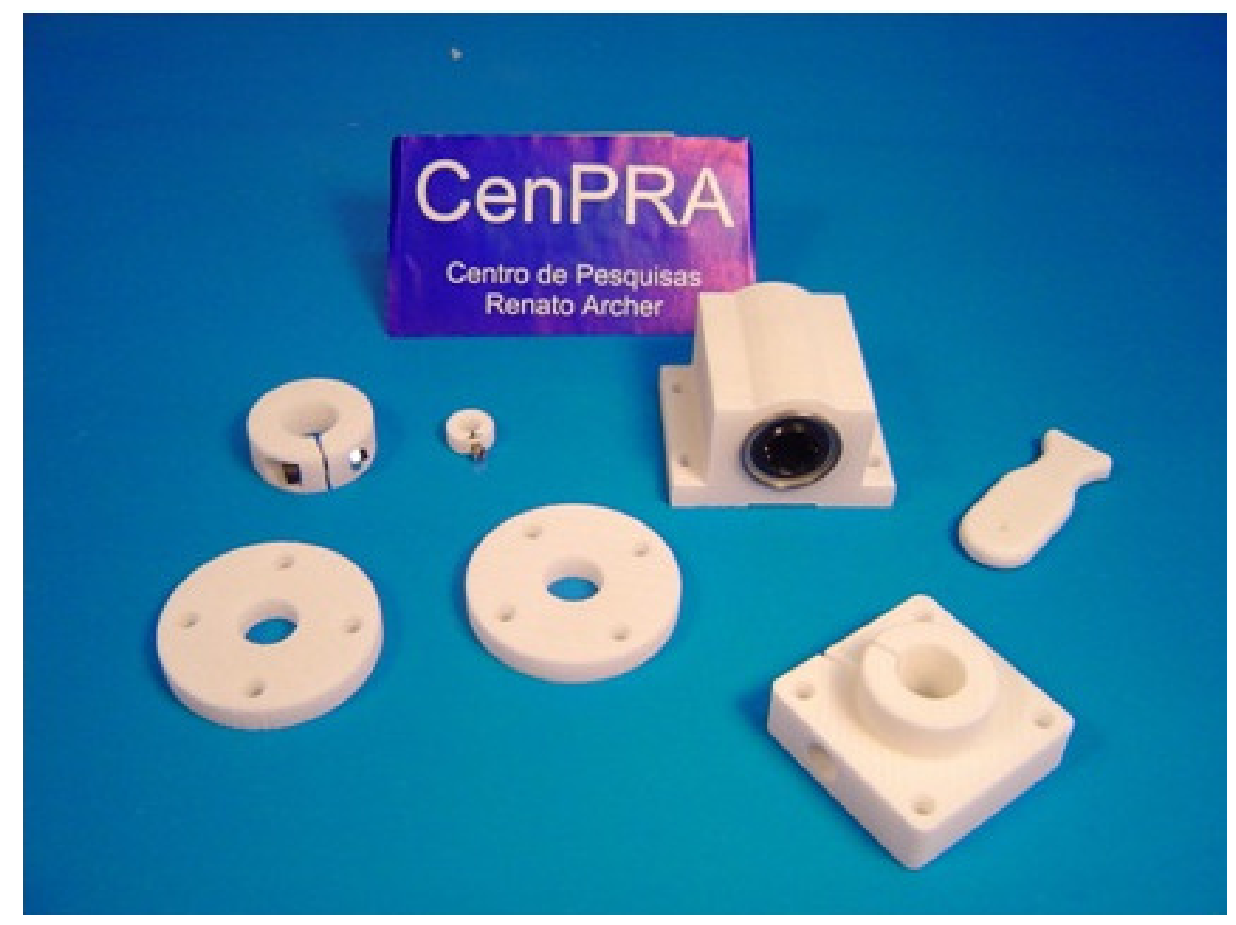

Figura 3.5 - Pillow blocks e suportes com flanges da Fab@CTI construídos com a tecnologia SLS.

Para realizar o acionamento dos cinco motores de passo bipolares contidos no projeto, foram utilizadas duas placas amplificadoras, conforme Figura 3.6. Estas placas foram escolhidas por apresentarem uma boa relação custo-benefício, pois, de acordo com os dados do fabricante, cada uma delas era capaz de controlar até 4 motores passo simultaneamente, trabalhando com controle de movimentação PWM (Pulse Width Modulation), controlando motores de até 2,5 Amperes/fase a partir de regulagem por potenciômetro. Além disso, este tipo de placa possibilita trabalhar com controles por meio de passo e direção, sendo que o tipo do passo pode ser cheio, meio passo, um quarto de passo e também $1 / 8 \mathrm{~mm}$ do passo. Finalmente, as placas possuem um sistema de proteção de desativação caso haja um excesso de temperatura nos circuitos integrados. 


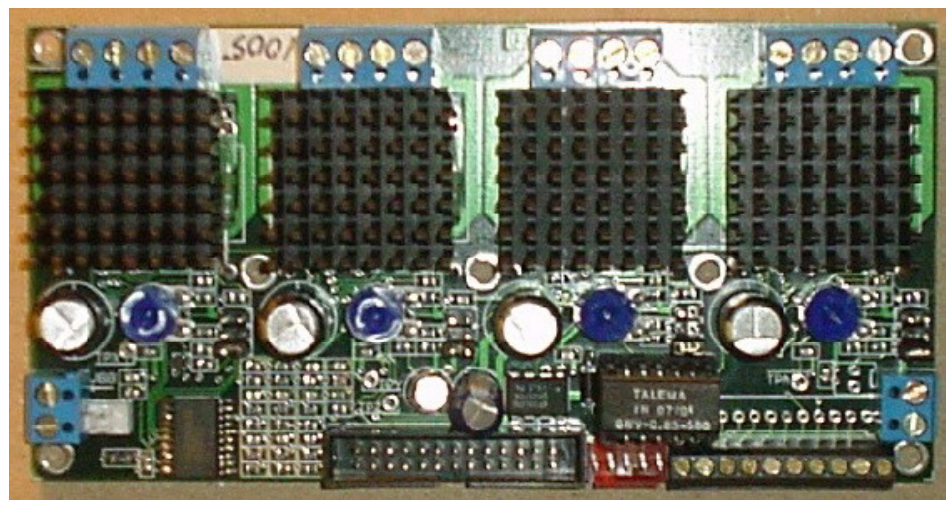

Figura 3.6 - Placa amplificadora da Xylotex para 4 motores de passo bipolares com padrão de controle step/dir.

Assim, com o objetivo de fazer a conexão dos motores de passo com a placa amplificadora, montaram-se cabos de acordo com a estrutura física da máquina. Depois de montado e ligado todos os cabos, as correntes dos motores foram ajustadas, conforme Figura 3.7, de acordo com as especificações do fabricante, com o intuito de se obter um melhor funcionamento dos mesmos.

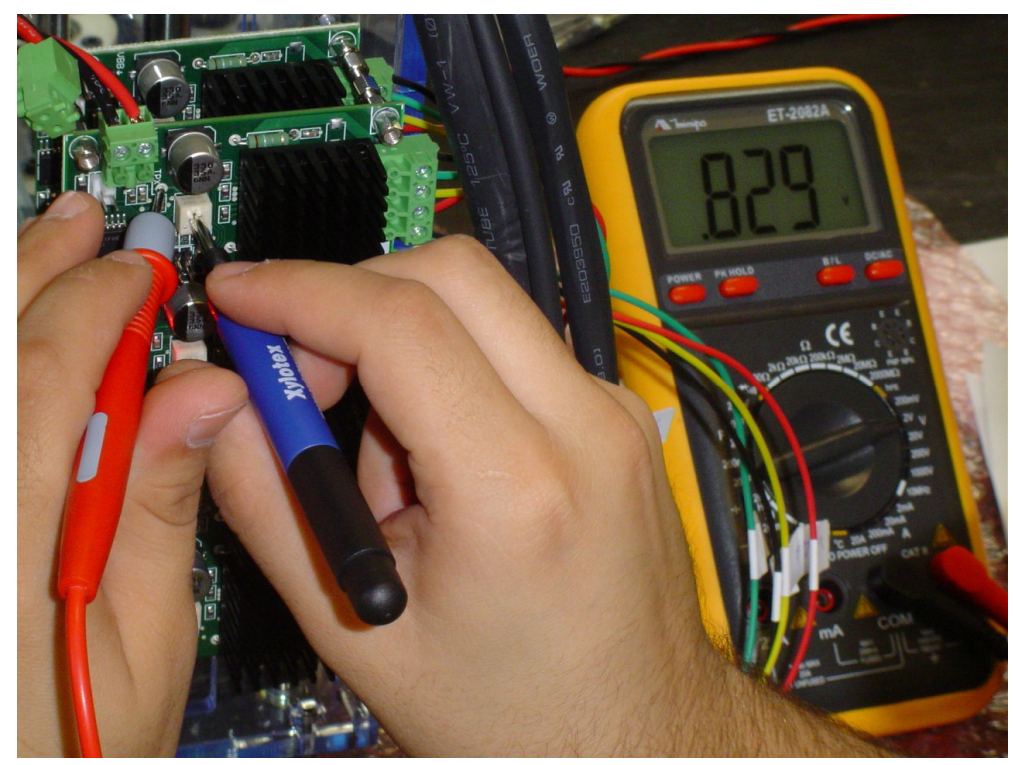

Figura 3.7 - Configuração das correntes dos motores na placa amplificadora Xylotex.

O sistema de comunicação entre a máquina e o PC é feito utilizando um dispositivo USB conforme descrito por Inforçatti Neto, 2007.

Para o sistema de controle da máquina, utiliza-se um software proprietário, open source com interface gráfica bastante amigável (Figura 3.8), pois, além de possibilitar ao usuário visualizar em tempo real toda movimentação da máquina por 
meio de uma imagem 3-D da mesma, este permite que o usuário faça a movimentação manual de cada um dos eixos e visualize por meio de uma janela de status, diversos parâmetros como: comunicação com o firmware, quantidade de comandos enviados e recebidos, posicionamento de cada eixo, posicionamento das chaves de fim de curso, entre outros.

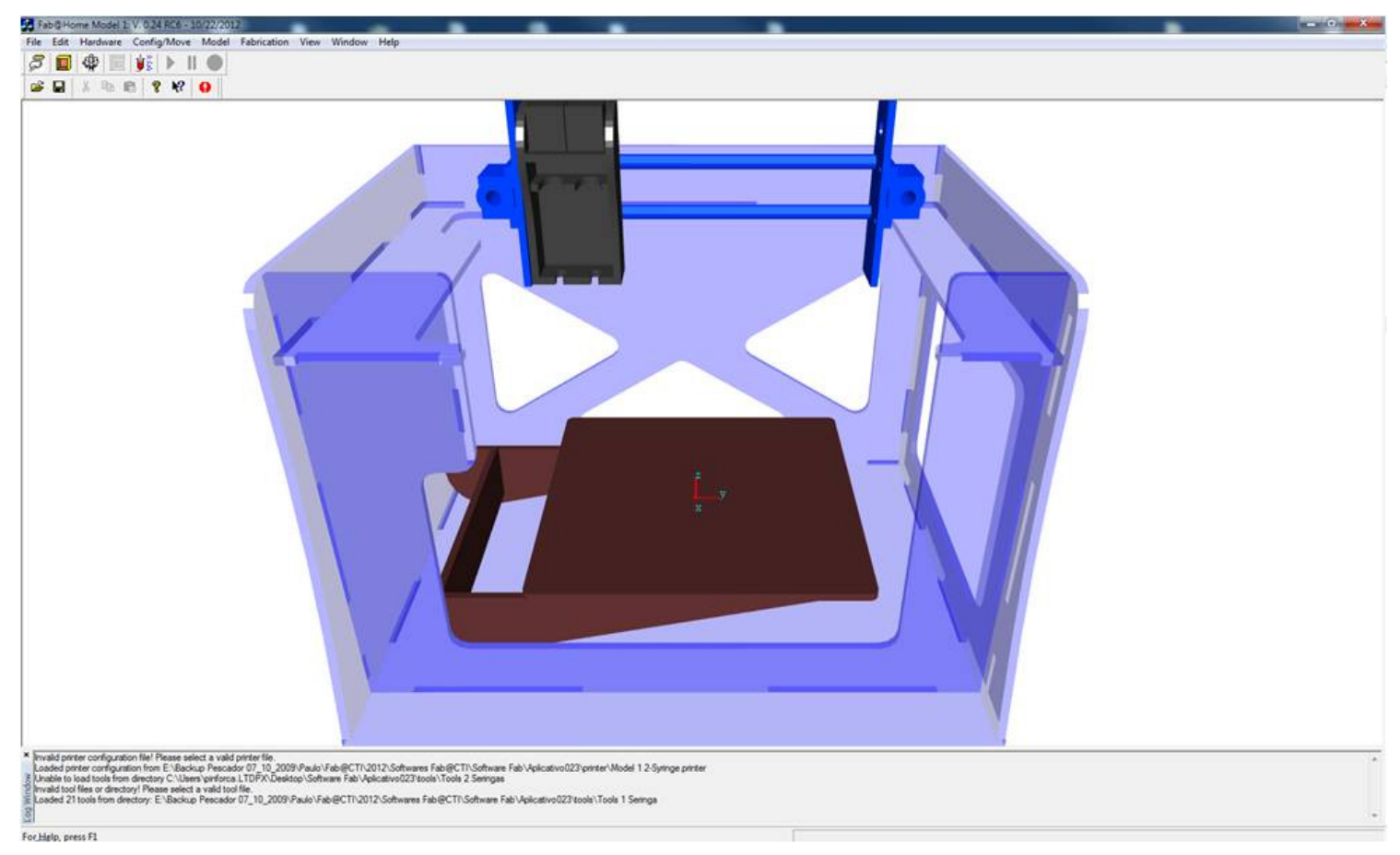

Figura 3.8 - Software Fab@Home versão 0.24.

Outro fator importante deste software é sua flexibilidade, pois de acordo com a necessidade do usuário, pode-se configurar, por meio de arquivos de textos lidos por ele, diversos parâmetros da ferramenta de deposição e do material utilizado. $\mathrm{Na}$ ferramenta de deposição os parâmetros de controle mais importantes são mostrados na tabela 3.1. Todos estes parâmetros são de grande importância para a elaboração e precisão do protótipo e consequentemente devem ser ajustados com bastante critério. 
Tabela 3.1 - Principais parâmetros de controle do software Fab@Home versão 0.24.

\begin{tabular}{l|l}
\hline \multicolumn{1}{c|}{ Parâmetro } & \multicolumn{1}{c}{ Função } \\
\hline PATHWIDTH & $\begin{array}{l}\text { Define a espessura da camada } \\
\text { Define a altura da camada } \\
\text { Define o tempo de avanço do êmbolo para iniciar o fluxo de } \\
\text { deposição }\end{array}$ \\
PUSHOUT & $\begin{array}{l}\text { Define o tempo de retroação do êmbolo antes de parar o fluxo } \\
\text { Define a movimentação do êmbolo durante o trajeto de deposição na } \\
\text { camada }\end{array}$ \\
DECKBACK & $\begin{array}{l}\text { Define a viscosidade do material } \\
\text { Define a compressibilidade do material }\end{array}$ \\
VISCOSITY & $\begin{array}{l}\text { Define a elasticidade do material } \\
\text { Define o tempo de espera para iniciar a camada }\end{array}$ \\
ELASTICITY & $\begin{array}{l}\text { Define o tempo de cura do material } \\
\text { Define a inclinação máxima suportada sem a queda da camada }\end{array}$ \\
LAYERWAIT &
\end{tabular}

O processo básico para a fabricação de um protótipo na Fab@CTI consiste em:

- conectar a máquina ao PC utilizando cabo USB;

- ligar a fonte de alimentação da máquina;

- iniciar o software Fab@Home;

- ler os arquivos de parâmetro de configuração da máquina;

- preparar a seringa, o material, e o bico a ser utilizado;

- inserir o êmbolo na seringa por meio do software;

- importar em STL a geometria da peça a ser fabricada;

- atribuir as propriedades do material e da ferramenta de deposição;

- gerar automaticamente o fatiamento da peça a ser fabricada;

- se desejado, executar uma simulação do processo por meio do software;

- inicializar o hardware da máquina;

- alinhar a mesa com o cabeçote;

- configurar a posição inicial (homing), a origem (origin) e a posição de

pausa e/ou troca de material (safe);

- inicializar o processo de fabricação.

$\mathrm{Na}$ Figura 3.9, observa-se a máquina montada, realizando teste funcional, concluindo assim a proposta inicial de uma estrutura modular para pesquisa utilizando tecnologia de MA. 


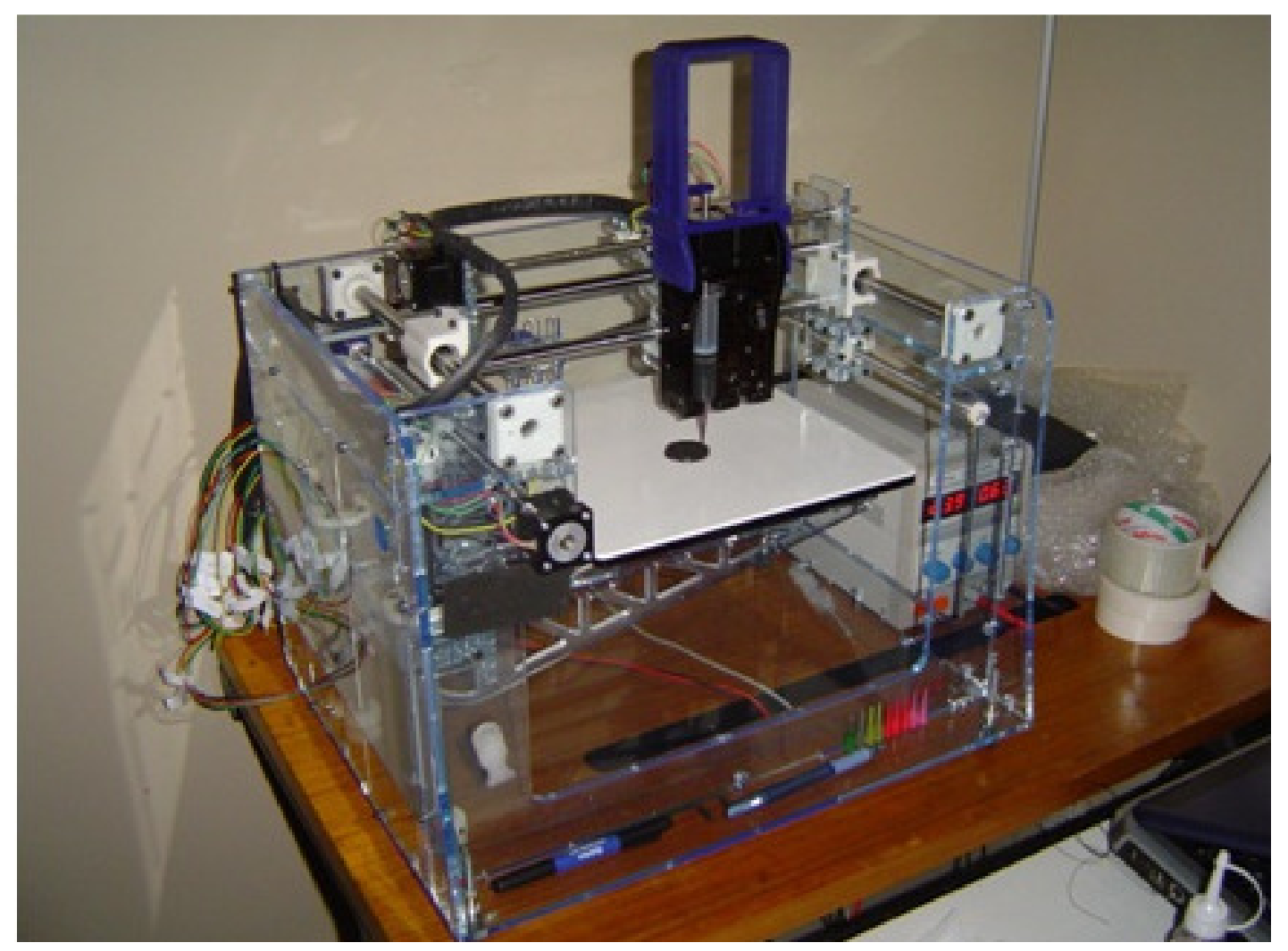

Figura 3.9 - Máquina Fab@Home construída no CTI.

A partir desta base, foram implementadas melhorias aproveitando a característica open source do projeto.

Com o objetivo de ampliar a usabilidade da máquina em ambiente de pesquisa, foi considerado fundamental aumentar sua flexibilidade em termos de modularidade e intercambiabilidade de tecnologias. Para tanto, foi desenvolvido e implementado um sistema de intercambiabilidade no cabeçote original possibilitando o desenvolvimento de novos cabeçotes adaptáveis à estrutura original da máquina através desta solução.

Na Figura 3.10 é possível visualizar a solução de intercambiabilidade composta pelo sistema de fixação mecânico e placas de conexão eletrônica padronizados, garantindo uma troca de cabeçotes rápida, confiável sem utilização de ferramentas especiais. 

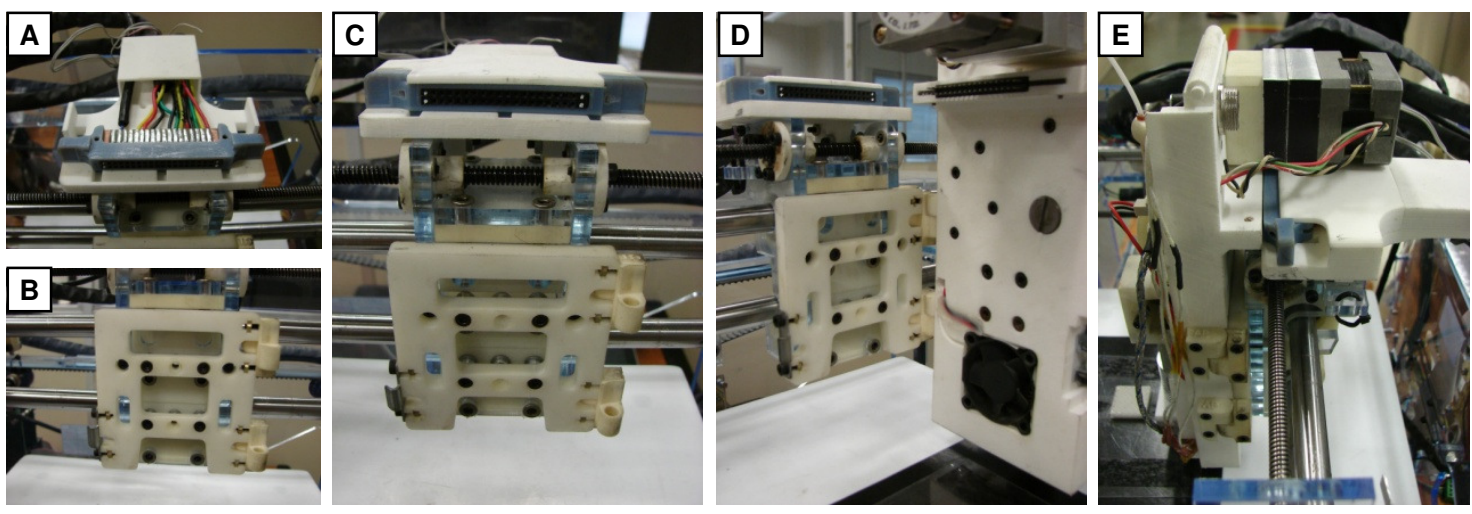

Figura 3.10 - Sistema intercambiável da Fab@CTI. a) Conexão eletrônica; b) Fixação mecânica; c) Sistema intercambiável completo; d) Acoplamento do cabeçote FDM nas dobradiças do sistema intercambiável; e) Acoplamento completo do cabeçote FDM na máquina Fab@CTI.

A partir da consolidação deste sistema com teste sobre o cabeçote original (seringa), visando aumentar a variedade de tecnologias e matérias-primas disponíveis para uso com esta plataforma de pesquisa, foi projetado e construído um cabeçote de extrusão de filamento (INFORÇATTI NETO et al., 2012) baseado em tecnologia FDM (CRUMP, 1994).

A Figura 3.11 mostra a aplicação do sistema de intercambiabilidade para o novo cabeçote de extrusão de filamento.

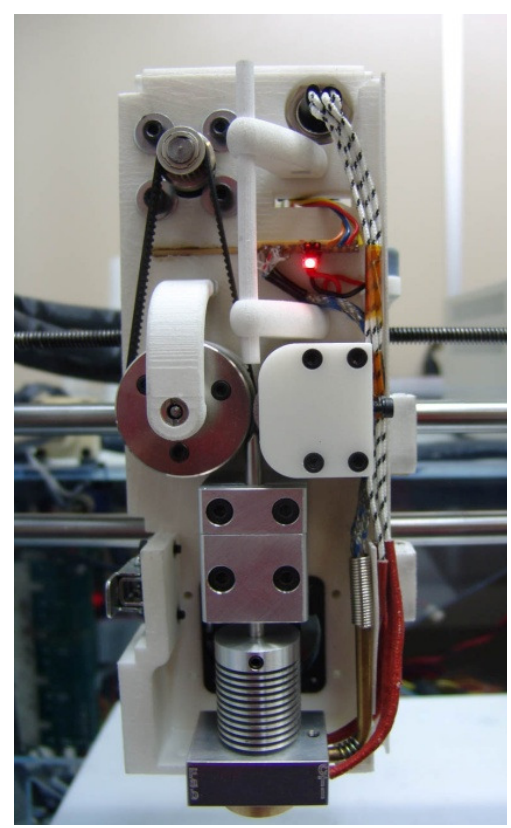

Figura 3.11 - Cabeçote de extrusão de filamento da Fab@CTI. 
Como pode ser observado, a intercambiabilidade trouxe flexibilidade $\mathrm{e}$ praticidade para o uso de novos materiais e tecnologias na Fab@CTI, o que se vê na Figura 3.12 que mostra a variedade de tecnologias até o momento disponíveis.

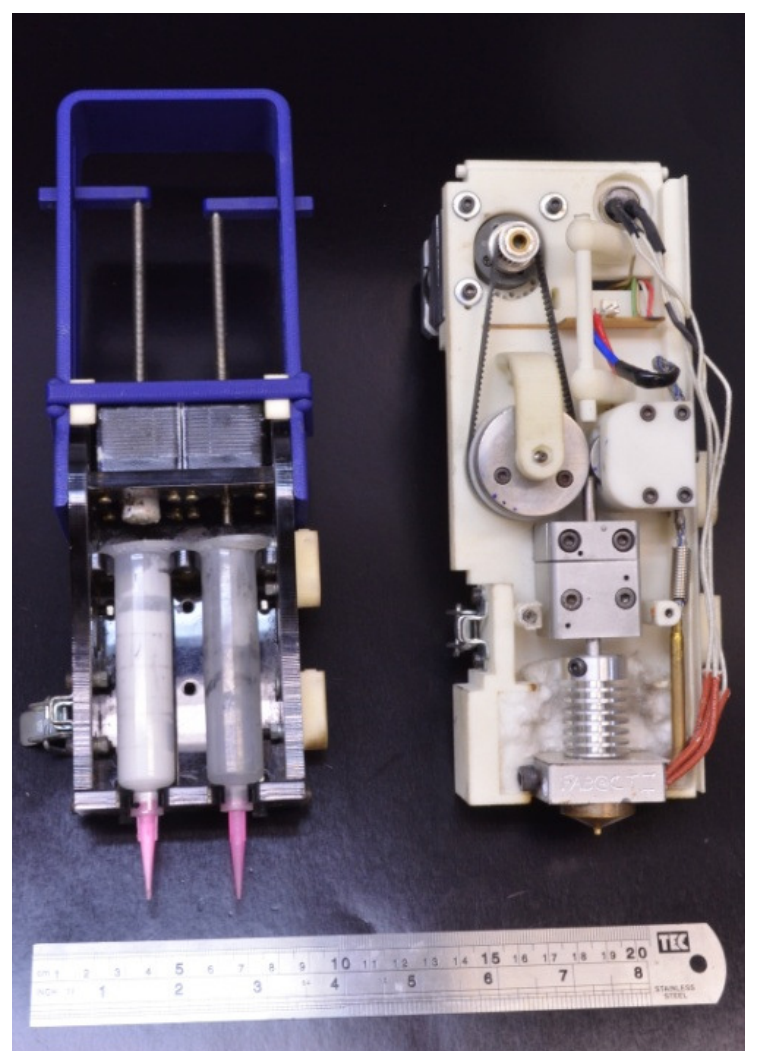

Figura 3.12 - Tecnologias de MA disponíveis na Fab@CTI. Na esquerda temos o cabeçote de deposição por meio de seringas e na direita o cabeçote de extrusão de filamentos.

Seguindo as linhas de pesquisa em bioengenharia e biofabricação desenvolvida no âmbito do CTI, a disponibilidade de uma plataforma flexível e multifuncional como a Fab@CTI torna-se fundamental. Sua utilidade ao estudo do uso de tecnologias de MA para a biofabricação, bem como de seus produtos para a bioengenharia e o desenvolvimento de dispositivos biomédicos é evidente, levando a diversas propostas de aplicação em pesquisa.

A utilização da manufatura aditiva para construção de bio-prototótipos utilizando biomateriais, principalmente nos centros de pesquisa e em algumas universidades começam a fornecer contribuições significativas e promissoras na área da saúde, como por exemplo, os scaffolds. Uma das grandes dificuldades é a utilização de equipamentos comerciais de MA em áreas de pesquisas interdisciplinares como na bioengenharia, porque estes equipamentos possuem 
parâmetros inacessíveis de controle da máquina, além da dificuldade de aquisição de matéria-prima do próprio fabricante. Além disso, a quantidade de matéria-prima necessária para construção de um protótipo nestes equipamentos comerciais é elevada, tornando inviáveis as pesquisas com novos biomateriais. Os custos elevados que envolvem a manipulação e aquisição de biomateriais devem ser levadas em consideração, além da necessidade de adaptar o equipamento de MA para utilização com este tipo de matéria-prima.

Uma primeira proposta de aplicação refere-se ao uso de biomateriais como matéria-prima para tecnologias de MA, viabilizando o desenvolvimento de dispositivos biomédicos personalizados e de geometria de alta complexidade. Neste contexto, a facilidade de controle e utilização de materiais diversos é uma exigência básica. O sistema open source da Fab@CTI permite este tipo de uso, desde que adaptado adequadamente.

Como consequência da necessidade de utilização de uma variedade crescente de novos materiais deve haver adaptações de tecnologias tradicionais de MA em relação à melhoria dos materiais, bem como o desenvolvimento de novas soluções construtivas de partes fundamentais da máquina. 


\section{Viabilidade técnica e física de um mini-cabeçote de extrusão com rosca de seção variável}

O processamento de polímeros industriais tem se beneficiado do processo extrusão, sob a forma de injeção e rosca, para se obter alta produção e qualidade nos produtos finais. A distribuição comercial mais comum destes materiais é na forma de pó ou pellets, mais adequados a este tipo de processamento. A partir dessas características, dentro do contexto de MA para máquinas de impressão tridimensional portáteis, para o cabeçote de deposição foi escolhida a tecnologia de extrusão, adaptada a uma rosca de seção variável de dimensões reduzida que seja intercambiável. Essa solução construtiva traz desafios de miniaturização e mudanças no projeto a fim de garantir as características necessárias para obter protótipos com qualidade dimensional.

Identificada a demanda descrita no item anterior e se tratando de um projeto tecnológico foi feito um levantamento em duas frentes: revisão da literatura e pesquisa em patentes. O Fluxograma representado na Figura 4.1 apresenta a abordagem sistemática utilizada para a concepção, desenvolvimento e validação do mini-cabeçote vertical de extrusão.

Há alguns conceitos de design para impressoras tridimensionais portáteis open source de custo reduzido. O projeto RepRap tem a proposta de autorreplicação de grande parte de seus elementos. A Universidade de Cornell desenvolveu a impressora Fab@Home construída como um pórtico com 3 eixos cartesiano, em que o deslocamento é feito por um motor de passo e a deposição de material é feita por meio de seringas. 


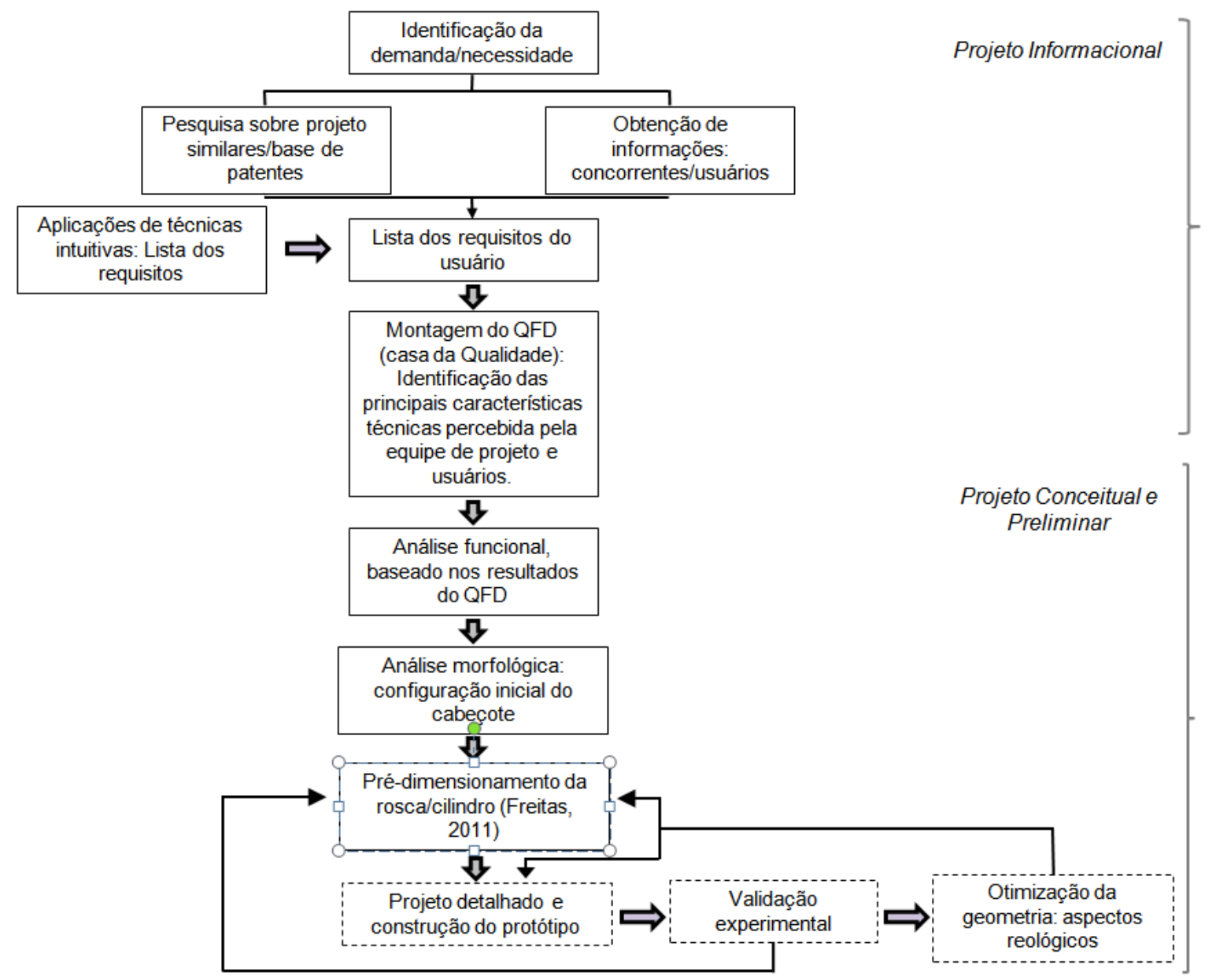

Figura 4.1 - Fluxograma desenvolvido para o estudo da viabilidade do mini-cabeçote de extrusão

O segundo modelo adaptado e projetado no CTI, apresenta melhorias em relação ao tempo de fabricação e montagem, que contribuíram para a redução de custos, com a melhoria nas interfaces eletrônicas e o conceito de um sistema de cabeçote intercambiável.

Há um conjunto de soluções encontradas na literatura para se conformar polímeros, como apresentado na seção 2.1. Os processos de extrusão realizados por injeção e rosca extrusora são largamente utilizados na indústria, nos quais a entrada da matéria-prima é feita previamente sob a forma amolecida ou algumas vezes em estado sólido como citado na seção 2.1.1. O material deve ser pressurizado de acordo, com um dos mecanismos e inserido em uma matriz ou molde. 
Entretanto, a proposta deste trabalho é obter o estudo da viabilidade física, concepção, construção e validação de um novo cabeçote de deposição, para impressoras tridimensionais de pequeno porte. Com essa premissa e com as soluções intercambiáveis descritas no capítulo 3, a idéia inicial do projeto se baseou em um sistema de extrusão com posição vertical, com uma mini-rosca de seção variável.

Ainda no capítulo 3 foi feita uma breve revisão das impressoras tridimensionais de estrutura aberta e de pequeno porte encontradas na área de pesquisa, indústria e de "hobbistas". Em praticamente todos os projetos abordados, a deposição é realizada com filamento fundido, através de seringas (simplificação de injetoras) e uso da tecnologia FDM (Filament Deposition Modelling).

Neste sentido, para complementar essa revisão foi feita uma pesquisa sobre soluções construtivas utilizando as bases de patentes: Derwent (www.derwent.com), USPTO (http://www.uspto.gov) e INPI (www.inpi.gov.br).

A patente número US 8287959 B2, com co-autoria da empresa Stratasys denominada "Syringe tip assembly and layered deposition systems utiling the same", com data de aprovação 16/10/2012 representa as soluções mais utilizadas para impressoras tridimensionais de pequenas dimensões e baixo custo. Nesta patente há uma variação na ponta do sistema de injeção que aplica uma pressão na região entre os elementos 28 e 32 conforme Figura 4.2. 


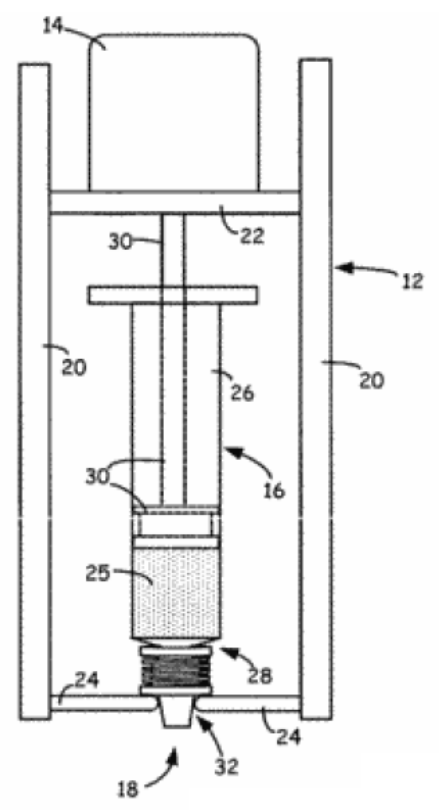

Figura 4.2 - Esquema da solução construtiva (uso de seringa) da patente número US 8287959 B2.

A patente de número US 6.866.807 B2 aprovada em 15/03/2005 intitulada "High-Precision Modelling Filament' assinada também com co-autoria da empresa Stratasys consiste em um sistema de modelagem de filamento composto por um sistema de extrusão de rosca simples com seção variável, que alimenta um cabeçote de FDM. Um sistema de controle atua após a saída do filamento do sistema de extrusão para corrigir o desvio-padrão do diâmetro do filamento. A Figura 4.3 ilustra o sistema esquematizado. 


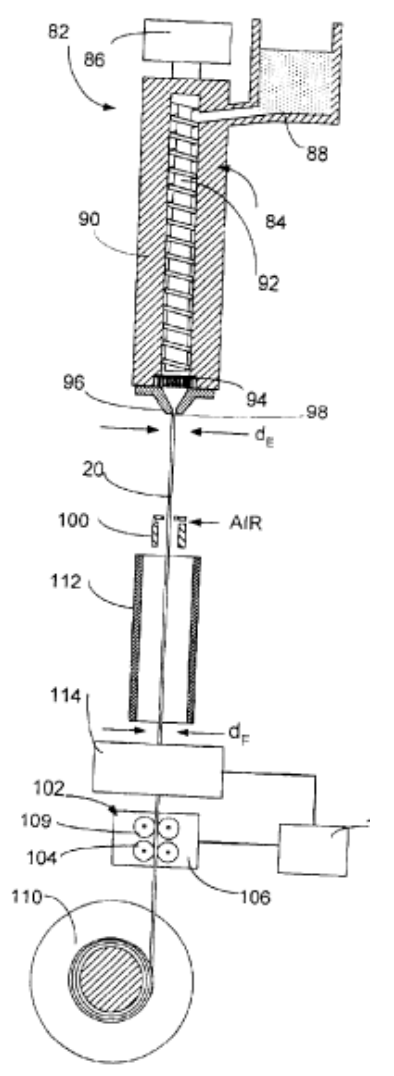

Figura 4.3 - Esquema da Patente número US 6.866.807 B2 (2005)

A patente número PT 104247 B, depositada em 04/11/2008 em Portugal sob o título "Processo e Equipamento de fabrico rápido por bioextrusão", consiste em equipamento e processo de prototipagem rápida por bioextrusão destinado para a produção de próteses ósseas aplicadas no ramo médico, especificamente scaffolds. Nesta solução, o cabeçote funciona apenas como um sistema de transporte, uma vez que o material já é inserido na rosca sob a forma amolecida.

Destacam-se diferenças fundamentais entre os detalhes evidentes na patente e as soluções propostas neste capítulo e nos capítulos 5 e 6 deste projeto:

- A patente propõe uma aplicação não comercial da solução enquanto este trabalho propõe aplicações em pesquisa na área de tecnologia de MA e aplicações diversas como as necessárias para a biofabricação. Além disso, estas soluções poderão ser comercializadas; 
- O dispositivo patenteado propõe-se a produzir filamentos como matéria-prima para uso em tecnologia de MA, enquanto o dispositivo proposto neste trabalho aplica-se diretamente como parte de um sistema de MA;

- O sistema de alimentação do dispositivo patenteado trabalha por gravidade e é passivo, enquanto a solução proposta neste trabalho possui um mecanismo de raspagem ativo para facilitar a condução do pó para a zona de alimentação da rosca de extrusão;

- O dispositivo patenteado utiliza uma única matriz de extrusão para um diâmetro fixo, enquanto a solução deste trabalho propôs e implementou bicos intercambiáveis capazes de gerar diretamente um filamento com precisão para aplicação em técnicas de MA.

Dessa forma, há diferenças fundamentais entre a solução proposta por este trabalho e a patente US 6.866.807 B2.

\subsection{Definição das necessidades do usuário}

As necessidades para o desenvolvimento do cabeçote proposto se baseia nas seguintes características: matéria-prima, uso e desenvolvimento tecnológico.

Das necessidades vinculadas à matéria-prima destaca-se o interesse no uso de polímeros e sua mais fácil obtenção na forma de pó, como dito anteriormente. Além disso, por se tratar de uma máquina com objetivo principal de aplicação em atividades de pesquisa, é fundamental que esta seja capaz de operar com quantidades mínimas de matéria-prima. Finalmente, por serem materiais de pesquisa, as condições de operação podem ser muito variadas, exigindo uma plataforma flexível e robusta.

Para atender a necessidade de trabalho com polímeros termoplásticos em pó, uma das técnicas mais empregadas é a de extrusão por rosca similar ao sistema de injeção por canhão. Como visto na fundamentação teórica, esta técnica é largamente aplicada a uma grande variedade de polímeros termoplásticos, mas ainda com equipamentos de dimensões e peso excessivamente grandes para 
aplicações de pequeno porte. No entanto, trata-se de uma técnica pouco empregada em manufatura aditiva, principalmente em máquinas de pequeno porte e para uso experimental, dadas as dimensões da tecnologia atual. $O$ desafio de trabalhar com pó também pode ser enfrentado como uso desta tecnologia, uma vez que esta seja miniaturizada, o que possibilitará alteração do uso do material em pellets para pó.

Finalmente, quanto às necessidades vinculadas ao desenvolvimento tecnológico é possível destacar a miniaturização da tecnologia de extrusão por rosca bem como sua aplicação em uma máquina de MA de pequeno porte. Outra necessidade veio da ampliação do conceito de intercambiabilidade de cabeçotes para o aumento da flexibilidade de uma mesma plataforma de MA. Quanto ao público alvo, a tecnologia foi desenvolvida em ambiente de pesquisa. Portanto seu primeiro público natural encontra-se neste ambiente, como por exemplo, laboratório de universidades, institutos de pesquisa, entre outros. Um segundo público alvo seria o usuário doméstico, dada a facilidade de controle do processo e obtenção da matéria-prima seja em seu estado natural ou na forma combinações de resíduos reciclados. Um terceiro público alvo seriam empresas de base tecnológica interessadas no uso das características específicas da tecnologia desenvolvida para o cabeçote, para aplicações inovadoras. Com relação ao custo, a proposta é ter uma solução de baixo custo em comparação às propostas comerciais, também levando em conta o ambiente de aplicação.

Para projeto informacional, o qual compreende reunir informações importantes para realização do projeto, foi utilizado o método intuitivo brainstorming para definir o escopo do projeto e mercado consumidor. Para tanto foram entrevistados verbalmente mais de 50 pessoas entre as quais pesquisadores, alunos de graduação em Engenharia Mecânica, e usuários experientes no uso deste tipo e tecnologia. Também foram realizadas pesquisas para reunir informações sobre o que já existe no mercado relativo às máquinas de manufatura aditiva e estudos da parte de interesse (cabeçote), materiais usados na injeção e patentes que forneceram informações sobre soluções já existentes.

A Tabela 4.1 apresenta os requisitos selecionados, após remoção de ambiguidades para melhoria do projeto de uma impressora 3-D portátil e de baixo, a 
partir das sessões de Brainstorming com membros da equipe do grupo PROIND do CTI e de usuários (pesquisadores).

A partir dos principais requisitos indicados pelo usuário definidos na Tabela 4.1 foi feito um desdobramento em características técnicas, que implicam em desdobramentos posteriores, diretamente relacionados à escolha dos materiais, propriedades mecânicas, geometria e escolha do conceito do cabeçote de deposição.

\subsubsection{Montagem e análise do QFD (Quality Function Deployment) para uma impressora 3-D portátil e de baixo custo}

Uma vez definidos os requisitos do usuário foi elaborada a primeira matriz do QFD. Essa matriz, conforme descrito no item 2.3.1 gera três procedimentos: tradução dos requisitos do usuário em características técnicas; correlação entre a "Voz do Usuário" e a "Voz da Empresa" e extração das características de maior importância indicadas por esse processo. No caso deste trabalho, os usuários foram compostos por pesquisadores dentre os quais: engenheiros mecânicos, de computação, dentistas, químicos e especialistas em prototipagem rápida, portanto uma equipe multidisciplinar. 
Tabela 4.1 - Lista de requisitos do usuário

\begin{tabular}{|l|l|l|}
\hline Design moderno & Não vibrar & Diferentes aplicações \\
\hline $\begin{array}{l}\text { Resistência a variações } \\
\text { externas }\end{array}$ & Baixo peso & Alta rigidez \\
\hline Silenciosa & Alta precisão & Compacta \\
\hline Transportável & Econômica & $\begin{array}{l}\text { Portável para diferentes } \\
\text { sistemas operacionais }\end{array}$ \\
\hline $\begin{array}{l}\text { Visualização esquemática } \\
\text { das etapas de deposição }\end{array}$ & $\begin{array}{l}\text { Não falhar durante a } \\
\text { operação }\end{array}$ & $\begin{array}{l}\text { Rápido processamento } \\
\text { computacional }\end{array}$ \\
\hline $\begin{array}{l}\text { Interface com sistemas } \\
\text { CAD }\end{array}$ & $\begin{array}{l}\text { Permitir o uso de } \\
\text { diferentes materiais }\end{array}$ & $\begin{array}{l}\text { Diferentes técnicas de } \\
\text { estruturação }\end{array}$ \\
\hline Não liberar odor & $\begin{array}{l}\text { Permitir a utilização de } \\
\text { pequeno volume de } \\
\text { material }\end{array}$ & Fácil de operar \\
\hline Fácil limpeza & $\begin{array}{l}\text { Resistente a variações } \\
\text { ambientais }\end{array}$ & \\
\hline
\end{tabular}

A equipe técnica compreendeu o grupo de desenvolvimento e aplicação de tecnologias de prototipagem rápida. A Tabela 4.2 apresenta a lista de características técnicas desdobradas (correlacionadas), com os requisitos identificados na Tabela 4.1.

Tabela 4.2 - Características técnicas obtidas para uma impressora 3-D portátil e de baixo custo.

\begin{tabular}{|l|l|l|}
\hline Estrutura da máquina & Estrutura dos materiais & Sistema de transmissão \\
\hline Sistema de movimentação & Volume de construção & $\begin{array}{l}\text { Dimensões do } \\
\text { equipamento }\end{array}$ \\
\hline Interface gráfica & Controle & Software \\
\hline Sistema de comunicação & Fonte de Energia & Intercambiabilidade \\
\hline Cabeçote & Montagem & \\
\hline
\end{tabular}

A Figura 4.4 apresenta uma correlação de conflitos entre os pares das características técnicas. Nesta parte da matriz da qualidade é possível antecipar eventuais contradições técnicas, que podem conduzir à tomadas de decisões técnicas, ainda na fase do projeto informacional. 


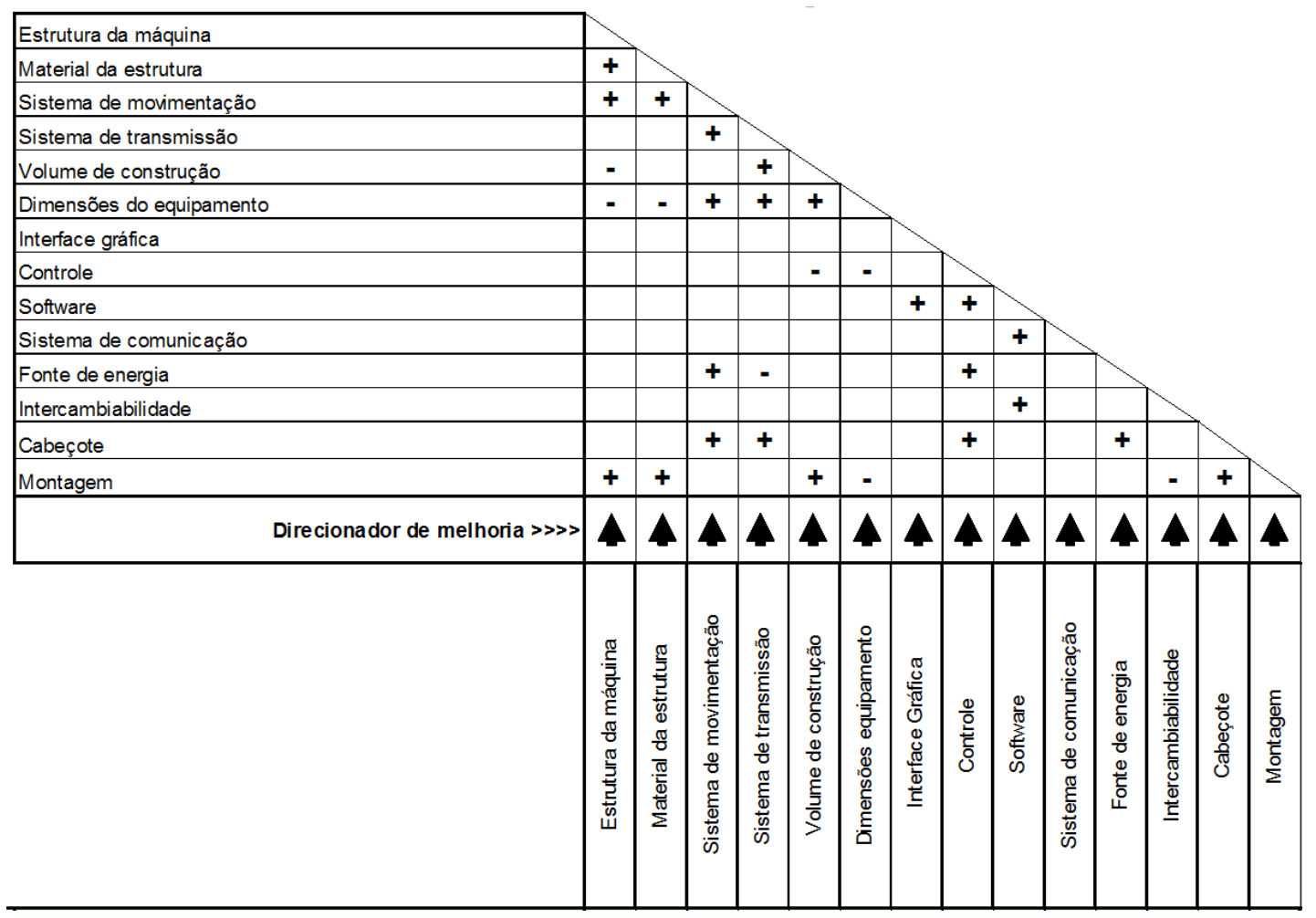

Figura 4.4 - Matriz de contradições técnicas (ver apêndice A.1).

Os valores negativos na Figura 4.4 indicam potenciais conflitos, como por exemplo:

- Fonte de energia x sistema de transmissão;

- Dimensões do equipamento x montagem;

- Intercambiabilidade x montagem.

Essas contradições são decorrentes, principalmente devido às dimensões da impressora 3-D e escolha dos sistemas de acionamento.

As informações obtidas da primeira matriz do QFD seguem parcialmente o procedimento explicado na Figura 2.14: extração de informações a partir dos requisitos do usuário, sob a forma de características técnicas (apresentados nas Tabelas 4.1 e 4.2); correlação entre requisitos do usuário e características técnicas; conversão dos requisitos do usuário com valoração e correlação, para classificar as características de maior importância. Simplificadamente obtém-se da Figura 4.5 (matriz da qualidade) as seguintes informações: 
- Lado direito da matriz: obtenção dos valores relativos de cada requisito do usuário, utilizando "benchmarketing" com outras impressoras de mesmo segmento e valoração dos requisitos potencialmente atraentes para os usuários finais;

- Porção inferior da matriz (sentido vertical): obtenção dos valores relativos de cada característica técnica (poderia ser considerado as impressoras de mesmo segmento), que não foi neste caso por impossibilidade de compra das mesmas. Com a matriz de correlação central da matriz, os pesos de cada linha (requisitos técnicos) são considerados, na somatória de cada coluna (características técnica).

Com o resultado desse processo foram elencadas, em escala decrescente de importância, as seguintes características técnicas, conforme pode ser observado na Figura 4.5.

- Cabeçote de deposição (13\%);

- Software (11\%);

- Material da estrutura (11\%). 


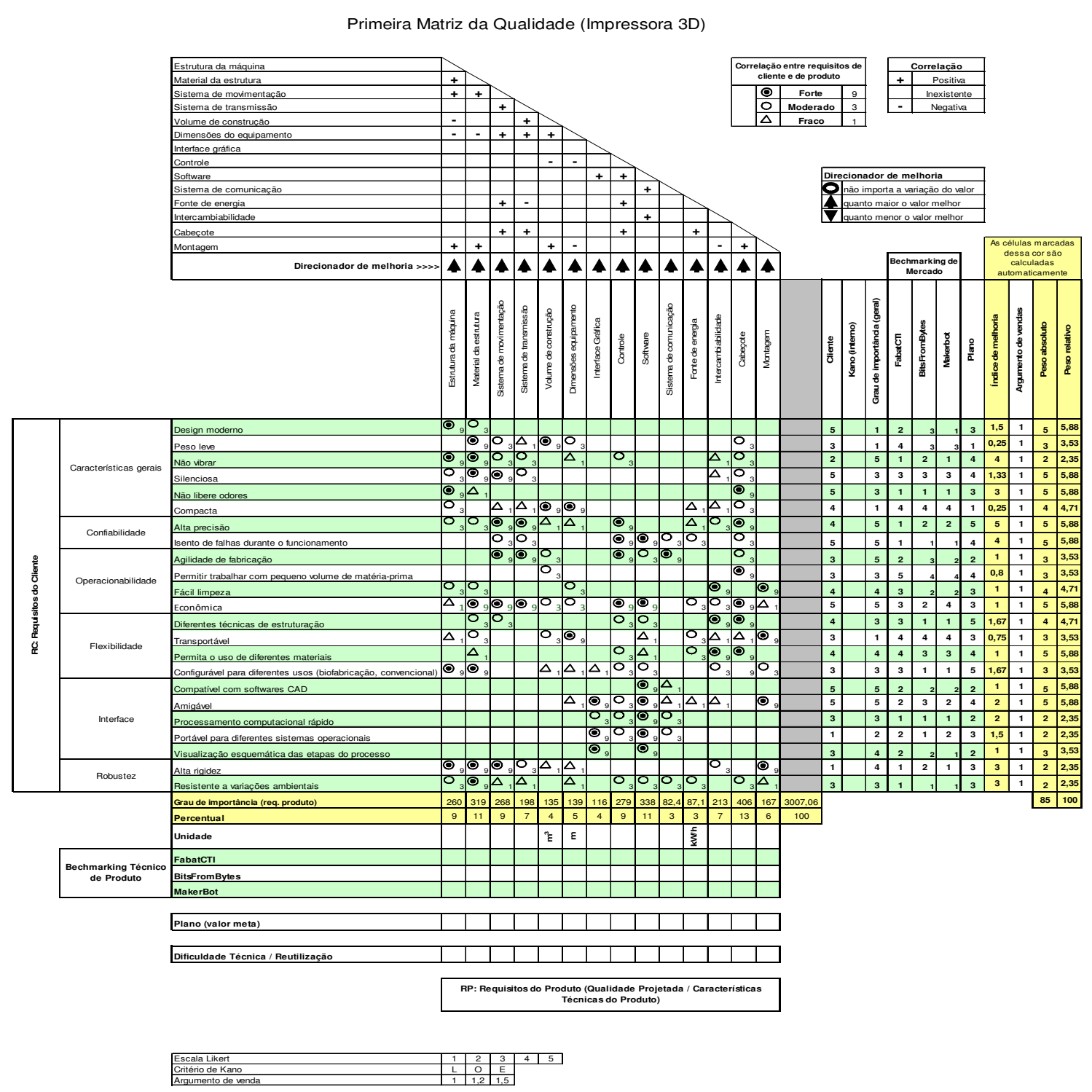

Figura 4.5 - Matriz da qualidade para melhoria de um projeto de impressora 3-D de deposição. (ver apêndice A.1).

$\left.1^{\circ}\right)$ Cabeçote: Novas técnicas de MA, para o cabeçote da máquina devem ser estudadas e melhoradas. O cabeçote incorpora a função do produto da máquina, e quase sempre, está ligado com os requisitos do cliente: ela deve ser leve, livre de vibrações, silenciosa, não deve liberar odores, deve ser compacto, de alta precisão, tolerante a falhas, ser ágil, permitir trabalhar com um pequeno volume de matériaprima, ser econômico, utilizar diferentes técnicas de estruturação (dependendo da matéria-prima), permitir a utilização de diferentes materiais, permitir configuração para diferentes geometrias, ser de fácil manutenção e possuir uma rigidez adequada. 
$2^{\circ}$ ) Software: O outro sistema de grande importância é o programa de interface com o usuário. A função básica do programa em uma máquina de impressão tridimensional é transformar o modelo matemático, em uma sequência de operações também matemáticas, a fim de gerar o protótipo físico.

3º) Material da estrutura: Os diferentes tipos de materiais estão diretamente relacionadas com as variações do peso, a melhoria da estabilidade, reduzir ou eliminar as contaminações, possuir durabilidade, influenciando a portabilidade do equipamento. Assim, devem ser utilizados materiais resistentes leves e que ao mesmo tempo torne a impressora ainda mais portátil.

A partir da pesquisa sobre patentes de cabeçotes de deposição por extrusão com rosca e com a experiência do grupo do CTI em manufatura aditiva, as características técnicas escolhidas para melhoria de projeto forma: solução construtiva de um cabeçote de extrusão e material da estrutura do mesmo.

O desenvolvimento de uma primeira versão da matriz de qualidade do QFD permite a geração de um banco de dados técnicos, para acompanhar as alterações do produto ao longo de sua vida útil. 


\section{Desenvolvimento do projeto conceitual}

A utilização do QFD na fase do projeto informacional permitiu um estudo sistematizado do projeto da impressora 3-D portátil por deposição, com programa de interface e construções abertas, permitindo a extração de informações sobre os requisitos mais percebidos pelo usuário. A partir deste conjunto de requisitos, juntamente com a pesquisa de soluções comerciais identificou-se as características de maior importância para a melhoria do projeto. A característica com maior valor relativo foi o cabeçote de deposição. Portanto, a segunda parte deste trabalho está focada em uma solução construtiva para um cabeçote de deposição diferenciado, em relação às soluções existentes no meio acadêmico e até industrial, para esse segmento de impressoras tridimensionais de pequeno porte.

Os requisitos do usuário tiveram uma distribuição de pesos relativos bastante dispersos, devido ao uso ainda restrito deste tipo de tecnologia no meio acadêmico, principalmente no Brasil. Entretanto, o requisito "alta precisão" teve uma representação de 5,88\%, que o caracteriza como um requisito de importância elevada dentre os valores encontrados. Pela experiência do grupo de MA do CTI, o uso de pequena quantidade de material e elevada resistência do dispositivo de deposição, para geração de protótipos de apoio à pesquisa são requisitos importantes, mesmo sendo avaliado pelos usuários em 3,53\% (uma importância média). Esses dois requisitos correlacionados com a importância da característica "cabeçote de deposição" nortearam a concepção e o projeto do cabeçote proposto neste trabalho.

Para impressoras 3-D por deposição de materiais, as soluções construtivas definidas genericamente como "processos de extrusão", normalmente estão relacionadas com a utilização de seringas, filamentos e transporte por rosca de seção constante, de material amolecido, conforme descrito no item 2.2.

Com base nas soluções encontradas na indústria de processamento de polímeros industriais, o cabeçote será intercambiável, conforme proposta do capítulo 3 , considerando uma mini-extrusora vertical com rosca de seção variável. 
O projeto conceitual se caracteriza pela investigação de configurações viáveis para o produto. A fase inicial dessa etapa do projeto procura investigar o projeto do produto de forma abstrata retirando os nomes técnicos dos elementos e subconjuntos tratando-os como funções descritas em uma estrutura de verbosubstantivo. Essa abordagem facilita a procura por soluções físicas alternativas e 0 uso de analogias, que pode resultar em soluções diferenciadas e até mesmo inovações. À medida que o produto, inicialmente como um sistema, é entendido, são obtidas as soluções técnicas. O resultado desta etapa são esboços de soluções tecnicamente viáveis, que serão analisados e definidos tecnicamente no projeto preliminar.

Para entender de forma lógica o funcionamento da impressora tridimensional e do subsistema "cabeçote baseado em processo de extrusão" foram feitos dois Diagramas MSE (Matéria, Sinal e Energia), conforme apresentado nas Figuras 5.1 e 5.2.

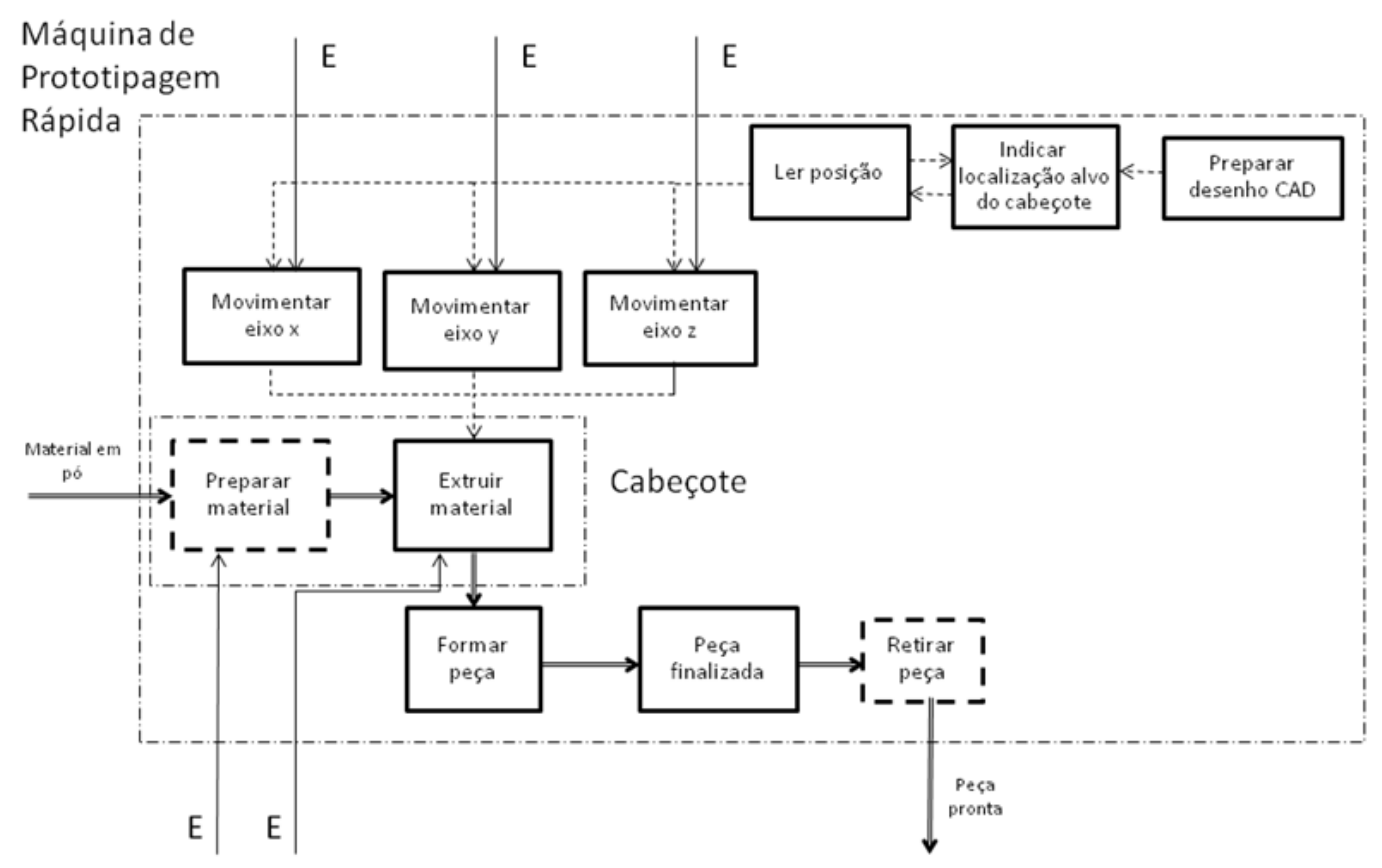

Figura 5.1 - Diagrama Matéria-Sinal-Energia da impressora 3-D. 


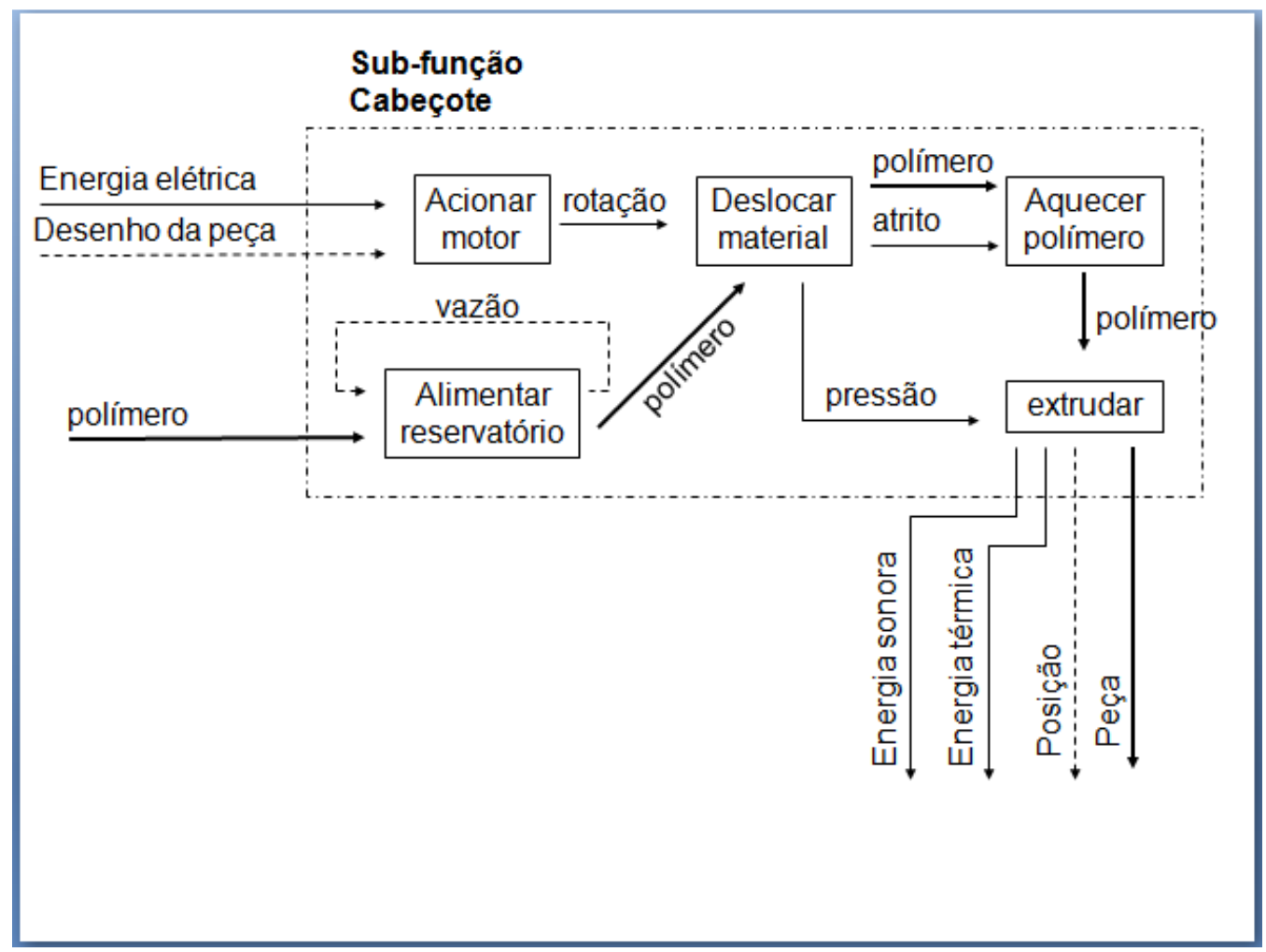

Figura 5.2 - Diagrama Matéria-Sinal-Energia do subsistema "cabeçote de extrusão".

A primeira opção de soluções técnicas é apresentada pelas setas para atender as restrições do projeto descritas anteriormente. Dentro do sistema técnico da impressora 3-D, a produção de um protótipo é a principal função da concepção de um projeto de engenharia da máquina. Na Figura 5.2 o fluxo do processo de formação do protótipo é detalhado. Para cada função descrita, as decisões do desenho devem ser feitas com base em soluções convencionais e alternativas que contemplem as restrições deste subsistema, como a localização do centro de gravidade do cabeçote em relação à máquina, espaços reduzidos, portabilidade e baixo custo.

A partir das características técnicas obtidas no QFD, com foco no cabeçote foram desdobrados os principais parâmetros de projeto do cabeçote de extrusão vertical. A Tabela 5.1 apresenta de forma resumida as soluções técnicas para cada parâmetro e o percurso indicado pelas setas indica o conjunto de soluções técnicas escolhidas para a primeira configuração de projeto do mini-cabeçote de extrusão. 
Tabela 5.1 - Análise morfológica do cabeçote de extrusão.

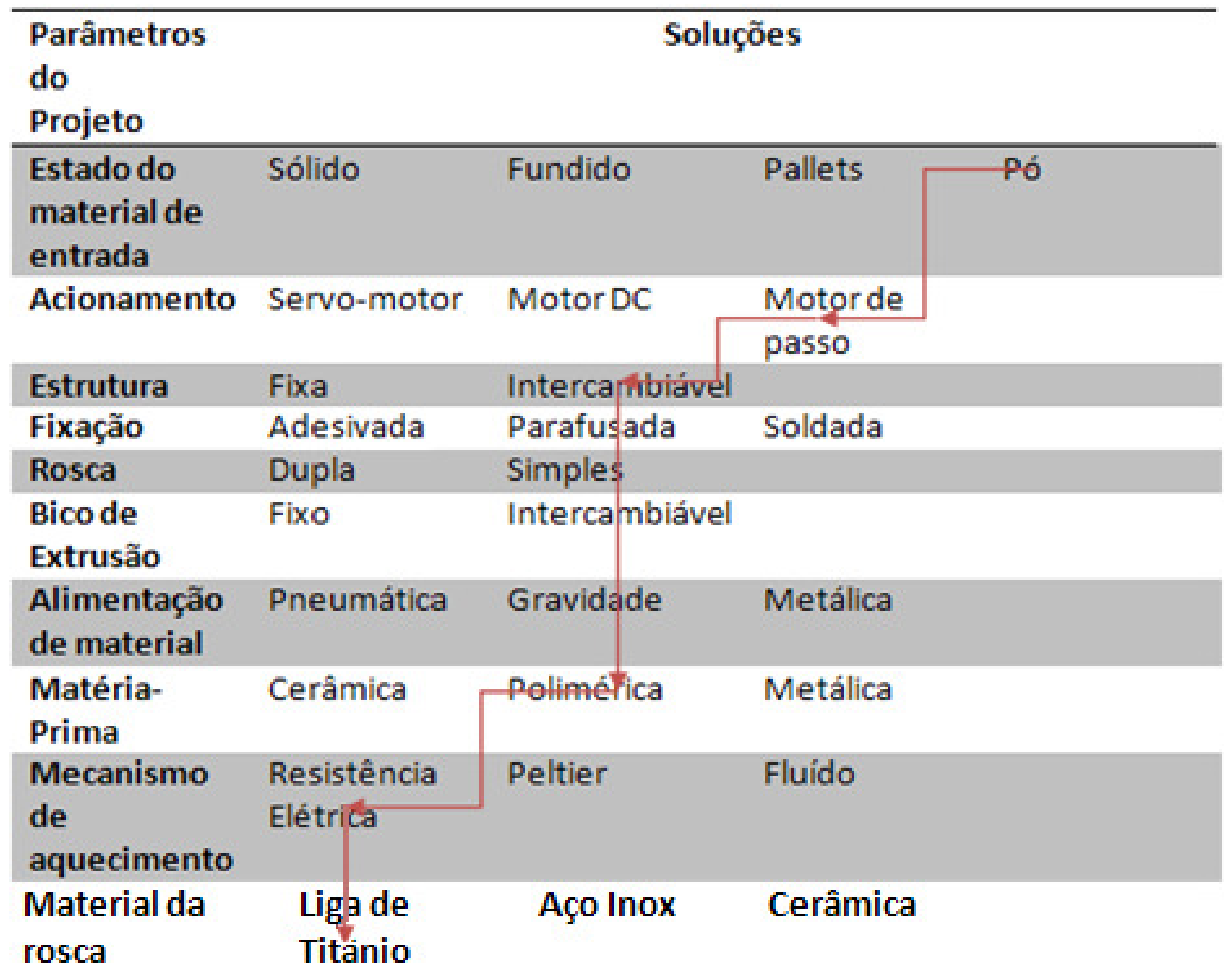

A escolha de pó como material de deposição vem da disponibilidade de material polimérico no mercado, que é facilmente adquirido nessa configuração. Além do fato da vantagem, de obter a mistura dos materiais mais facilmente podendo-se ter como resultado um material composto.

Para o acionamento do cabeçote escolhe-se o motor de passo, devido à préconfiguração da máquina neste sistema que é de fácil controle e ajuste. A estrutura do cabeçote é intercambiável, apresentando a vantagem da possibilidade de utilização de várias técnicas de manufatura aditiva com a mesma máquina. Grande parte das fixações foram por parafusos devido à facilidade de montagem, manutenção e limpeza do equipamento.

A rosca é simples devido à sua configuração mais adequada para a aplicação, sendo ela mais leve e de mais fácil projeto e fabricação. O bico de extrusão é intercambiável, para possibilitar diversos diâmetros de filetes de material na saída, possibilitando diferentes resoluções e acabamento na superfície na peça. 
Além disso, dada a proposta de aplicação do sistema para pesquisa, que demanda a utilização de diversas matérias-primas com características diversas foi escolhida uma solução de bico de extrusão intercambiável de forma possibilitar a adaptação das características do processo a cada material para atingir os resultados desejados.

A alimentação de material é feita por gravidade com uso de um misturador, composto de uma haste giratória acoplada no parafuso na fase de alimentação do mesmo, para evitar a compactação do material. A matéria-prima para a extrusão é de base polimérica, cujo principal motivo da escolha foi a facilidade de utilizar este tipo material em processo de extrusão. O mecanismo de aquecimento é feito por resistências elétricas, devido à possibilidade de enrolá-las ao longo do cilindro externo no processo de extrusão e garantir aquecimento controlado em todas as fases do processo.

Inicialmente, o material para fabricação da mini-rosca extrusora foi definido como titânio por se tratar de um material com alta resistência mecânica em alta temperatura e baixa densidade. Além disso, a alta complexidade geométrica de seu projeto indicou sua construção por processo de manufatura aditiva, sendo que o processo disponível para a DT3D/CTI utilizava uma liga de titânio TiAl6V4 (liga de alta resistência mecânica, resistência a corrosão e a altas temperaturas, utilizada em aplicações aeroespaciais) como matéria-prima.

Apesar da indicação do uso da manufatura aditiva em liga de titânio, incertezas com relação a capabilidade do processo não permitiram descartar o uso de técnicas convencionais de manufatura e aço inoxidável como possível escolha para a fabricação da mini-rosca extrusora. 


\section{Construção do protótipo funcional do mini-cabeçote de extrusão com rosca variável}

A construção do protótipo iniciou-se tendo em vista os requisitos levantados nas ferramentas de projeto conforme capitulo 3 , os quais definiram suas características funcionais. Com o objetivo de atender a esses requisitos dentro das limitações do projeto original da máquina Fab@CTI foram necessárias diversas soluções de projeto.

Inicialmente observou-se o volume disponível na Fab@CTI, bem como as características do sistema intercambiável de cabeçotes a fim de restringir os limites para o dimensionamento do protótipo. A amplitude de movimentação nos eixos $\mathrm{X}, \mathrm{Y}$ e $Z$ definiram limites dimensionais de $200 \times 200 \times 200 \mathrm{~mm}$ (volume de trabalho Build) os quais serviram de valores máximos que nunca poderiam ser atingidos uma vez que quanto mais próximo destas dimensões, menor seria o volume de trabalho do equipamento.

Além disso, a existência de uma placa padrão de intercambiabilidade definiu a geometria do acoplamento do protótipo à máquina igualmente limitando suas dimensões dada a capacidade suporte que é oferecida pela placa. Disto, resultou uma expectativa de dimensões máximas do protótipo de $140 \times 200 \times 250 \mathrm{~mm}$ (profundidade $\mathrm{x}$ largura $\mathrm{x}$ altura) e volume de trabalho de $8000 \mathrm{~mm}^{3}$.

Além das restrições de dimensionais, foram observadas características do sistema de controle e acionamento disponíveis visando eliminar quaisquer necessidades de alteração nos módulos de funcionamento originais da máquina. No caso deste protótipo, isto se traduziu na escolha de motor de passo bipolar para o acionamento mecânico, sistema de aquecimento por resistência elétrica e controle de temperatura por termopar tipo J, feito de uma liga de Ferro e Constantan possibilitando operar na faixa de temperatura de - 40 a $750{ }^{\circ} \mathrm{C}$. Um esboço inicial é apresentado na figura 6.1 


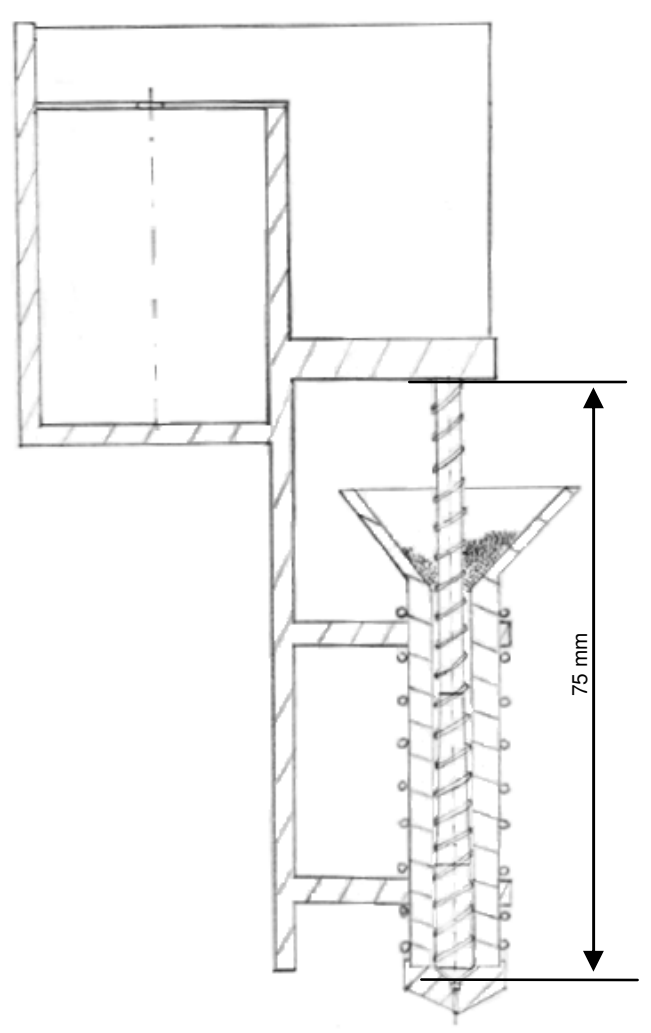

Figura 6.1 - Esboço da primeira solução de construção para o mini-cabeçote de extrusão.

Os cálculos iniciais, necessários para a construção da rosca e do sistema de acionamento foram realizados em trabalho complementar apresentado por Freitas (2011).

Além desses cálculos, os materiais selecionados para uso do cabeçote para curto e médio prazo foram: polímeros termoplásticos ABS, Poliamida (virgem e degradada após 200 horas de utilização em equipamento MA SLS) e o bio-polímero Policaprolactona (PCL). Para os dois últimos polímeros foi feito um estudo de reometria (apêndice A.3) com a finalidade de dimensionar o dispositivo de aquecimento, a rosca e o sistema de acionamento. O PCL apresenta um ponto de fusão baixo (em torno de $60^{\circ} \mathrm{C}$ ), sendo não hidrofóbica. A poliamida foi escolhida devido à possibilidade de reuso da mesma no contexto das aplicações de laboratórios de pesquisas com tecnologia de MA baseada em SLS.

Para o dimensionamento e escolha do torque do motor foi preciso obter a taxa de cisalhamento dos materiais utilizados conforme apêndice A.3. O material que apresentou a maior viscosidade e, portanto requer maior torque estático foi o PCL. 
Tanto o dimensionamento deste sistema quanto a análise do ensaio de reometria capilar e sua descrição foram realizados conforme mostrado em Freitas (2011).

Para o dimensionamento da temperatura máxima a ser atingida pelo cabeçote, levou-se em consideração o material ABS o qual apresentava uma maior temperatura de fusão. Com relação à velocidade máxima de extrusão do material, levou-se em consideração a velocidade máxima de movimentação do sistema da Fab@CTI de aproximadamente $15 \mathrm{~mm} / \mathrm{s}$ para um diâmetro de saída de 0,1 mm ( bico de extrusão) aceitável para o projeto.

Sendo assim, os valores definidos para os dimensionamentos foram:

- Torque: 20 N.m;

- Temperatura máxima de operação: 350ํㅡ.

Freitas (2011), a partir destes dados iniciais de projeto realizou o prédimensionamento mecânico dos principais elementos que compõem o minicabeçote: sistema de redução (coroa sem fim) e geometrias do cilindro (barril) e rosca de extrusão.

A rosca é o componente mecânico mais importante do cabeçote de extrusão agindo sobre os fenômenos reológicos durante o processamento do material e consequentemente influenciando diretamente sobre a qualidade final do protótipo. $\mathrm{O}$ dimensionamento correto do conjunto cilindro e parafuso em condições estáticas e dinâmicas e de sua melhoria realizada posteriormente é fundamental para o controle correto das duas ou três fases do processo de extrusão sendo elas: alimentação, compressão e mistura. Além disso, a estimativa correta da taxa de compressão também é fundamental para o desenvolvimento do projeto do parafuso de extrusão. Para este dimensionamento, dividiu-se o cabeçote em quatro subsistemas: o cilindro/rosca de extrusão, bico de injeção, sistema de controle do motor e o sistema de controle térmico. O sistema de controle do motor de passo controla o movimento de rotação do parafuso, enquanto que o sistema de controle do aquecimento controla a estabilidade da temperatura do material fundido dentro do cilindro até a sua passagem através do bico de injeção. A qualidade final do protótipo construído é 
obtida pela interação destes subsistemas. Já para o dimensionamento correto do parafuso de extrusão, foram considerados os seguintes parâmetros: dados iniciais do projeto da impressora 3-D (dimensão, peso, volume, entre outros), diâmetro do parafuso, profundidade da rosca, relação $L / D$ de cada seção, folga radial de cada seção e estimativas de fluxo de material. Sendo assim, para o pré-dimensionamento do par rosca-cilindro (FREITAS, 2011) foi considerado um conjunto de parâmetros com seus respectivos valores (adotados e calculados) representados na Tabela 6.1 e na Tabela 6.2.

Tabela 6.1 - Parâmetros de projeto para o pré-cálculo do conjunto cilindro e rosca.

\begin{tabular}{cc}
\hline Parâmetros de Projeto & Valores adotados \\
\hline$R$ (Raio da rosca) & $3,5.10^{-3} \mathrm{~m}$ \\
$G$ (Aceleração da gravidade) & $9,81 \mathrm{~m} / \mathrm{s}^{2}$ \\
$E$ (Módulo de Young) & $1,1.10^{5} \mathrm{MPa}$ \\
$\rho$ (Densidade do material) & $4430 \mathrm{~kg} / \mathrm{m}^{3}$ \\
\hline
\end{tabular}

Tabela 6.2 - Parâmetros de projeto para o pré-cálculo da rosca de extrusão.

\begin{tabular}{cc}
\hline Parâmetros de Projeto & Valores calculados \\
\hline$\sigma$ (Tensão de tração ou compressão) & $1150 \mathrm{MPa}$ \\
$\tau$ (Tensão de cisalhamento) & $772,5 \mathrm{MPa}$ \\
$\sigma_{\text {esc }}$ (Tensão de escoamento) & $1030 \mathrm{MPa}$ \\
$\mathrm{T}_{\mathrm{p}}$ (Torque na rosca) & $26 \mathrm{~N} \cdot \mathrm{m}$ \\
$\Delta \mathrm{p}$ (Gradiente de pressão) & $8,63.10^{-4} \mathrm{MPa}$ \\
$\mathrm{Y}(\mathrm{L})$ (Deflexão Lateral da rosca) & $2,36.10^{-6} \mathrm{~m}$ \\
$\mathrm{~L}$ (Comprimento da rosca) & $1,1.10^{-1} \mathrm{~m}$ \\
$\mathrm{H}_{\max }($ Profundidade máxima do canal da rosca) & $7,23.10^{-4} \mathrm{~m}$ \\
$\mathrm{H}_{\max }($ Profundidade máxima do canal de alimentação) & $7,23.10^{-4} \mathrm{~m}$ \\
Razão H/w (Profundidade/canal) & 546,2 \\
Buckling (devido à tensão de compressão) & $68 \mathrm{MPa}$ \\
Velocidade de rotação crítica & $2536,8 \mathrm{RPM}$ \\
\hline
\end{tabular}


Com o pré-dimensionamento da rosca do cabeçote de extrusão com base nos requisitos descritos acima, os dados finais para construção do parafuso de extrusão foram:

- Comprimento total do parafuso de extrusão: 171,30 mm;

- Comprimento da rosca de extrusão: 138,5 mm;

- Diâmetro do parafuso de extrusão: 6,35 mm ( zona de alimentação) e 7,00 mm (zona de deposição);

- Ângulo de hélice de $17,66^{\circ}$;

- Passo constante: $0,7 \mathrm{~mm}$.

- Massa do cabeçote: 2,2 kg

A figura 6.2 apresenta o desenho detalhado da rosca de extrusão projetada (Freitas, 2011).

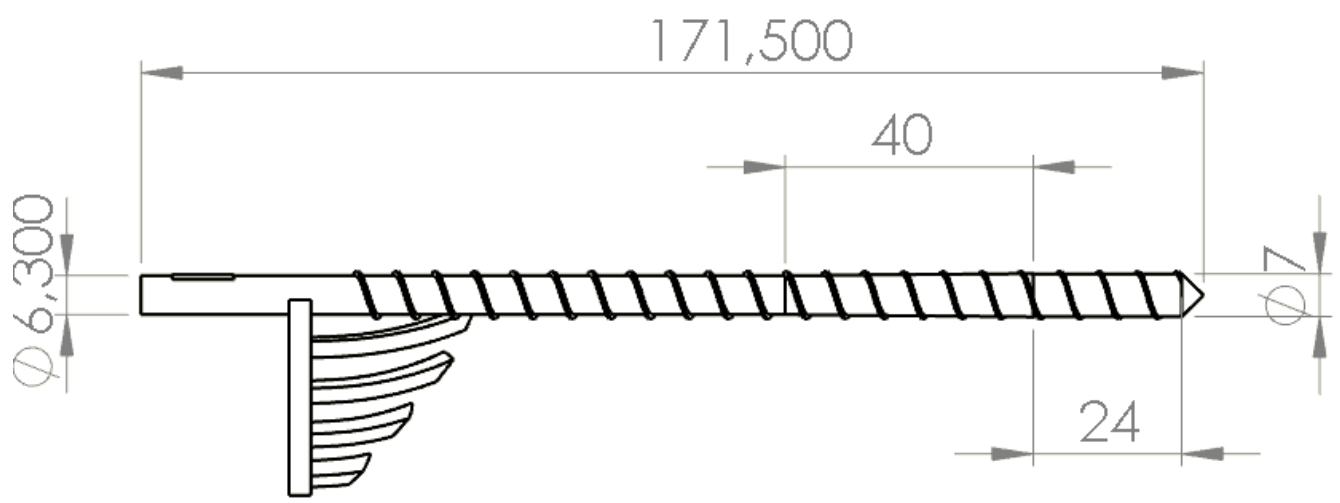

Figura 6.2 - Dimensionamento da rosca de extrusão.

O sistema de aquecimento foi dimensionado para ter capacidade de atingir $350^{\circ} \mathrm{C}$ utilizando resistência encapsulada em espiral de $120 \mathrm{~W}$ a $220 \mathrm{~V}$ com termopar tipo $\mathrm{J}$ interno e um segundo termopar tipo $\mathrm{J}$ localizado externamente. Atendendo aos requisitos de intercambiabilidade, o sistema foi controlado por um controlador industrial de temperatura externo.

Para dimensionamento dos motores de acionamento do sistema, verificou-se que os motores de passo disponíveis para o torque necessário resultam em motores 
excessivamente grandes e pesados o que se tornam inviável para uso no cabeçote. Sendo assim, optou-se por adquirir um motor de passo de tamanho NEMA 23 o qual possuía uma relação torque x peso aceitável e projetar um conjunto de redução 20:1 o qual foi dimensionado conforme gráfico torque $x$ velocidade para um melhor aproveitamento do torque do motor na velocidade especificada para o uso, fornecendo 1 N.m a 1200 RPM, conforme planilha mostrada em Apêndice A.2.

Dessa forma, foram dimensionados os quatro principais subsistemas que são: motor; redução; parafuso de extrusão e sistema de aquecimento. A disposição física destes subsistemas gerou a solução geométrica mostrada na Figura 6.3.

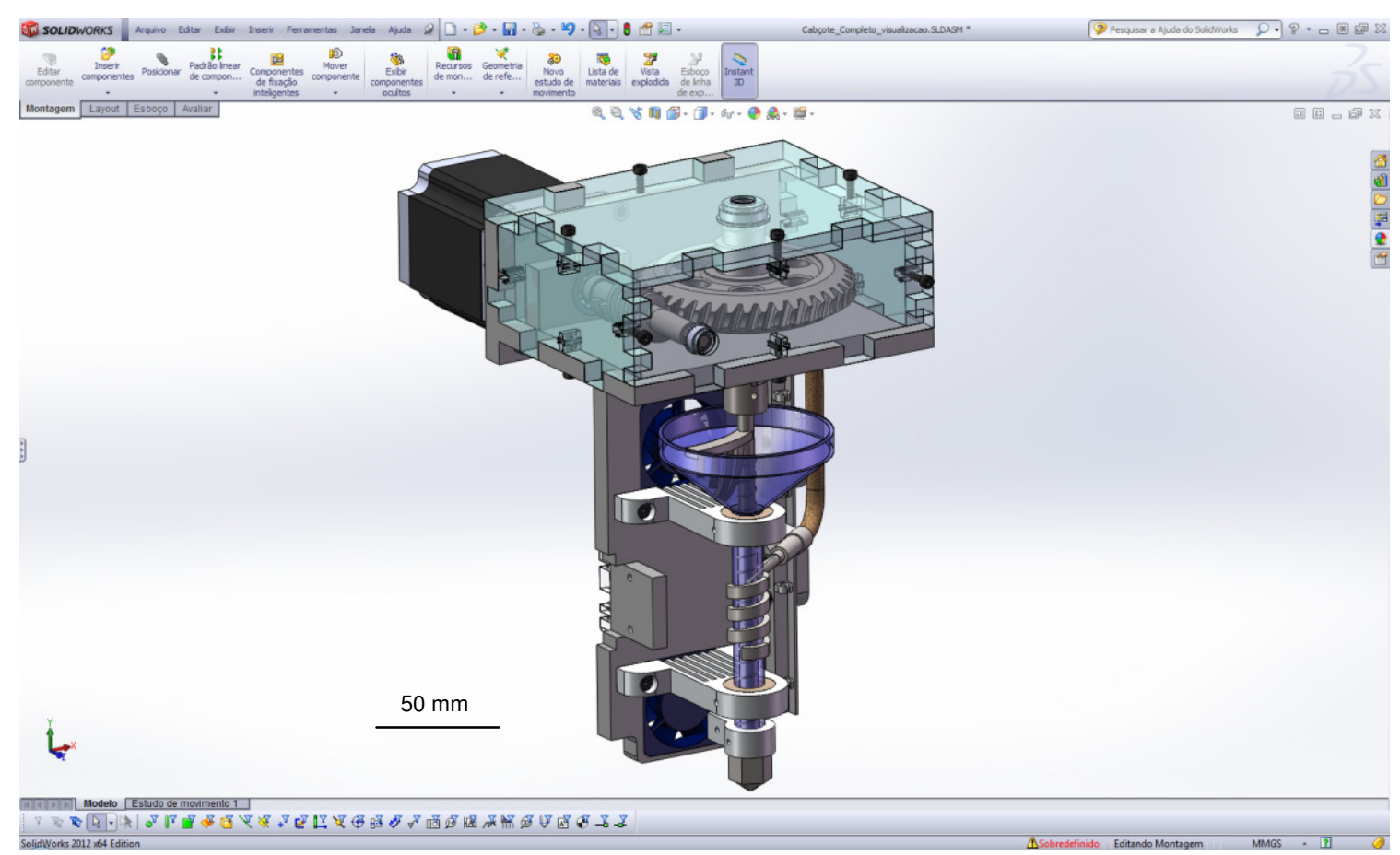

Figura 6.3 - Modelo tridimensional CAD da primeira proposta de solução do cabeçote de extrusão.

Como pode ser visto na figura 4.4 o motor foi colocado na parte superior, posterior, esquerda da placa de fixação, considerando a vista de frente da máquina como referência, de modo a equilibrar o centro de gravidade do conjunto sobre as guias de deslocamento em $Y$ da máquina. Além disso, o eixo foi colocado na posição horizontal favorecendo a disposição da redução. 
Ainda na Figura 6.3 é possível observar que a caixa de redução (coroa e sem fim) foi posicionada com a coroa na horizontal viabilizando o uso do parafuso de extrusão na vertical.

O posicionamento vertical deste parafuso por sua vez, explica-se pelas limitações dimensionais bem como pelo uso do processo de alimentação em pó por força gravitacional guiado por funil.

A Figura 6.4 mostra o diagrama de funcionamento do cabeçote de extrusão inserido no sistema intercambiável da Fab@CTI. Observa-se que houve um mínimo de alteração no sistema necessário para compatibilidade com o sistema de intercambiabilidade, mantendo as soluções de controle originais do projeto Fab@Home, atendendo a demandas de projeto relacionadas com a redução nos custos relacionados ao re-projeto exigido para o funcionamento de múltiplas soluções potencialmente incompatíveis em um único equipamento de MA.

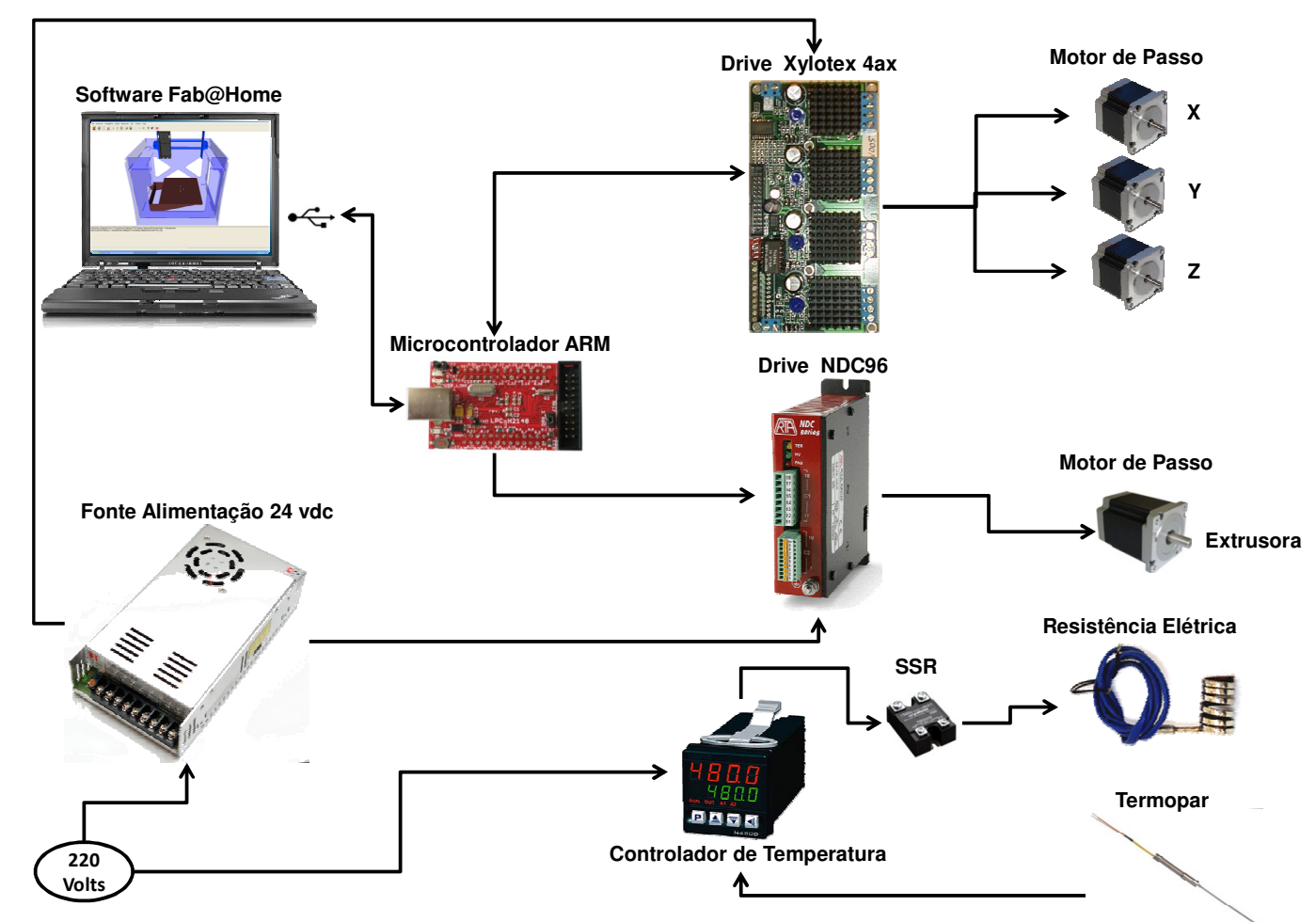

Figura 6.4 - Diagrama de funcionamento do cabeçote de extrusão no sistema da Fab@CTI. 
Basicamente o sistema funciona utilizando o mesmo software de controle da Fab@CTI, o mesmo microcontrolador ARM e as mesmas placas amplificadoras dos motores de passo que controla a movimentação x, y e z. No entanto, foi adicionado uma nova placa amplificadora para o controle do motor de passo que fará a rotação do parafuso de extrusão, o qual possui uma corrente de operação superior ao dos cabeçotes já existentes na Fab@CTI. Esta placa comunica com o microcontrolador por meio de controle step/dir similar aos demais cabeçotes disponíveis e a configuração para ligação com o microcontrolador é feita nas mesmas pinagens do motor U (STEP U e DIR U) destacado em verde oliva na tabela 3.1. Além disso, para o controle de temperatura do sistema, utilizou-se um controlador externo o qual faz a leitura do sistema por meio de um termopar tipo $\mathrm{J}$ e o acionamento térmico por resistência elétricas microtubular.

Para configuração e acionamento do sistema do cabeçote de extrusão foram utilizados os mesmos parâmetros de software como PATHWIDTH (espessura da camada), PATHHEIGHT (altura da camada), PUSHOUT (tempo para rotação do parafuso para extrusão do material), SUCKBACK (tempo de retroação do parafuso para parar o fluxo do material) e DEPOSITIONRATE (movimentação na rotação do parafuso de extrusão durante 0 trajeto na camada). Estes parâmetros são configurados com base nas temperaturas predeterminadas no controlador de temperatura de acordo com a reologia de cada matéria-prima utilizada.

\subsection{Mock-up utilizando tecnologias de MA}

A fim de verificar a viabilidade de montagem e integração entre as peças projetadas para o novo cabeçote, bem como sua adequada intercambiabilidade ao equipamento Fab@CTI, foi construído um mock-up.

Mock-up é um termo utilizado no desenvolvimento de um produto para indicar um protótipo feito em escala ou em dimensão real com diversas finalidades, entre as quais a avaliação do projeto e sua funcionalidade. 
Neste trabalho o mock-up foi construído com diversas tecnologias de manufatura aditiva como pode ser visto na figura 6.5. Todas as peças foram feitas em polímeros para possibilitar o teste de montagem e movimentação do sistema, permitindo detectar falhas evidentes de projeto como problemas com acoplamentos, posicionamento de rolamentos, solução para conexão do sistema eletrônico da máquina ao cabeçote, entre outros.
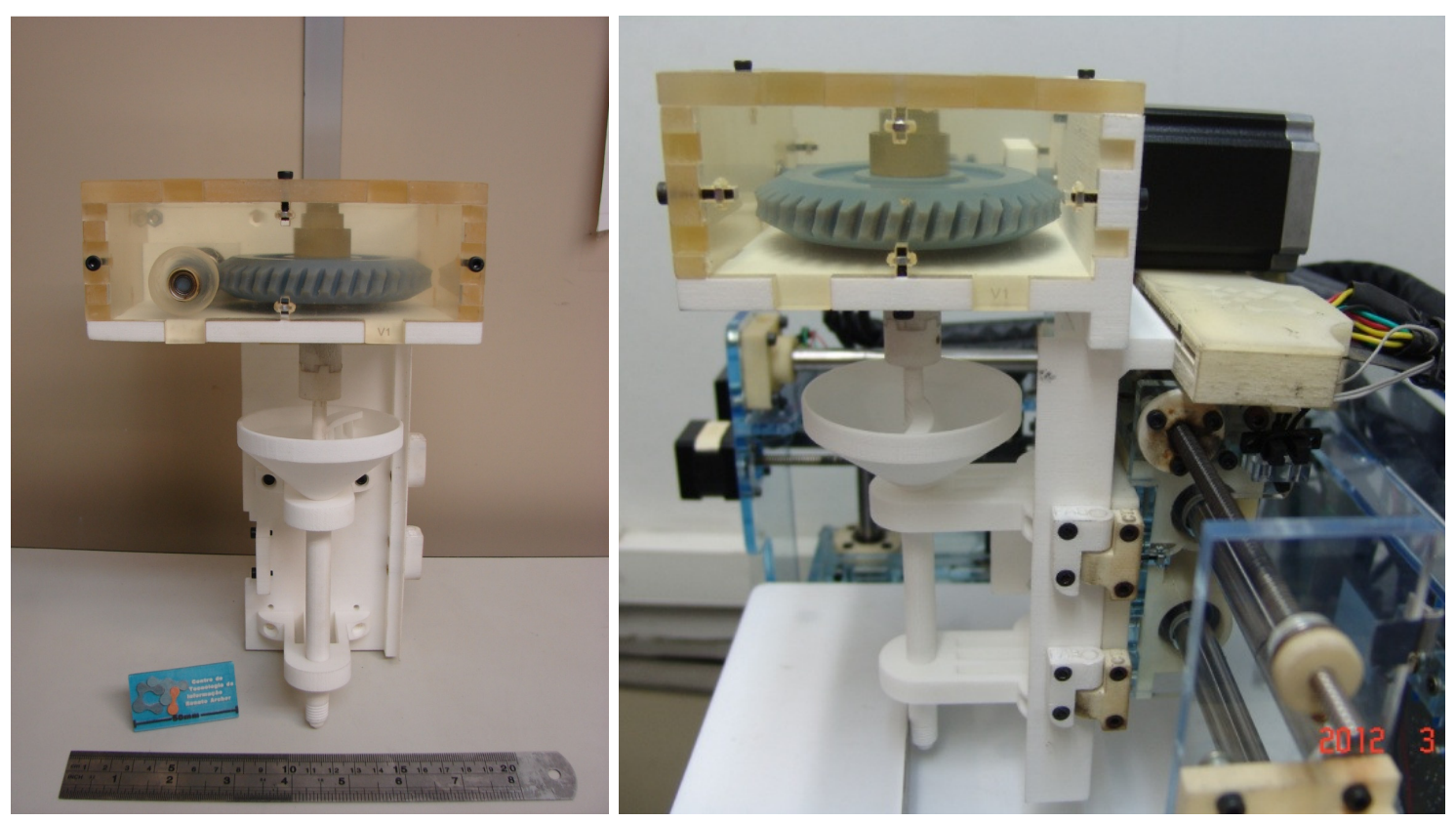

Figura 6.5 - Mock-up do cabeçote de extrusão e seu acoplamento no equipamento Fab@CTI.

Durante a montagem do mock-up considerou-se utilizar a mini-rosca extrusora feita em metal. Para tanto, foi utilizada um equipamento SLM da EOS que utiliza liga de titânio em pó e processo de sinterização por laser. Os primeiros protótipos mostraram problemas de empenamento além de acabamento superficial inadequado (figura 6.6). 


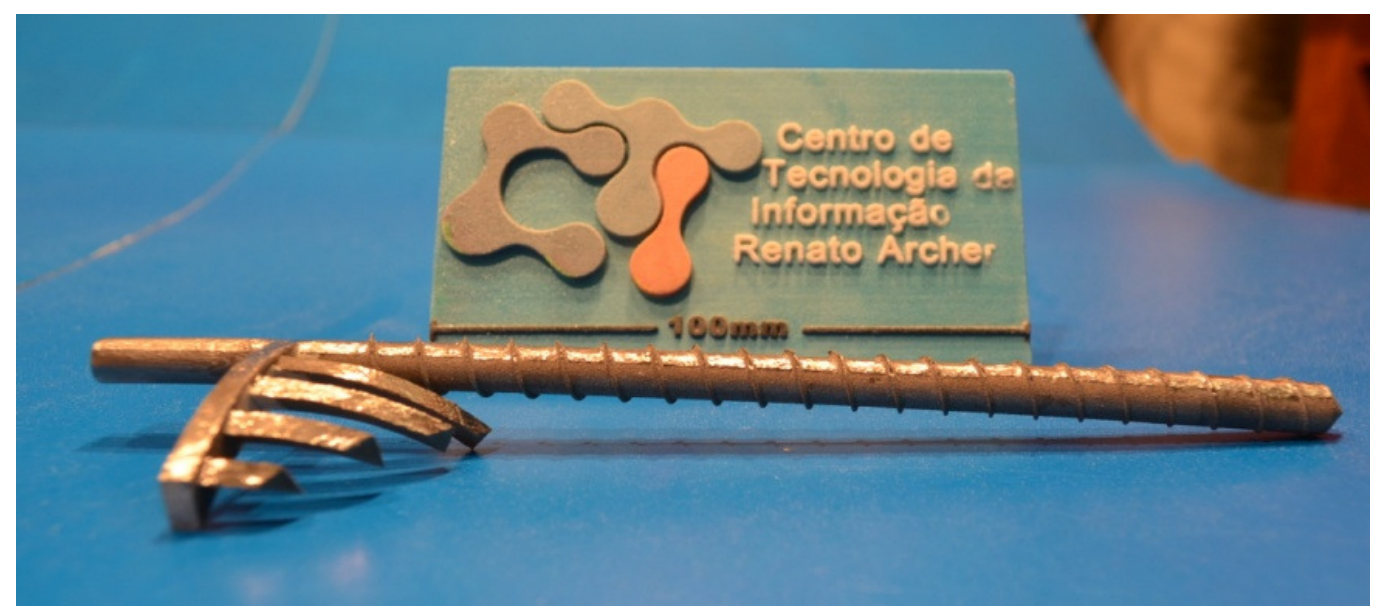

Figura 6.6 - Mini-rosca extrusora empenada produzida em SLM após pós-processamento e remoção de suporte.

Após diversas tentativas para solução do problema de empenamento e das sequelas produzidas na superfície da peça pelo processo de remoção do suporte produzido durante sua fabricação, observou-se a inviabilidade do uso deste processo. Dessa forma, optou-se por fabricar a peça com tecnologia de usinagem convencional feita em aço inoxidável 304 (figura 6.7).

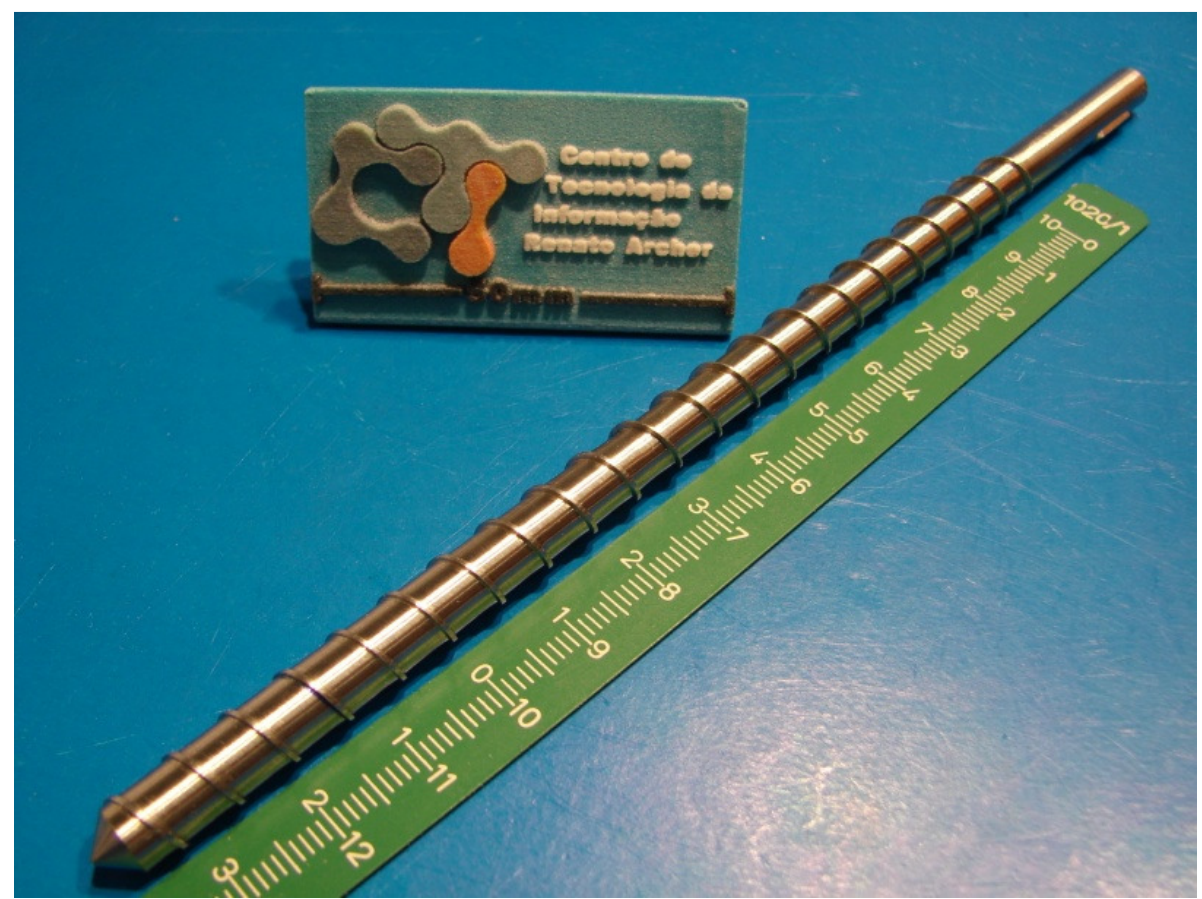

Figura 6.7 - Mini-rosca extrusora produzida por usinagem em aço inoxidável 304. 
Já o sistema de redução composto de coroa e rosca sem fim, após testado no mock-up, foi produzido pela tecnologia SLM da EOS a qual mostrou-se adequada para esta aplicação.

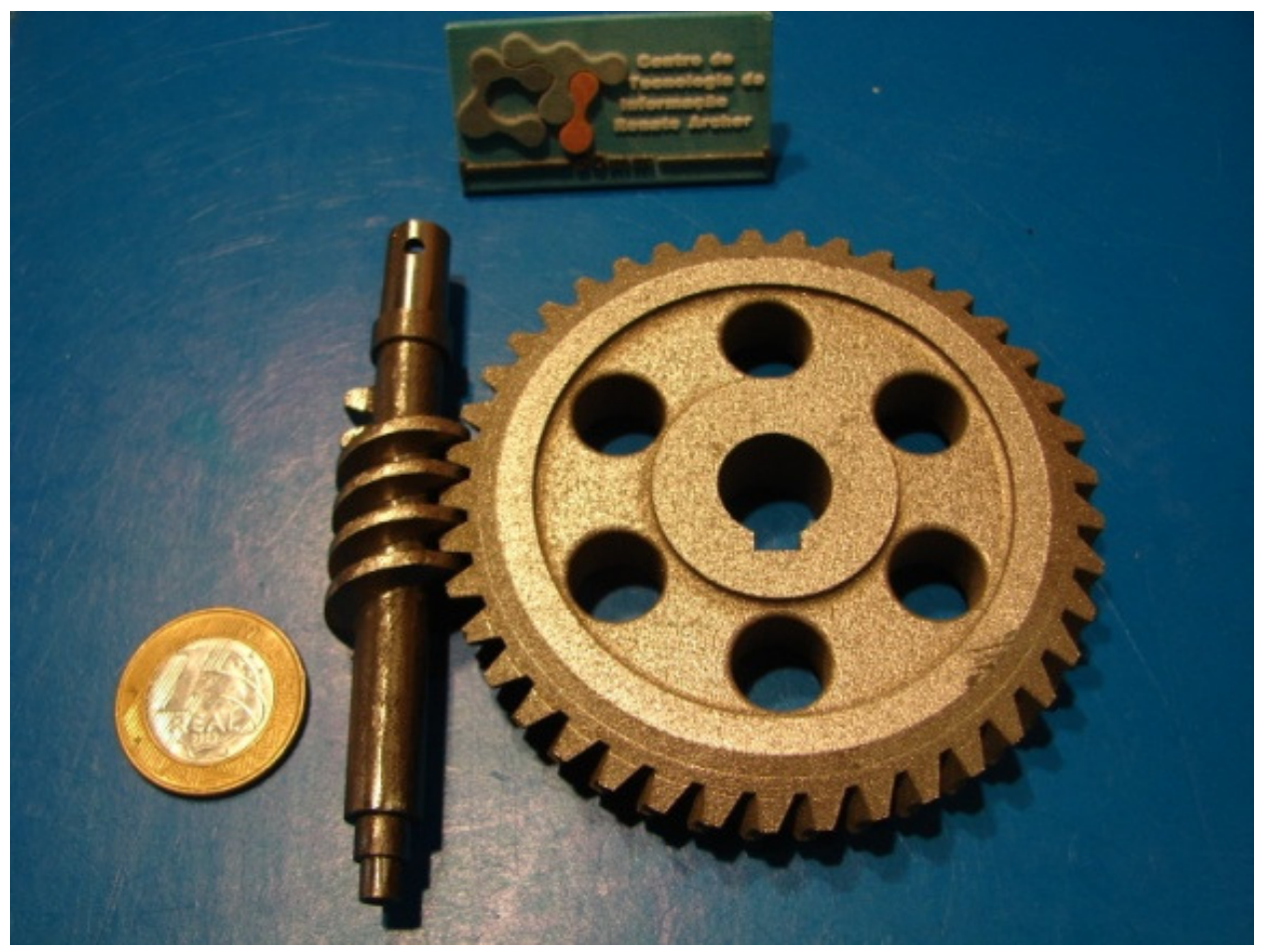

Figura 6.8 - Sistema de redução produzido em SLM após pós-processamento e remoção de suporte.

\subsection{Testes de validação do mini-cabeçote de extrusão}

Após construção e aquisição de todos componentes do cabeçote de extrusão por rosca foi feita uma montagem do sistema em bancada de testes, conforme ilustra a figura 6.9, com a finalidade de validar o funcionamento e iniciar os ciclos de teste preliminar do cabeçote. 


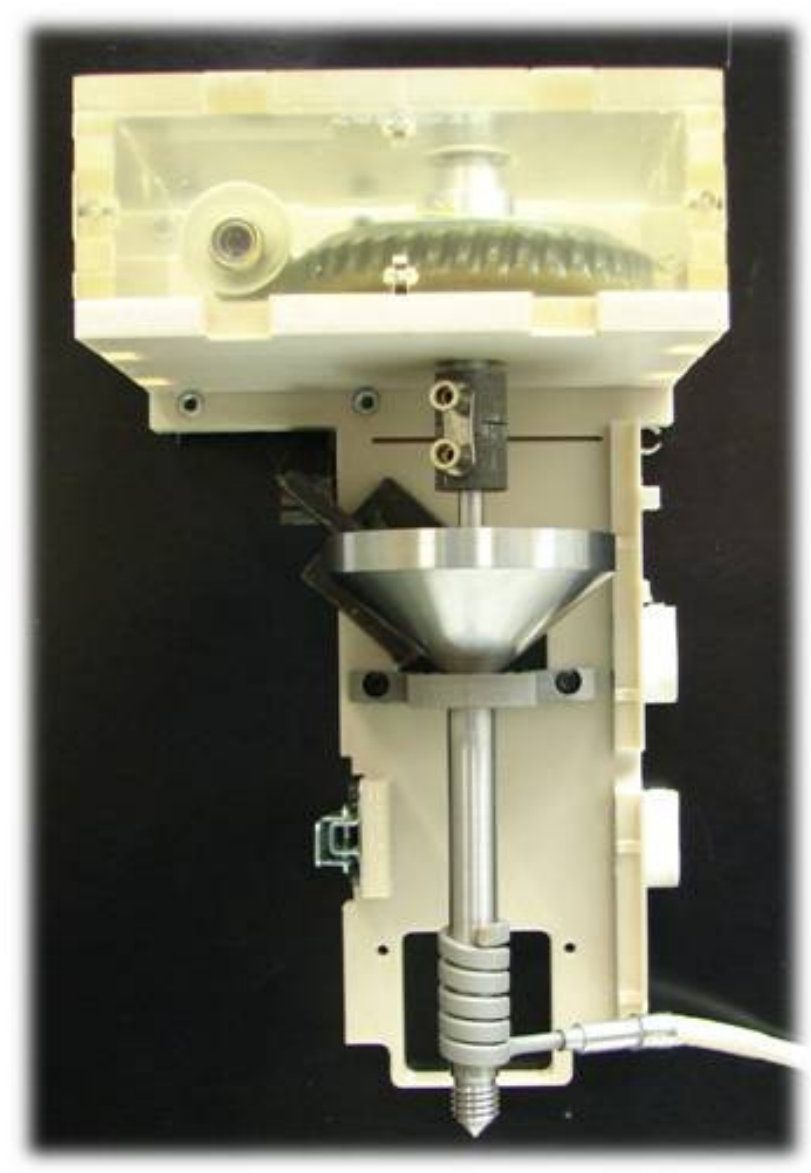

(a)
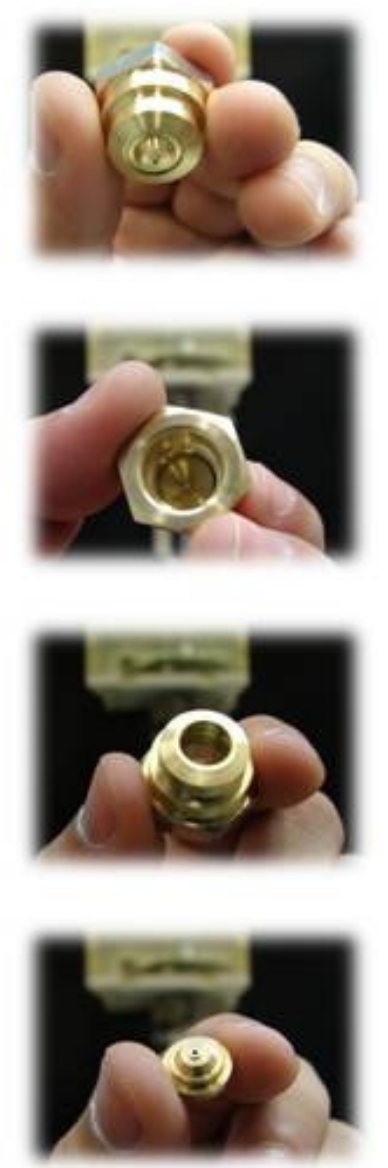

(b)

Figura 6.9 - a) Montagem do cabeçote na bancada de testes; b) bico de extrusão intercambiável

No primeiro teste foi avaliada a facilidade na montagem e desmontagem do sistema, para procedimentos de limpeza e manutenção, bem como testes de fixação dos acoplamentos e das demais estruturas mecânicas do cabeçote.

Após este procedimento, foram feitos testes de acionamento do motor com o sistema na temperatura ambiente, avaliando a movimentação do sistema de redução bem como a rotação do parafuso de extrusão dentro do conjunto cilindro e bico de extrusão. Durante esta movimentação, observou-se uma folga no sistema de redução quando se faz a inversão da rotação. Entretanto, esta folga pode ser minimizada nos parâmetros de configuração do software ou por sistema de ajustes da coroa e parafuso sem fim. 
Com os testes iniciais do sistema de movimentação seguiu-se o teste de deslocamento de material em temperatura ambiente. Neste teste foi adicionada a poliamida em pó no cilindro, para verificar o transporte da matéria-prima, desde a parte superior da rosca até a região de deposição apresentado nas Figuras 6.10 (a) e (b).

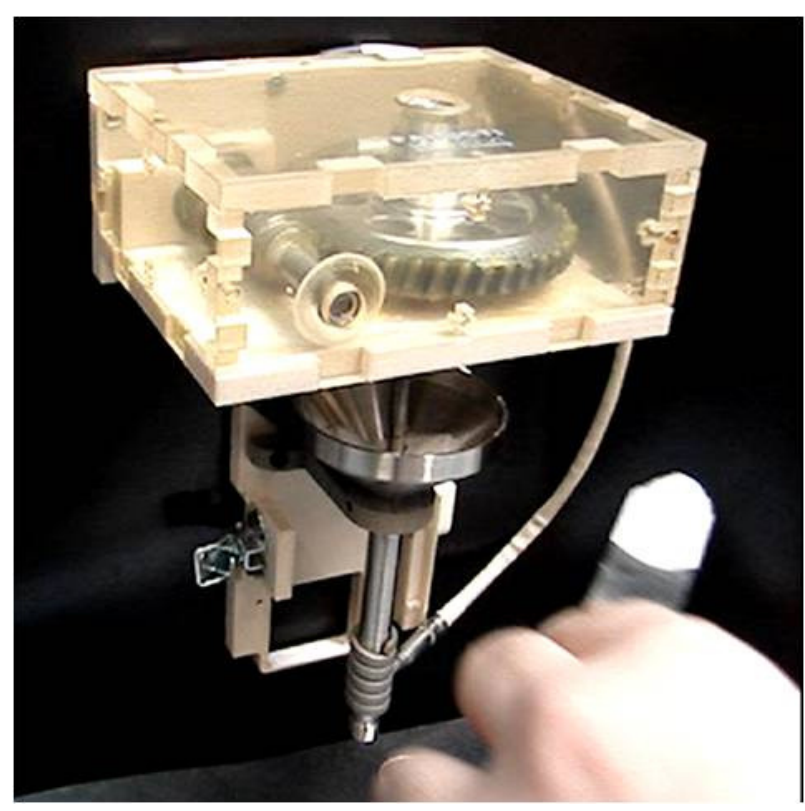

(a)

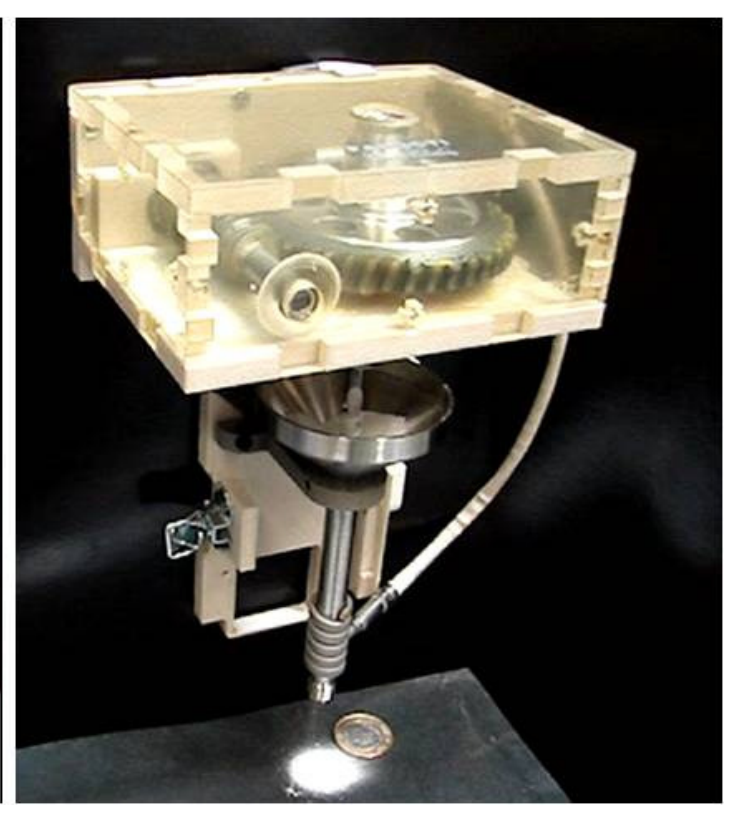

(b)

Figura 6.10 - a) Alimentação do cabeçote com nylon Duraform® PA; b) Carreamento do pó a frio até a superfície de extrusão.

Com a validação do transporte do pó desde o reservatório do pó e ao longo das três seções da rosca foi feito um novo teste utilizando-se um material viscoso (creme dental) conforme ilustram as Figuras 6.11 (a) e (b). 


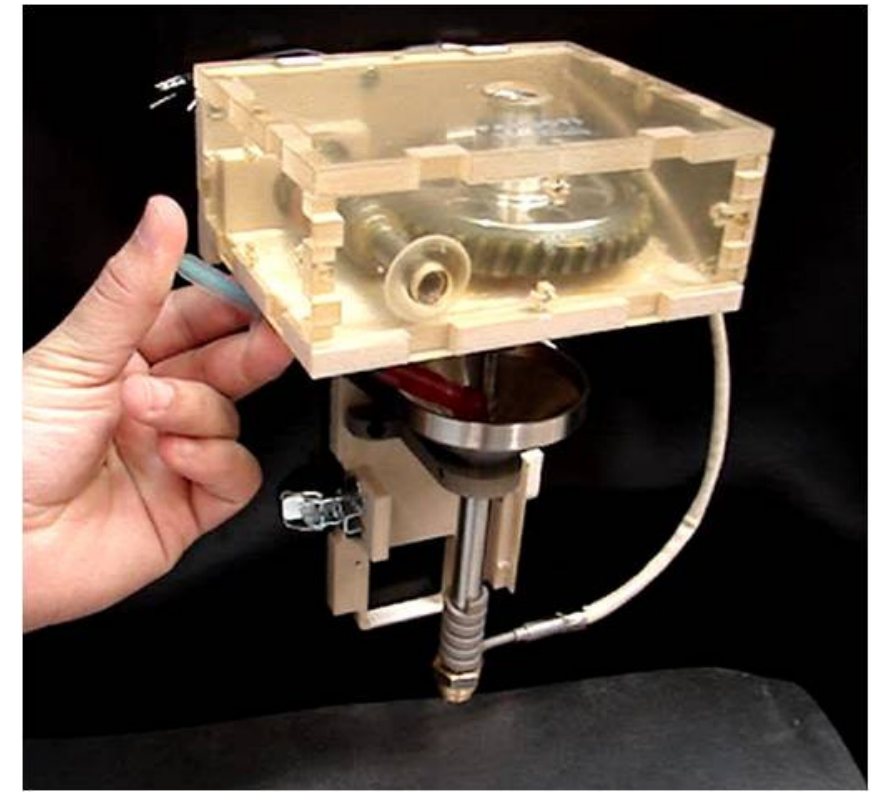

(a)

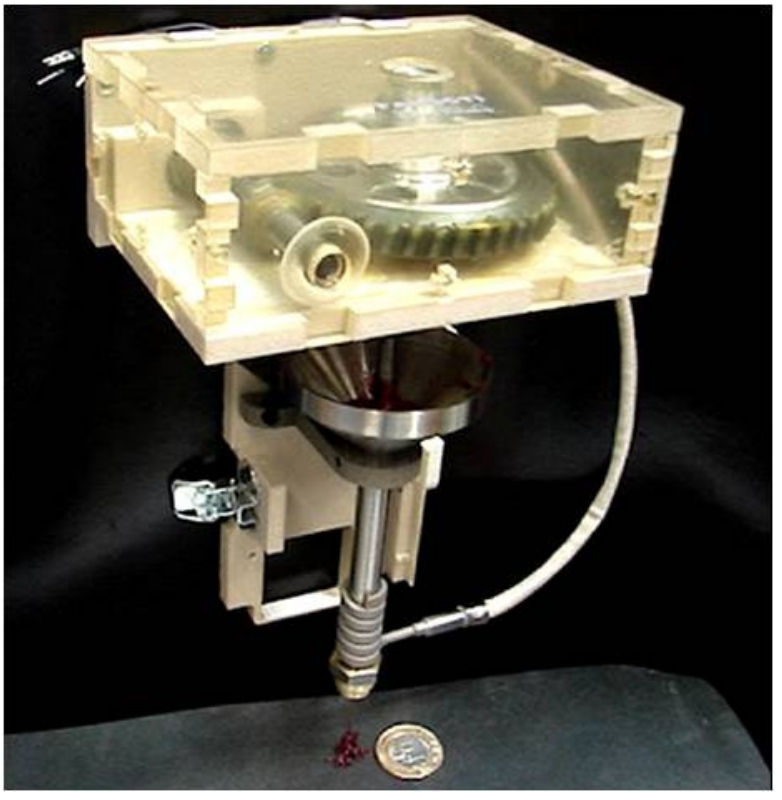

(b)

Figura 6.11 - a) Alimentação do cabeçote com creme dental; b) Carreamento do creme dental a frio até a superfície de extrusão.

Após o teste em temperatura ambiente do material viscoso, o sistema foi desmontado com objetivo de avaliar as zonas do parafuso de extrusão. Como previsto no projeto, observa-se perfeitamente na figura 6.12 as três zonas précalculadas no projeto do conjunto cilindro-rosca de extrusão que são: alimentação, compressão e mistura.

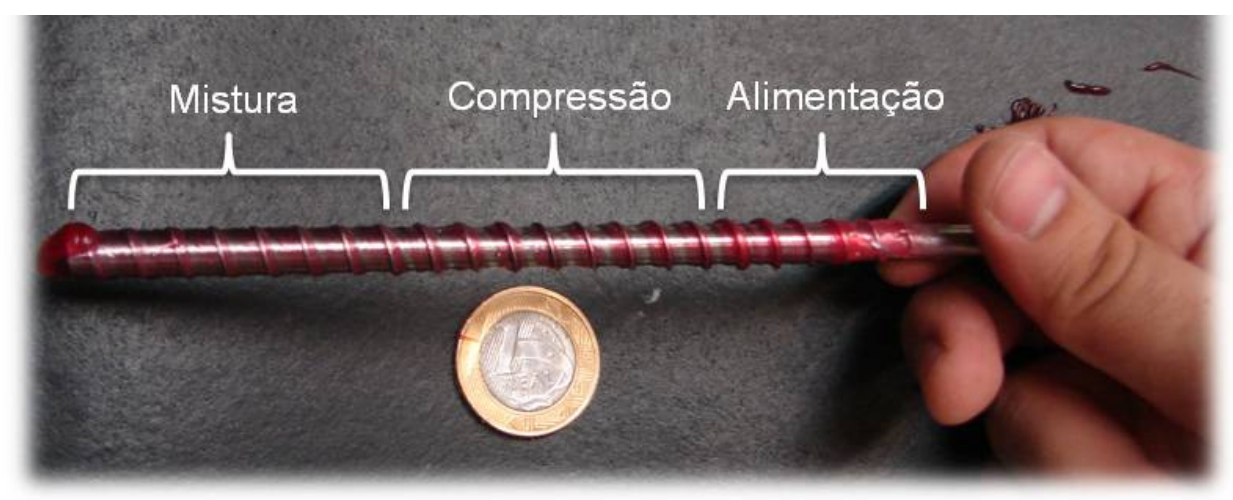

Figura 6.12 - Verificação das zonas do parafuso de extrusão conforme previsto no pré-dimensionamento do parafuso.

Após estas etapas procedeu-se ao teste com o aquecimento para extrusão da poliamida 12 degradada. A temperatura de trabalho foi configurada em $230{ }^{\circ} \mathrm{C}$ para extrusão utilizando um bico de 0,8 mm de diâmetro. 
Foram obtidos filamentos extrudados com diâmetro entre $0,5 \mathrm{~mm}$ e $0,9 \mathrm{~mm}$ conforme mostra a figura 6.13.

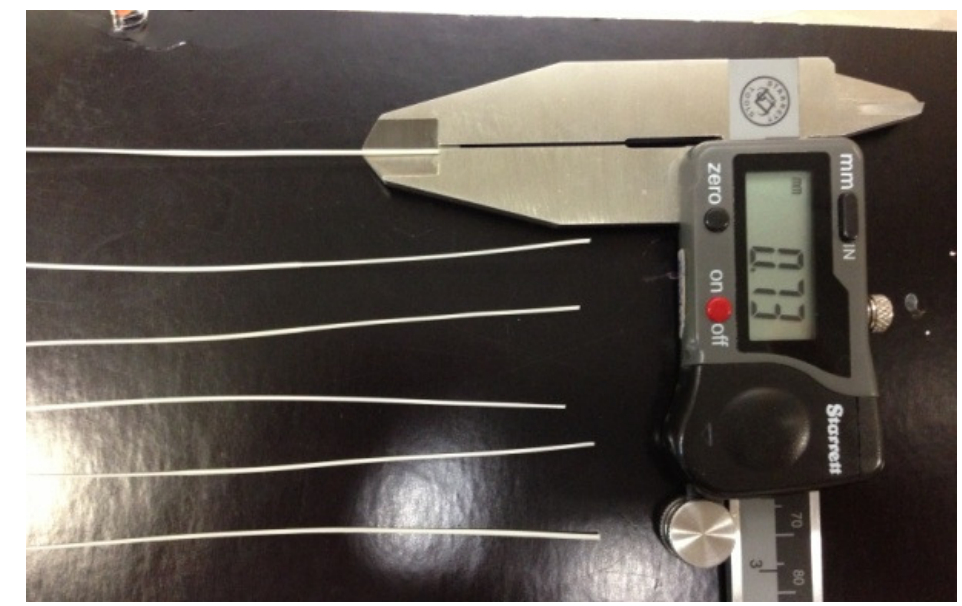

Figura 6.13 - Filamentos de poliamida 12 obtidos nos testes e validação.

Finalizado o teste de extrusão à quente foi removida a mini-rosca extrusora para observação das zonas do parafuso de extrusão conforme feito anteriormente em teste à frio. A figura 6.14 mostra a presença das três zonas fundamentais.

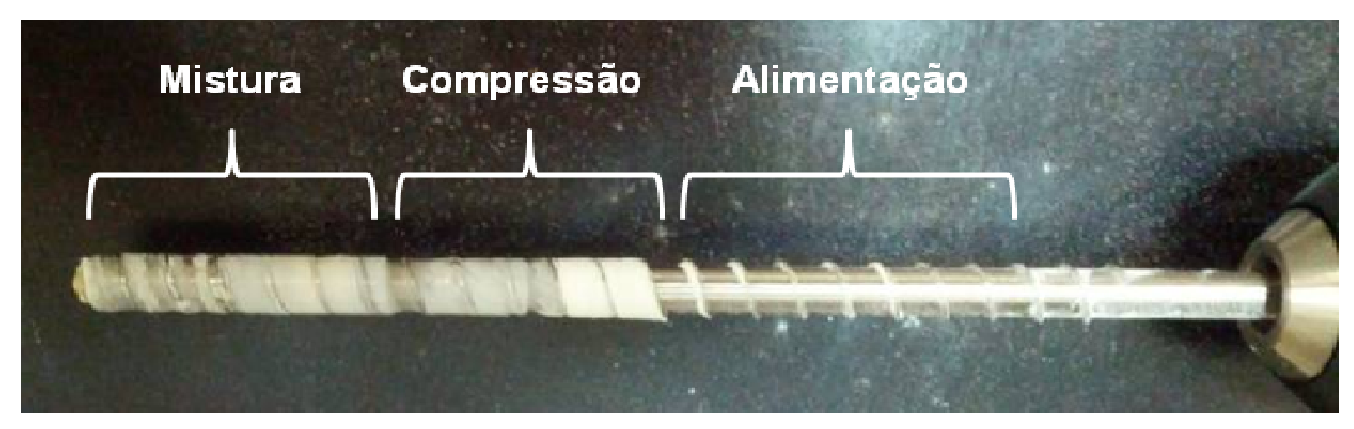

Figura 6.14 - Verificação das zonas do parafuso de extrusão conforme previsto no pré-dimensionamento do parafuso após teste à quente.

Após os testes realizados em bancada, acoplou-se o cabeçote no sistema intercambiável da Fab@CTI e então iniciou-se os testes de impressão 3-D utilizando o equipamento e o software de controle da máquina Fab@CTI.

Inicialmente foram configurados parâmetros default de PATHWIDTH, PATHHEIGHT, PUSHOUT, SUCKBACK e DEPOSITIONRATE (parâmetros de controle do software da Fab@Home Model 1 V.0.24) levando em consideração o diâmetro do bico de extrusão de $0,8 \mathrm{~mm}$ e os parâmetros do material poliamida 12 , 
retirado anteriormente com os testes de extrusão feitos em bancada. No controlador de temperatura foi configurada a temperatura de $230 \stackrel{\circ}{\circ}$, semelhante ao que foi feito anteriormente no teste em bancada.

Para extrusão, notou-se a necessidade de utilizar uma plataforma de deposição aquecida a fim de evitar o empenamento e o descolamento das camadas depositadas na plataforma no decorrer da impressão. Sendo assim, utilizou-se uma mesa aquecida com temperatura de $100 \stackrel{\circ}{\circ}$ a qual mostrou-se inicialmente adequada para impressão 3-D de um paralelepípedo de $200 \times 200 \times 100 \mathrm{~mm}$ conforme figura 6.15 .

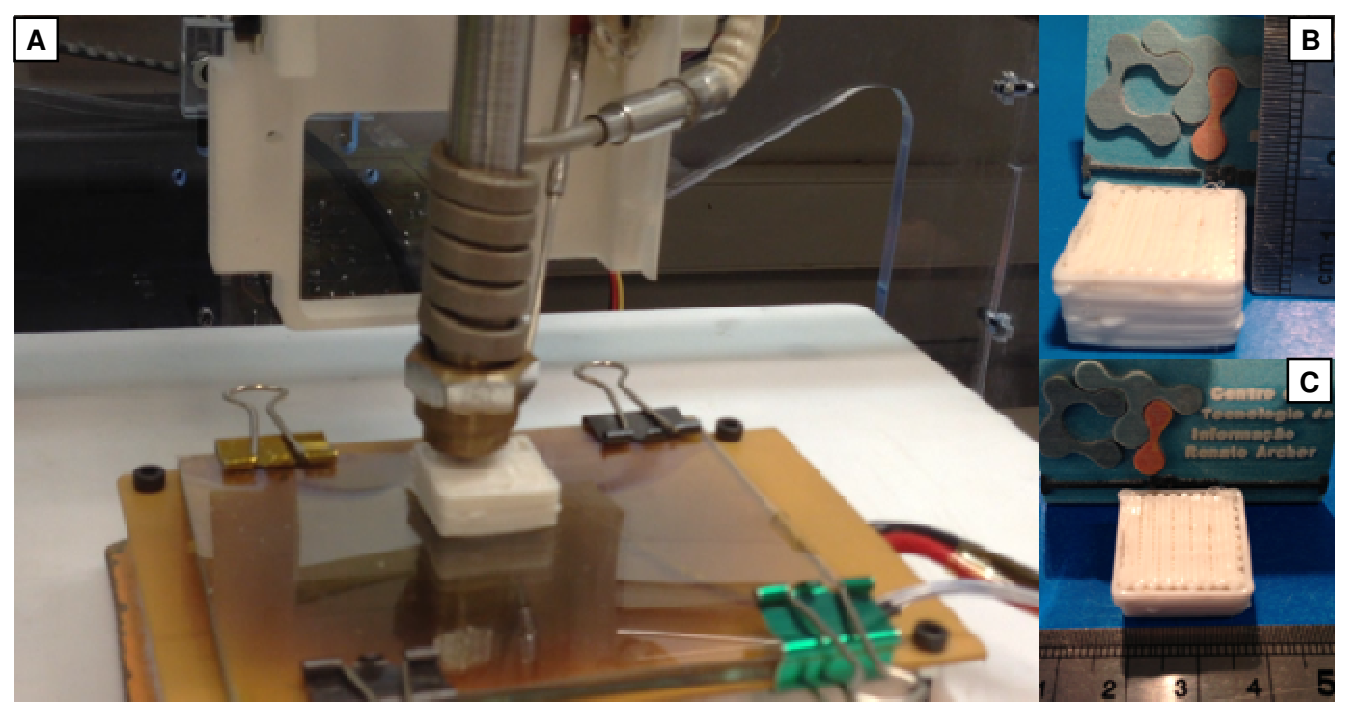

Figura 6.15 - a) Impressão 3-D utilizando o cabeçote de extrusão no equipamento Fab@CTI; b) Vista das camadas do objeto produzido em poliamida 12; c) Vista da parte superior do objeto produzido em poliamida 12.

Estes resultados validam 0 projeto desenvolvido bem como atestam 0 funcionamento adequado da mini-rosca extrusora, demonstrando sua funcionalidade na geração de filamentos controlados e geração de modelos 3-D impressos camada a camada a partir de um modelo CAD 3-D utilizando matéria-prima em pó. 


\section{Conclusões e trabalhos futuros}

Como pôde ser visto no capítulo 4, foi apresentado o estudo da viabilidade técnica de um mini-cabeçote de extrusão vertical com rosca de seção variável. Segundo o estudo, foram obtidas características e diretrizes de projeto as quais minimizaram os possíveis equívocos gerados na busca de soluções ao guiar o desenvolvimento com foco nos componentes mais críticos.

Este estudo viabilizou o desenvolvimento de um projeto que resultou em um protótipo funcional, o qual cumpriu os requisitos de projeto, quais sejam:

- Conectividade mecânica e eletrônica com a máquina Fab@CTI incluindo compatibilidade à solução de intercambiabilidade de processos de MA em uma mesma plataforma previamente implementada;

- Capacidade de utilizar material polimérico em pó em pequenas quantidades;

- Funcionamento da rosca extrusora miniaturizada conforme processo de extrusão por rosca convencional, obedecendo a divisão em zonas característica deste processo;

- Tecnologia adequada ao uso em processo de MA.

Com base nisso, conclui-se que o uso das ferramentas de desenvolvimento de projeto é efetivo para obtenção de uma solução adequada reduzindo os custos com retrabalho de projeto por erros ocasionados pela falta de orientação provida por estas ferramentas. O conceito desenvolvido foi implementado na forma de um protótipo funcional cujos testes demonstraram sucesso no atendimento as especificações tanto de funcionamento mecânico quanto de qualidade de impressão 3-D camada a camada para sua aplicação em MA.

Para a utilização deste protótipo há necessidade de configurar diversos parâmetros de controle de acordo com a matéria-prima utilizada e as condições escolhidas para o processo de MA, que torna seu funcionamento complexo e motivo de futuros estudos para melhorias e novas aplicações. 
Como trabalhos futuros, podem-se citar:

- Estudo e otimização das correlações de parâmetros como temperatura de operação, velocidade de movimentação, taxa de extrusão, diâmetro do bico, entre outras sobre a qualidade do filamento depositado e sua adesão sobre camada anterior;

- Ensaios experimentais com outros materiais como o PCL para geração de protótipos;

- Análise e caracterização de FTIR, GPC, DSC, TGA e MEV dos protótipos obtidos nos diferentes tipos de matéria-prima.

- Caracterização do tempo de residência do material;

- Caracterização mecânica do protótipo obtido pelo cabeçote sob tração e compressão;

- Otimização de dimensões e peso do cabeçote;

- Estudo do controle térmico do processo e sua influencia sobre o comportamento do sistema a partir de análise numérica para avaliação do gradiente de temperatura desenvolvido ao longo da rosca/cilindro, nas seções da rosca, para possíveis controles de variações de temperatura dos polímeros propostos;

- Implementação de um sistema de comunicação do controle de temperatura com o software da máquina;

- Adaptações necessárias para o uso com outros tipos de polímeros incluindo novos projetos para a rosca extrusora como rosca dupla e outros componentes;

- Estudo da viabilidade do uso de matérias-primas em distribuições alternativas ao pó;

- Processo contínuo de melhoria para aprimoramento das soluções implementadas;

- Testes com matéria-prima e aplicações na área de saúde. 


\section{Referências}

ASTM F2792-10 (2010) Standard terminology for additive manufacturing technologies, copyright ASTM International - 2010, 100 Barr Harbor Drive, West Conshohocken, PA 19428.

Back, N. (1983). Metodologia de projeto de produtos industriais, Editora Guanabara Dois, 389p.

Back, N.; Ogliari, A.; Dias, A.; Silva, J.C. (2008). Projeto integrado de produtos. $1^{a}$. edição. Editora: Manole.

Barbanti S. H., Zavaglia C. A. C., Duek E. A. R., Polimeros Bio-reabsorviveis na Engenharia teciduals, Polimeros: Ciencia e Tecnologia, vol. 15, n. 1, nd, pp. 13-21, 2005.

Baxter, M. (2003) Projeto do Produto. 2ª . Edição. Edgard Blücher. 260p.

Béreaux Y., Charmeau J., Moguedet M, A. (2009) Simple model of throughput and pressure development for single screw. Journal of materials processing technology Num. 209, pp. 611-618.

Callister, W.D. (2002) Ciência e Engenharia de materiais: uma introdução. 589p.

Campbell, I.; Bourell, D.; Gibson, I. (2012) Additive manufacturing: rapid prototyping comes of age. Rapid Prototyping Journal. V. 18, Num.4, p. 255-258.

Carlos, R. (2009) Aplicações de técnicas de metodologia de projeto, na melhoria do projeto conceitual de uma sopradora industrial. Trabalho de Conclusão de Curso. Departamento de Engenharia Mecânica, Escola de Engenharia de São Carlos, Universidade de São Paulo. 75 p.

Cheng, L.C.; Melo Filho, L.D.R. de (2010) QFD - Desdobramento da função qualidade na gestão de desenvolvimento de produtos. Editora Blucher. 2a Edição revisada. 
Chung, C.I. (2000) Extrusion of polymers: theory and practice. Hamser: Cincinnati. 369p.

Crump, S.S. (1994) Modeling apparatus for three-dimensional objects. United States Patent. Site: www.inpi.gov.br

Freitas, M.S. de (2011) Projeto conceitual e preliminar de uma rosca de extrusão para uma impressora 3-D de pequeno porte. Trabalho de Conclusão de Curso, Departamento de Engenharia Mecânica, EESC, USP. 117p.

Gibson I, Rosen D.W, Stucker B. (2010) Additive Manufacturing Technologies: Rapid Prototyping to direct digital manufacturing. Springer.

Ikegami R. A. (2007) Desenvolvimento de corpos cerâmicos compostos bioativos com estrutura de gradiente funcional. Tese de doutorado, Escola de Engenharia de São Carlos, Universidade de São Paulo. 110p

Inforçatti Neto, P.I. (2007) Máquina básica de prototipagem rápida de projeto aberto de hardware e software, para uso de pesquisas em bioengenharia, desenvolvimento, inovação e aplicações de prototipagem rápida. Trabalho de Conclusão de Curso. Faculdade Independente do Nordeste, BA - Brasil.

Inforçatti Neto, P.I.; Lixandrão Filho, A. L.; Pereira, F.D.A.S; Silva, J.V.L.; Silveira, Z. C.; Bártolo, P. (2012) Thermoplastic filamento extruder head for desktop Additive Manufacturing machines. In: Innovative developments in Virtual and Physical Prototyping. London: Taylor \& Francis Group, p. 635-638, ISBN 978-0-41568418-7.

Luo, R.C.; Tzou, J-H; Hsieh, C-Y.; Chou, H-H. (2002) The development of a thermal extrusion based rapid prototyping mechatronics system. 28th Annual Conference of the IEEE Industrial Electronics Society. V.1, Num.5-8. p. 2237-2242.

Malone E. and Lipson H.: Fab@Home: the personal desktop fabricator kit. Rapid Prototyping Journal, Vol.13. ํㅡ 4, 245-255, 2007. 
Pahl, G.; Beitz, W.; Feldhusen, J.; Grote, K.H. (2007) Engineering Design: a systematic approach. Springer, $3^{\text {a }}$. edition. $617 p$.

Pearce, J. M. (2012) Building research equipamento with free, open source hardware. Vol. 337. p.1303-1304. Disponível em: www.inovação tecnológica.com.br./notícias/notícias.php?artigo=quarta-revolucao-industrial-era-dasmaquinas. Acesso em: em: 24/09/2012.

Powers M. T.; Lavernia E. J.; Groza J. R.; Shackelford J. F. (2007) Materials Processing Handbook. Cap. 26. ISBN 978-0-8493-3216-6.

Rauwendaal, C. (2001) Polymer extrusion. Editora: Hanser-Verlag Gardner Publications. p. 1-20; p.119-153; p. 425-434.

Rozenfeld, H.; Forcellini, F.A.; Amaral, D.C.; Toledo, J.C., et al. (2006) Gestão de desenvolvimento de produtos: uma referência para melhoria do processo. São Paulo: Editoria Saraiva.

Senedese, A. L. C. (2011) Estruturação tridimensional de scaffolds de policaprolactona via manufatura. Dissertação de Mestrado. Faculdade de Engenharia Química da Universidade Estadual de Campinas. No prelo

Silva J. V. L.; Meurer E.; Meurer M. I. (2004) Prototipagem Biomédica - Aplicações Cirúrgicas, Anais do III Congresso Latino Americano de Órgãos Artificiais e Biomateriais, Campinas.

Slack, N. et al. (2002) Administração da Produção. 2 ed., São Paulo: Atlas. STRATASYS INC.; Batchelder, J. S. Syringe tip assembly and layered deposition systems utiling the same. INT PI 8287959, 16 out. 2012. Disponível em: < http://www.uspto.gov/>Acesso em: 20 dez. 2012.

STRATASYS INC.; Comb, J. W.; Priedeman, W. R.; Leavitt, P. J.; Skubic, R. L.; Batchelder, S. High-Precison modeling Filament. PI INT US 6,866,807 , 16 mar. 2005. Disponível em: < http://www.uspto.gov/>. Acesso em: 20 out. 2012. 
Vert M. (2009) Bioabsorbable polymers in medicine: an overview. Eurolntervention. V. 5, Suppl. F. ISSN 1774-024X.

Vozzi G., Microfabrication Techniques for the Realization of Organised Engineered Tissue, Politecnico di Milano e Università di Padova e Pisa, Dottorato Di Ricerca In Bioingegneria, 2001.

Wohlers, T. T. (2012) Wohlers Report 2012. Editora Wohlers Associates, Inc., Fort Collins CO, U.S.A.

Ximenes, R. (2011) Estudo e aplicação da metodologia TRIZ: Desenvolvimento de um projeto conceitual para escolha de mancais para cabeçote de uma máquina de ultraprecisão. Dissertação de mestrado, Escola de Engenharia de São Carlos, Universidade de São Paulo. 189p

\section{Referências digitais}

Print me a Stradivarius.

http://www.economist.com/node/18114327? story id=18114327. Acesso: 16/03/2011.

http://emc5744.barra.prof.ufsc.br/parte\%202\%20 revisada.pdf. Acesso em 05/2012.

http://web.ncsu.edu/abstract/technology/3d-printing/ Acesso: 01/10/2012.

http://www.reprap.org (Acesso: 10/01/2012)

http://www.impressora3d.com.br/ (Acesso em: 10/01/2012).

http://www.derwent.com (Acesso em: 11/01/2012).

http://www.inpi.gov.br (Acesso em: 11/01/2012). 
Apêndice A 


\section{A.1 - Matriz da qualidade (QFD) para o mini-cabeçote de extrusão}



\section{A.2 - Tela de interface do programa utilizado para o cálculo de redução coroa e sem fim}

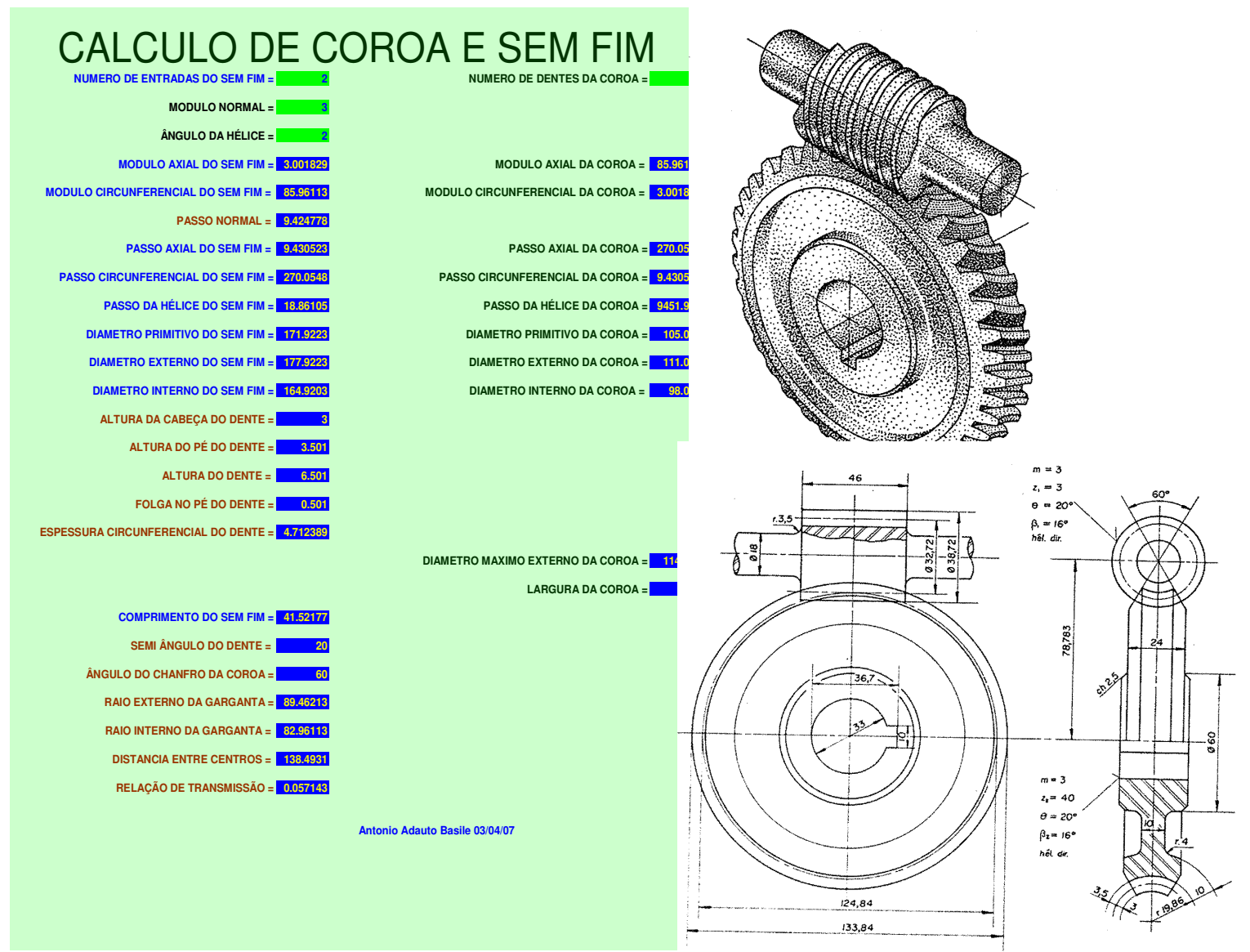

Fonte: Antonio Adauto Basile, planilha microsoft excel disponível para download em http://www.pronew.com.br/down/CALCULOS.xls 


\section{A.3 - Gráficos obtidos a partir de estudos de reometria conforme Freitas, 2011.}

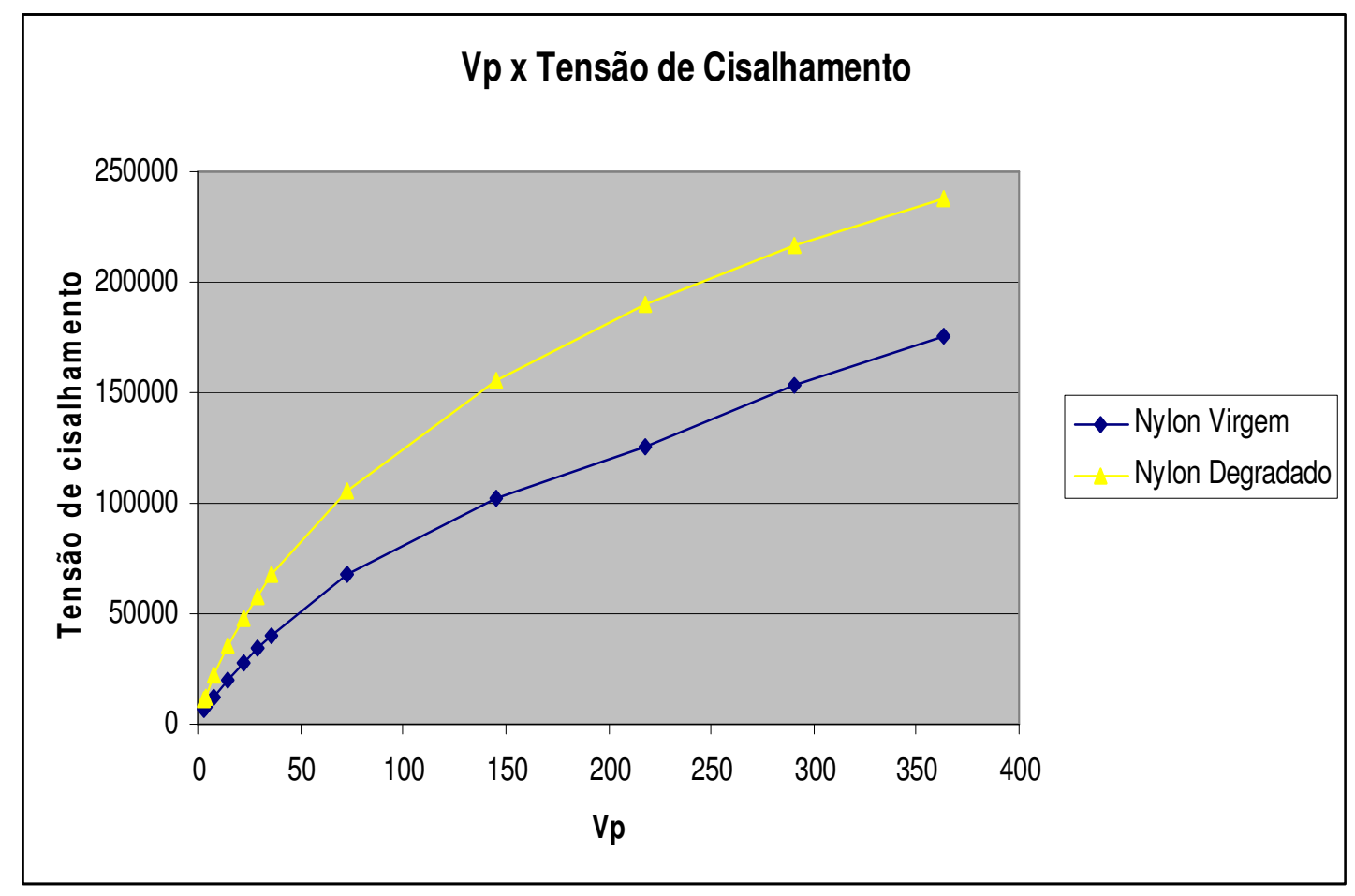

Curva tensão de cisalhamento por velocidade, para a poliamida 12 virgem e degradada utilizada em processo SLS. 


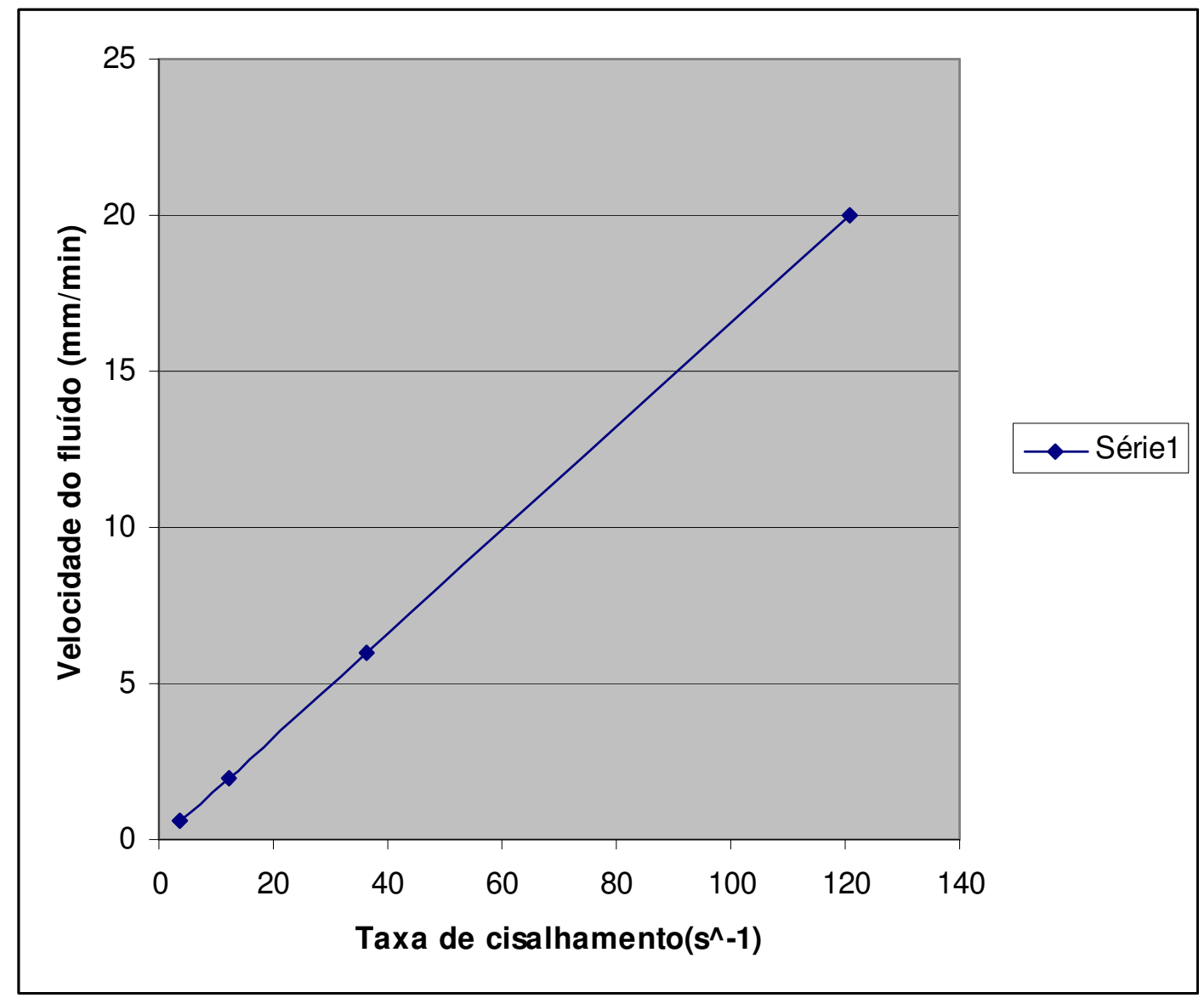

Velocidade do fluído x Taxa de Cisalhamento do PCL CAPA 6505 da Solvay. 